\title{
TRANSFERENCE OF SELF CONCEPT IN FIRST IMPRESSIONS OF SIMILAR OTHERS
}

BY

CEARA NICOLLS

\author{
A thesis \\ submitted to Victoria University of Wellington \\ in fulfilment of the requirements for the degree of \\ Doctor of Philosophy
}

Victoria University of Wellington

2018 


\section{Acknowledgements}

Completion of this thesis would not have been possible without an army of remarkable people who have supported me along the way. First and foremost, I would like to thank my fiancé Jamie for putting up with a grouchy PhD Student for so many years. I would have given up long ago without his understanding, patience, support, and willingness to talk me through my writer's block! Similarly, to my friends and family, thank you for supporting me, reading my work, listening to me complain, and for keeping me going through the rough patches. I couldn't imagine what the last few years would have been like without all of you.

Many thanks to my amazing supervisors Matt Crawford and Garth Fletcher. My secondary supervisor Garth pulled me through a stressful honours year and continued to support me throughout my PhD, for which I am hugely grateful. My Primary supervisor Matt went above and beyond to make sure that I had all of the support I needed to make it through my PhD. He also provided a never-ending source of feedback, knowledge, advice, observations, and hilarity, that made my PhD experience truly unforgettable; and for which I cannot thank him enough! I consider myself very lucky to have been able to work both of these academics in my time at Victoria University of Wellington.

Finally, thank you to the School of Psychology lecturers and Admin team who have helped me in my academic journey. There are too many incredible academics and staff to thank by name - but my experience at Victoria University of Wellington has shaped who I am today and has given me the knowledge and tools to make it this far. Thank you so much to you all for your help and inspiration. 


\section{Table of Contents}

Chapter 1: An Evolutionary Basis for Facial First Impressions. ............................................

1.1 The Universality of Facial First Impressions.........................................................

1.2 The Biological Underpinnings of Facial First Impressions ......................................... 10

1.2.1 Early Development of a Neural Face-Processing System. .................................. 10

1.2.2 Neurological Evidence for a Face-Processing System ............................................ 11

1.2.3 Research into Patients with Brain Damage.......................................................... 12

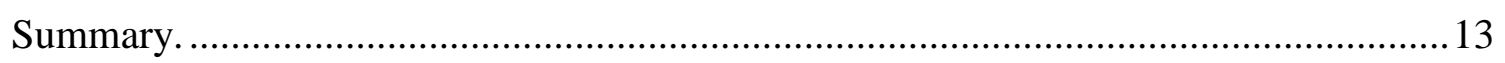

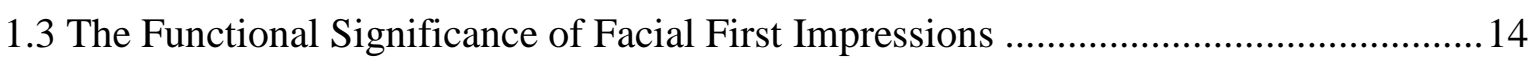

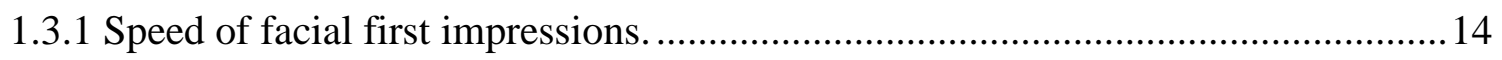

1.3.2 Warmth/ competence model of first impressions. ............................................ 15

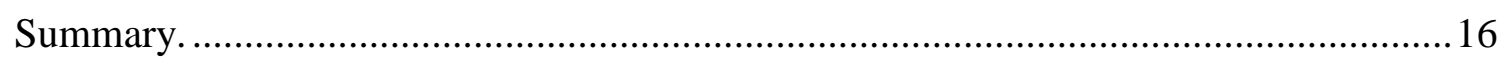

Conclusion; an evolutionary basis for first impressions............................................ 17

Chapter 2: Biases in First Impression Formation ........................................................... 18

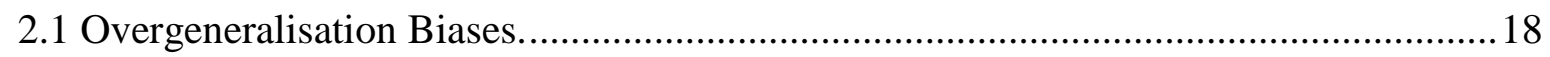

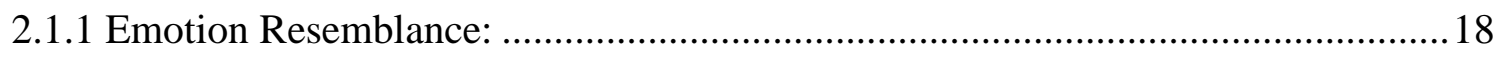

2.1.2 Baby-facedness overgeneralisation effect....................................................... 19

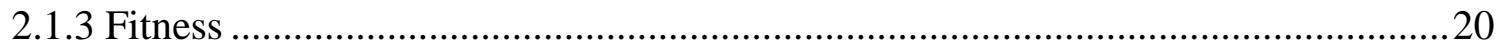

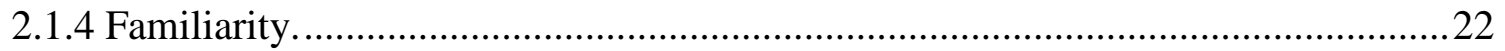

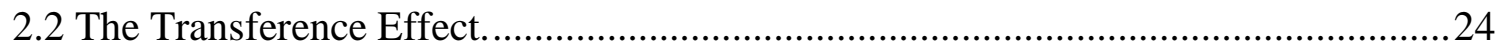

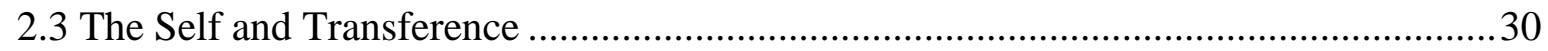

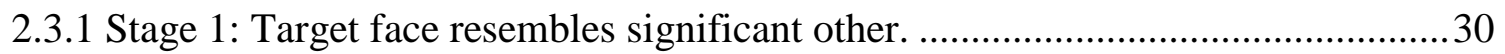

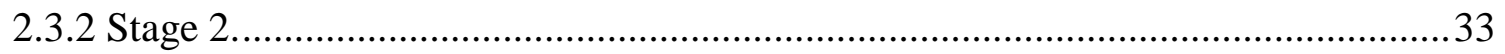

2.3.3 Stage 3: The subsequent judgement of the target stimulus incorporates the contents and/ or valence of the significant other representation .................................34

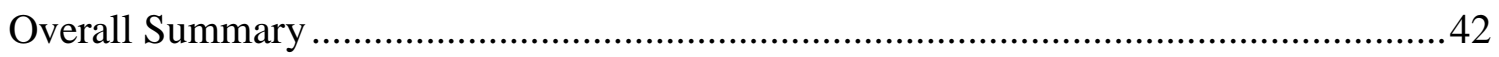

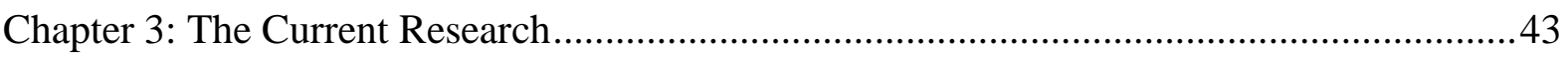

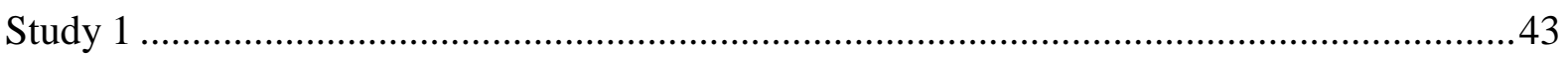

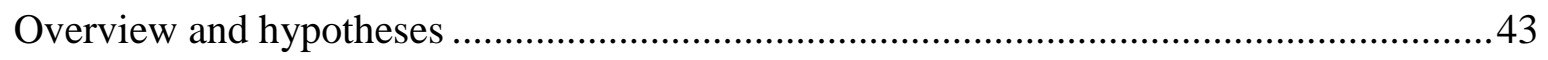

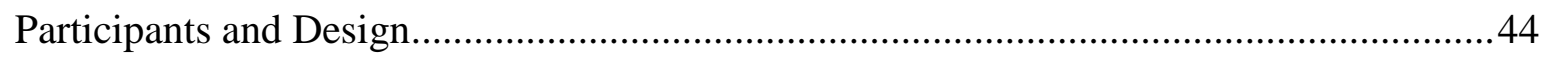

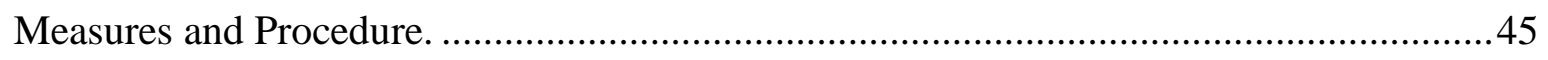

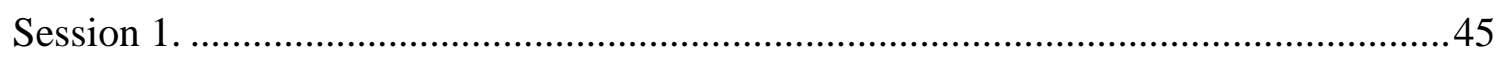




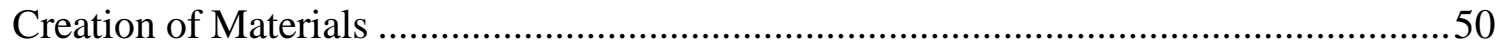

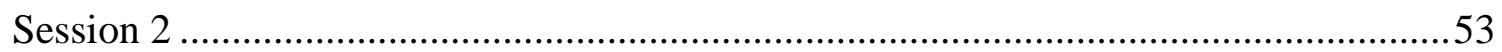

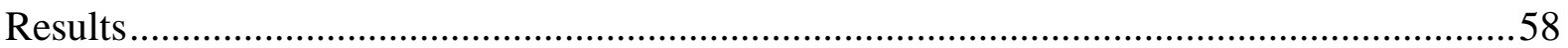

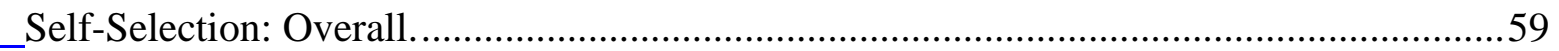

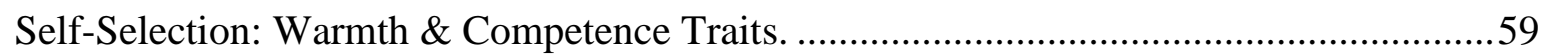

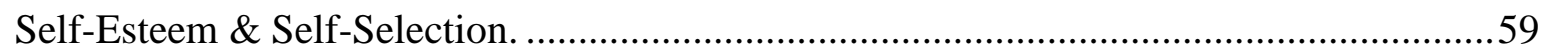

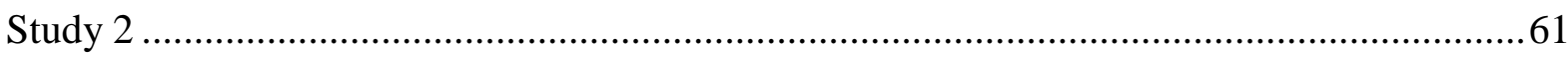

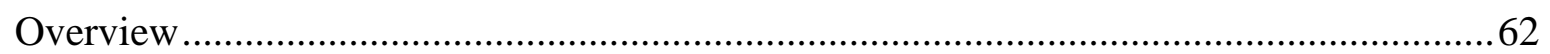

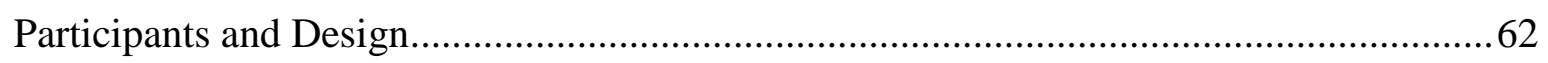

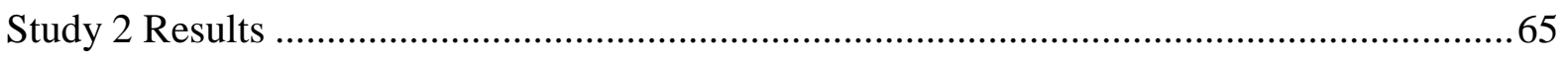

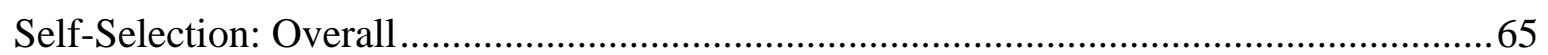

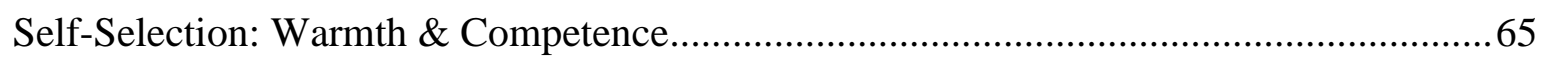

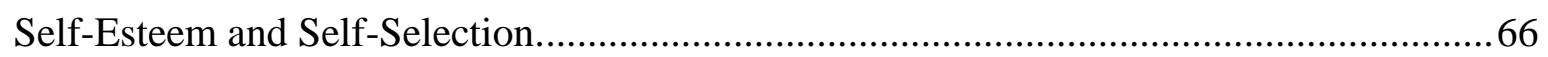

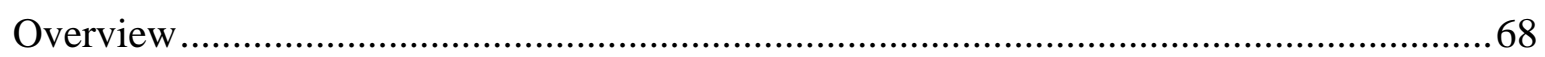

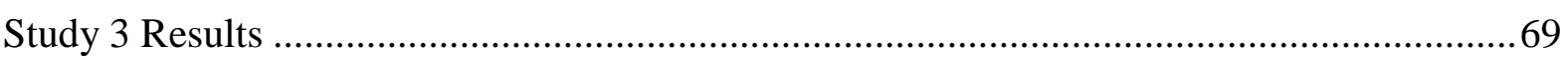

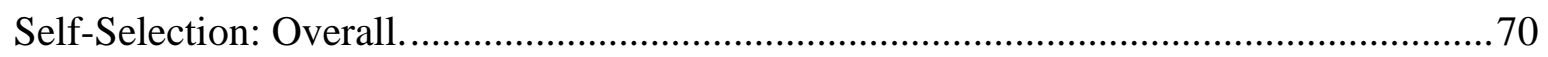

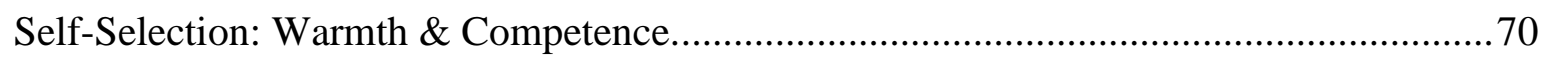

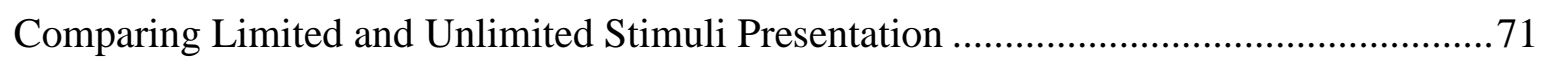

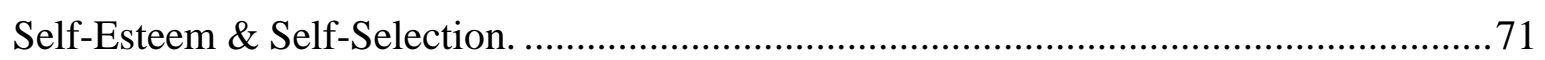

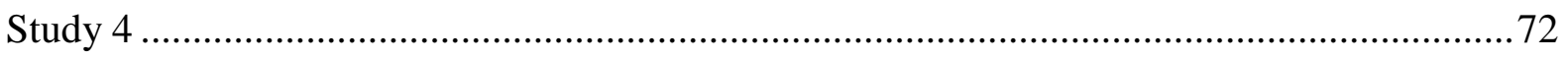

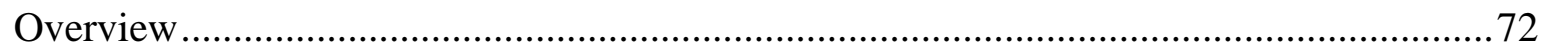

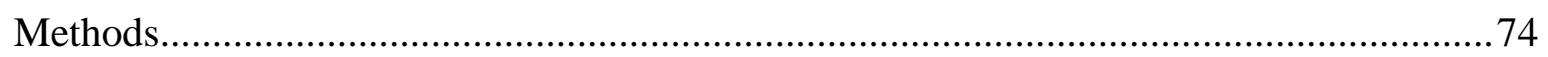

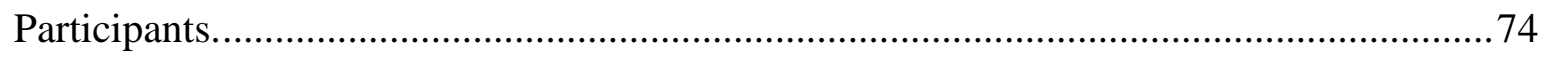

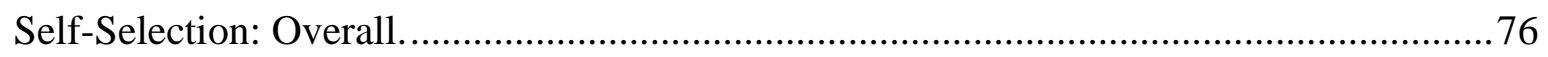

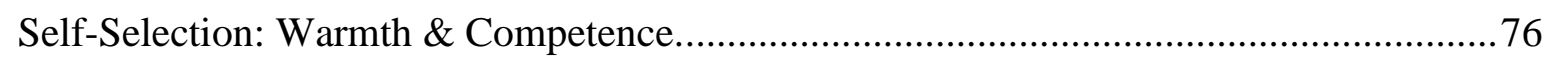

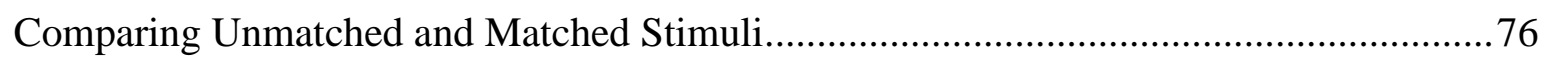

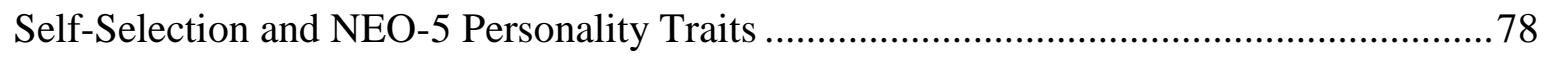

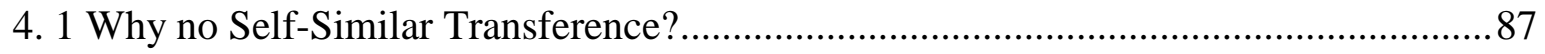

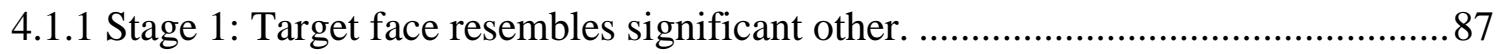

4.1.2 Stage 2: A mental representation of the significant other becomes activated in

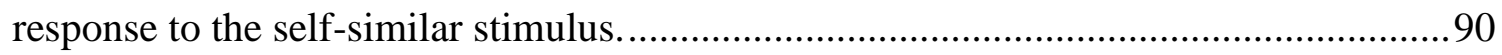

4.1.3 Stage 3: The subsequent judgement of the target stimulus incorporates the contents and/ or valence of the significant other representation.................................. 91

Possibility 2: Differential activation of Multiple Selves.................................................93 


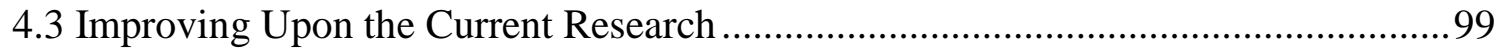

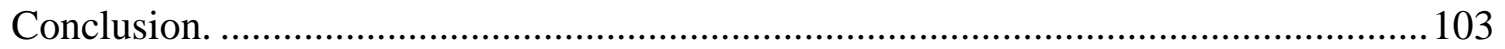

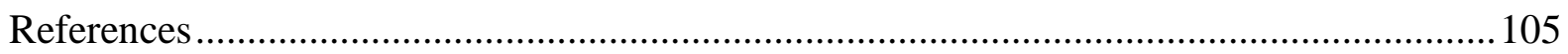

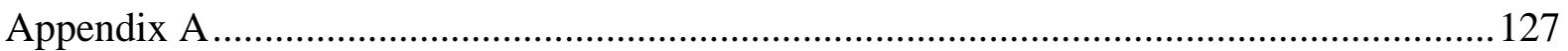

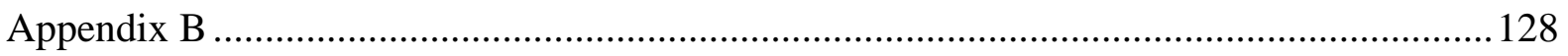

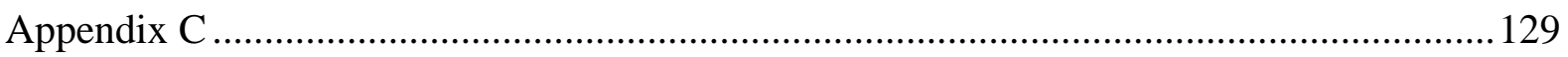

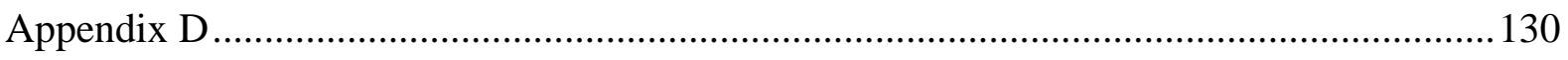

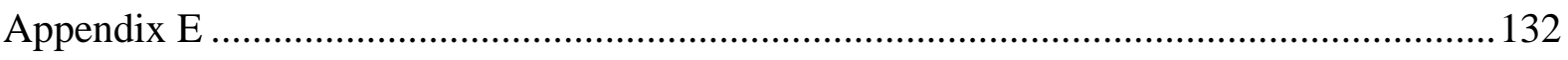

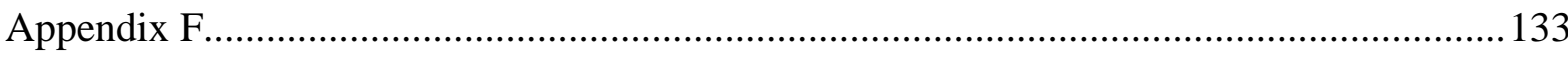

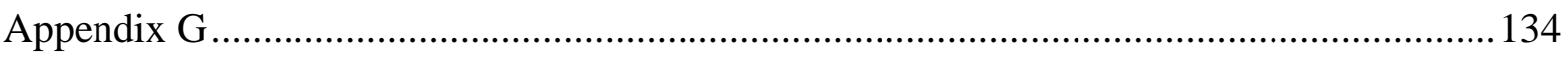

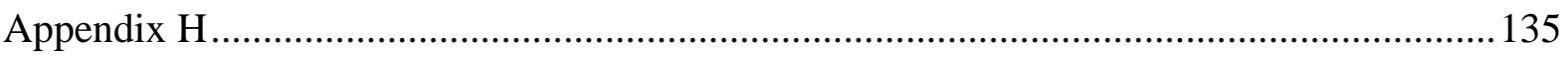




\begin{abstract}
Forming rapid and reasonably accurate impressions of other people to determine the potential for threat is a crucial human skill that has evolved over millennia. That said, often these first impressions may be inaccurate as the processes underlying person perception are subject to bias. Transference is one such bias which occurs when an encountered novel individual, for whatever reason, is similar enough that he or she activates the mental representation of a 'significant other' which is then "transferred" to that novel individual. In particular, judgments of the new person are assimilated to both evaluations (positive or negative) as well as the specific trait content of the activated representation. The current research proposed that the self-concept as activated by self-similar stimuli can act in a similar fashion. Specifically, it was proposed that activation of the self-concept - through encountering an individual who is similar to the self - may trigger transference of self-concept-related feelings and emotions to a novel other. The current research tested this prediction in four experiments by comparing participant judgements of own self-concept with trait-related judgements about novel targets, half of which were modified to resemble the perceiver. It was expected that participants would rate participant-similar stimuli as more similar to themselves than non-similar stimuli. Overall, experimental results did not support this hypothesis in that participant judgements and evaluations of self-resembling faces did not differ significantly from judgements and evaluations of stranger-similar faces in any reliable pattern. The implications of these findings are discussed in relation to previous research on first impressions, transference, and self-concept.
\end{abstract}


Look at the portraits of Locke, of Steele, of Boerhaave, of Maupertuis, and the rest, and you will not be surprised to find strong faces and eagle eyes. Look over a multitude of others, and you can always distinguish the man of talent from the man of genius, and often even an honest man from a scoundrel.

- Julian Offray de la Mettrie (Man a Machine, 1748)

\section{Introduction Overview}

First impressions are an integral part of our daily lives, affecting the way that we perceive and behave towards others. The face, being one of the first things that we notice when meeting someone new, is utilised as a rich source of information when forming first impressions. Research suggests, however, that our first impressions of target faces are not always accurate as they are subject to a number of errors and biases. Of particular interest in the current research is the phenomenon of transference. This occurs when a mental representation of a well-known other is integrated with, or otherwise affects our first impressions of novel targets. The current thesis seeks to understand the effects of this bias on first impressions of self-resembling faces.

The first chapter of the introduction outlines the viability of the thesis that spontaneous first impressions from facial information serve as an evolutionary adaption. The second chapter of the introduction provides a discussion of common errors and biases made during facial first impressions, followed by a more specific exploration of the self in a transference context. Chapter Three describes the four experiments conducted, along with the findings of those studies. Finally, Chapter Four provides a general discussion of the results of the current research and how these relate to the theory of transference, and other relevant literature. 


\section{Chapter 1: An Evolutionary Basis for Facial First Impressions.}

The importance and ubiquitous nature of forming impressions from faces is perhaps unsurprising if we are to consider them as an adaptive mechanism that has evolved over time. However, to provide a convincing account for the evolutionary utility of a particular process or mechanism, the existence of three key characteristics must first be demonstrated (Fletcher, Simpson, Campbell, \& Overall, 2013):

1) the mechanism must be universal;

2) there must be a clear biological basis for the mechanism; and

3) employment of the mechanism should increase the likelihood of the organism's survival and reproduction (functional significance).

\subsection{The Universality of Facial First Impressions}

When discussing the universality of first impressions several factors must be examined: antiquity, consensus across individuals, consensus across cultures, and consensus across ages. The antiquity of the relationship between the face and personality judgements is supported by entries in historical texts. As far back as 106-43 B.C., the ancient Roman Philosopher Cicero referred to the face as "the picture of the mind with the eyes as its interpreter" (as quoted in Speake, 2015, p.102). This belief, that a person's character may be deduced from the face, has continued to endure throughout our more recent history; discussed in essays (e.g. La Mettrie, 1748; Schopenhauer, 1788-1860), utilised in fiction (e.g. Chaucer, see Pace, 1962), and conveyed through art (Lindauer, 1984).

Recent research has demonstrated that the judgements we make from facial information can show a surprisingly high level of consensus amongst individuals, even when 
facial information is only available for a very short time. For example, Bar, Neta, and Linz (2006) examined the similarity of threat judgements made by participants of neutralexpression male faces (presented as greyscale photographs). Results indicated that these judgements of threat showed a significant level of similarity across participants, even when the presented faces were visible for as little time as $39 \mathrm{~ms}$ each. Similar consensus between individuals has been found in facial judgements of other traits or attributes such as intelligence (Zebrowitz, Hall, Murphy, \& Rhodes, 2002), competency (Ballew \& Todorov, 2007), sexual orientation (Rule, \& Ambady, 2008), trustworthiness (Rule, Krendl, Ivcevic, \& Ambady, 2013; Willis \& Todorov, 2006), and extraversion (Kenny, Albright, Malloy, \& Kashy, 1994). It is suggested that this consensus across individuals may be driven by the potential adaptive costs and benefits associated with such trait judgements (Zebrowitz, Franklin, Hillman, \& Boc, 2013). This thesis will be discussed later on.

In order to make the claim that trait-judgements from faces are universal, consensus in trait judgements of faces must be apparent not only at an individual level, but also at a crosscultural level. A stream of research in the area has found such a consensus between a wide range of cultures, such as: US and Korean (Zebrowitz, Montepare \& Lee, 1993), US, Asian, and Hispanic (Cunningham, Roberts, Barbee, Druen, \& Wu, 1995), and African, Caucasian, South Asian, and East Asian (Birkás, Dzhelyova, Lábadi, Bereczkei, \& Perrett, 2014).

In an example of the universality of trait judgements, Zebrowitz et al (2012) demonstrated generalisability of trait inferences from faces made by Americans to those made by the Tsimane' people (a culturally isolated people from the Bolivian rainforests). Participants (from the Tsimane and US) rated neutral expression photographs of 95 faces (40 American and 55 Tsimane') based on: attractiveness, babyfacedness, healthiness, intelligence/knowledge, dominance/respect, and warmth/socialness. Significant betweenculture agreement was found for all ratings of Tsimane' faces, and for most ratings of 
American faces (barring those of babyfacedness and dominance/respect). As noted by the Zebrowitz et al (2012), these findings are unique among other cross-cultural research in the area, due to the isolated nature of the Tsimane' people, and the subsequent lack of interaction with and exposure to other cultures. Finding agreement between trait inferences made by cultures that have not been in contact with one another greatly supports the universality of first impressions from faces.

Finally, recent research suggests that consensus in facial first impressions can be found across wide age brackets (Short et al., 2012). Children have been found to form consistent trait judgements of others from 8 years of age. For example, Ma, Xu, and Luo (2016) compared trait judgements of facial attractiveness and trustworthiness made by children between the ages of eight and twelve to the same judgements made by adults. Consensus for both types of trait judgement was found within children of the same age group, whilst the degree of consensus between those of the same age-group increased with age, suggesting a developmental trend. Furthermore, as noted by the authors, the overall pattern of the trait judgments made by children in this study was similar to that of adults, suggesting that both groups base these trait judgments on similar facial characteristics. This consensus in judgments of faces also seems to persist throughout the lifespan. For example, Zebrowitz et al., 2013 demonstrated significant similarity between first impressions of faces made by younger adults (18-22) and older adults (65-85). Other research has found similar consensus between younger and older adults in judgements of a number of traits such as: attractiveness (Kiisji et al., 2016), health and competency (Zebrowitz et al., 2014) and babyfacedness (Zebrowitz, \& Montepare, 1992).

In sum, considering the evidence for both the antiquity and cross-cultural nature of first impression formation discussed above, it would appear that trait inferences made from faces may well occur as a result of an underlying universal mechanism passed down through 
our common ancestry; a system that is likely to develop from a young age, and continue throughout our adult years. The next section will examine the evidence for this facial firstimpression mechanism at a biological level.

\subsection{The Biological Underpinnings of Facial First Impressions}

When examining evidence for a system or mechanism at a neurological level, there are several areas of research worth considering: early development; adult neurological evidence, and research into patients with brain damage. Examining the early development of a neural system for trait inferences allows investigation into the degree to which these judgements are learned versus innate, affording the opportunity to pare down the trait judgement mechanism to its most basic components. Adult neurological evidence then allows more thorough mapping of brain networks associated with facial first impressions, aided by the study of patients with brain damage from whom we can gain unique insights by examining what happens when this system goes wrong.

\subsubsection{Early Development of a Neural Face-Processing System.}

It is suggested that the ability to process complex facial information begins very early in life, and may even be present in new-borns (for review see Johnson, Senju, \& Tomalski, 2015). Specifically, research suggests that a certain degree of sensitivity to structural facial information is innate, allowing new-borns to discriminate the faces of conspecifics from other objects or patterns (Morton \& Johnson, 1991). For example, new-borns orient to face-like patterns over non-face-like patterns (Valenza, Simion, Cassia, \& Umiltà, 1996; Salva, Farroni, Regolin, Vallortigara, \& Johnson, 2011), differentiate between attractive and unattractive faces (Slater et al., 1998), and demonstrate preferential behavioural responses to faces with direct rather than averted gaze (Farroni, Massaccesi, Menon, \& Johnson, 2007). 
That which appears in new-borns to be a broad specialisation for the processing of faces is thought to go through a fine-tuning process as the child ages. This view is supported by research suggesting that whilst new-borns process human and animal faces in a similar way (Di Giorgio, Leo, Pascalis, \& Simion, 2012), by 6 months of age human faces are processed faster (and hold an infant's attention for longer) than the faces of other species (Jakobsen, Umstead \& Simpson, 2016). More advanced face-processing combined with greater experience is thought to lead to a general preference for stimuli that are perceived as "like me" (Melttzoff, 2013). For example, infants have been found to respond preferentially to own-race over other-race faces at 3 months of age (Liu et al., 2015). Finally, by 6 years of age children demonstrate the ability to process faces holistically (i.e. view faces as the sum of all facial features, not in parts), following the same method as both younger (20-32 year old) and older (65-78 year old) adults (Mondloch, Pathman, Maurer, Grand, \& de Schonen, 2007).

Taken together, evidence for the early emergence of a face-sensitive system highlights the importance of face recognition in social cognition, and suggests an innate sensitivity to faces. This sensitivity to faces ensures that faces are prioritised when a new-born attends to his or her environment, thus aiding in the development of a much more complex faceprocessing system, informed by experiences across the lifespan.

\subsubsection{Neurological Evidence for a Face-Processing System}

Research has identified a particular neurological system found in the occipitotemporal cortex, that is thought to be specialised for the processing of facial information (Haxby, Hoffman, \& Gobbini, 2000; 2002; Fairhall \& Ishai, 2007; Behrmann, Scherf, \& Avidan, 2016). This face-processing network has demonstrated a right hemispheric dominance for the processing of the self-face (Devue, \& Brédart, 2011; Zhen et al., 2015; Behrmann et al., 2016), and consists of two main neural networks ("core" and "extended") 
which process different kinds of facial information (Fairhall, \& Ishai, 2007; Behrmann et al.,2016; Haxby, et al., 2000).

The "core" region of the face-processing network is purported to include three main areas of the brain: the inferior occipital gyrus [IOG], the fusiform gyrus [FG], and the superior temporal sulcus [STS]), and is thought to mainly process invariant facial features (features of the face that do not change according to facial expression).The "extended" region involves the intraparietal sulcus, the AMG (amygdala) and insula, the anterior temporal region, IFG (inferior frontal gyrus), and OFC (orbitofrontal cortex) areas, and is thought to process aspects of the face that are subject to change (those features that change according to facial expression).

Brain regions included within this face-processing system are thought to contribute to the formation of facial first impressions through processing of specific facial information such as: facial components (the occipital face area; Pitcher, Walsh, \& Duchaine, 2011; Comfort \& Zana, 2015; Liu, Harris, \& Kanwisher, 2010; Pitcheret al., 2011) facial identity (face fusiform area; Grill-Spector, Knouf, \& Kanwisher, 2004; Liu, et al., 2010; Axelrod \& Yovel, 2015; Zhang et al., 2016) individual level-semantic knowledge (the anterior temporal region Collins \& Olson, 2014; and the inferior frontal gyrus Zhen, Fang, \& Liu 2013; Leveroni et al., 2000), facial familiarity (cingulate gyrus; Taylor et al., 2009) and facial expression (superior temporal sulcus; Narumoto et al., 2001; Zhang et al., 2016; and the amygdala; Zhang et al., 2016, Ahs, Davis, Gorka, \& Hariri, 2014; Chen, et al., 2009; Anders, Lotze, Erb, Grodd, \& Birbaumer, 2004; Chen, et al., 2009).

\subsubsection{Research into Patients with Brain Damage.}

Further evidence for a face-specific processing system can be found in people with damage to specific regions of the brain. Brain injury in the right cerebral hemisphere in 
general (but not exclusively) has been found to lead to deficits in ability to recognise faces and to identify facial expressions (Etcoff, 1984). For example, PS (an individual with damage to the right inferior occipital cortex and fusiform gyrus) lost the ability to identify faces yet retained other visual function such as object recognition (Sorger, Goebel, Schiltz, \& Rossion, 2007). It is also possible for brain injury to render an individual unable to process certain types of facial information while retaining the ability to process other types (Bruyer et al., 1983; Tranel, Damasio, \& Damasio, 1988). For example, Young, Haan, and Newcombe (1993) conducted a case study wherein a woman, SP, with brain damage to the right middle of the cerebellum, could correctly distinguish between faces and non-faces, but could not correctly judge facial expression or face familiarity. This research suggests that there are a series of interconnected functions that differ from processing of simple visual information, and allow the complex processing of faces including, facial identity, facial expressions, and identification of a visual stimuli as a face.

Summary. The research noted above suggests that face-specific processing emerges early on in development, and grows to become a two-part system specialised for the processing of facial structure and facial familiarity independently. The independent nature of these two systems, indicated by research into both healthy and brain damaged patients, allows for a face to be both identifiable as a face in general and, separately, to be remembered as a familiar face (with all of the individual level semantic knowledge that this entails). However, whilst the above information suggests a biological basis for the processing of facial stimuli, this facial processing must yet be found to contribute in a functional way to the survival of the individual in order to be held up as an evolutionary adaption. The next section will examine the evidence for the functional significance of facial first-impressions. 


\subsection{The Functional Significance of Facial First Impressions}

From an evolutionary perspective, impression formation is commonly viewed as an adaptive process through which humans are able to quickly assess the potential dangers or benefits afforded by a novel individual (Schaller, 2008). The current section will examine the comparative evidence suggesting that facial first impressions may meaningfully contribute to an individual's survival and reproduction.

\subsubsection{Speed of facial first impressions.}

Research suggests that first impressions of functionally significant traits, such as aggressiveness, trustworthiness, and sexuality, are fast and implicit (Bar, Neta \& Linz, 2006; Rule \& Ambady, 2008; Rule, Ambady \& Hallett, 2009). Indeed, the inferential speed and spontaneity of immediate first impressions provide a compelling argument for their origin as an evolutionary adaption (Johnson, 2005). Inferential speed allows for the rapid detection and avoidance of danger, as well as for quick action and decision making in mate selection situations, while spontaneity facilitates decisiveness over deliberation (Schaller, 2008).

For example, in the Bar et al (2006) study mentioned previously, threat judgements for faces presented for only $39 \mathrm{~ms}$ were remarkably consistent with those judgments made when the faces were presented for $1700 \mathrm{~ms}(r=.77)$. This consistency across exposure times was not found for judgements of intelligence. It is suggested by the authors that this pattern of results reflects the comparative importance of each judgement type to survival; that is, the survival-related importance of threat is greater than that of intelligence, meriting more rapid processing. This thesis is consistent with the warmth/ competence model of first impression formation put forth by Fiske, Cuddy, and Glick, (2007), as explained below. 


\subsubsection{Warmth/ competence model of first impressions.}

Research suggests that high-speed social judgements tend to fall into two broad dimensions, those of warmth and competence (Fiske et al., 2007). The dimension of warmth consists of traits which can be used to infer the intent of the target. Judgements of friendliness, trustworthiness, and sincerity for example, may help a perceiver to determine whether the target means to harm or deceive them. The dimension of competence, on the other hand, consists of traits (such as intelligence or creativity) which can be used to gauge the target's ability to carry out their intended behaviour. The foundational importance of these two trait dimensions in impressions of others is highlighted in research by Wojciszke, Bazinska, and Jaworski (1998) who asked participants to make global impressions of others in their social environment. They found that $82 \%$ of the variance in these global impressions was explained by trait judgements belonging to the warmth and dominance dimensions (referred to as morality and competence by the authors).

Trait evaluations specifically related to faces have been found to adhere to a very similar dichotomous model as that of warmth/ competence. Oosterhof and Todorov (2008) used a data-driven approach to examine the way in which neutral expression faces are spontaneously characterized by a perceiver. Using principal components analysis these authors were able to determine that most face evaluations fall within two main dimensions: valence/trustworthiness and power/dominance. The valence/trustworthiness dimension of Oosterhof and Todorov's model (2008) model is conceptually similar way to the warmth dimension in Fiske et al (2007), as it is strongly related to positive and negative trait judgements (e.g. trustworthiness, attractiveness, aggression) all of which, like warmth, assist in determining whether or not the other person has the intention to carry out a threat. Likewise, the power/dominance dimension of Oosterhof and Todorov's model is conceptually similar to Fiske et al's competence dimension (although not quite equivalent; 
see Sutherland, Oldmeadow, \& Young, 2016), as it is strongly related to judgements of confidence, aggressiveness, and dominance - all of which, like competence, assist in determining whether or not the other person has the capacity to carry out a threat.

When forming a first impression of another person, trustworthiness judgements occur prior to dominance judgements, and have more of an impact upon the resultant behaviours and feelings of the perceiver (Fiske et al., 2007). This makes evolutionary sense when considering the relative importance of warmth judgements to the survival of the perceiver; determining whether a person intends to harm us, as a first step, is more pertinent to survival than finding out whether or not they are capable of doing so. These trustworthiness and dominance judgements inform subsequent behaviours in a very functional way (Todorov, Baron, \& Oosterhof, 2008). That is, the judgments may lead to approach behaviours by motivating the individual towards positive stimuli or, alternatively, behaviours motivated by the avoidance of negative stimuli (Elliot, 2006). These approach and avoidance motivations are fundamental to human psychology, and integral to our survival as a species (Elliot, 2006). Thus, judgements of trustworthiness and dominance as pre-cursors to approach/avoidance behaviours may also be considered to be of evolutionary importance.

Summary. The research discussed above suggests that first impressions allow us to quickly assess the intentions and competency of a novel individual, whilst erring on the side of caution. The speed, order, and weighting of trait judgements give credence to the underlying functionality of trait judgements, pointing to their importance as part of our evolution as a species. 


\section{Conclusion; an evolutionary basis for first impressions.}

The research evidence discussed in the sections above suggests that first impressions are formed by way of a universal (and biologically-based) mechanism, which increases the chances of survival and reproduction. This provides a convincing argument for the evolutionary utility of first impressions. Whilst this chapter outlined the evolutionary nature of first impressions the next chapter will shift focus to look, more specifically, at the accuracy of first impressions. 


\section{Chapter 2: Biases in First Impression Formation}

As discussed in the previous chapter, first impressions are arguably driven by innate, biologically-based mechanisms which can often operate outside of conscious awareness. However, whilst providing a method of adaptive impression formation that requires a minimum of cognitive resources (Schaller, 2008) first impressions are not always accurate. Indeed, adaptive responses to certain types of target information are often overgeneralised beyond the point of functional adaptivity (Zebrowitz, \& Montepare, 2008; 2008a). That is, even though the heuristic value of these processes outweighs the potential for error, judgment error can still occur. The current chapter will discuss these biases with regards to the effect that they have on facial first impressions.

\subsection{Overgeneralisation Biases.}

Overgeneralisation biases are thought to share a basis in evolutionarily adaptability, wherein the bias itself provides an adaptive shortcut in impression formation, but continues to have an effect upon our inferences beyond the point of being adaptively advantageous (Zebrowitz, \& Montepare, 2008; 2008a). Four types of overgeneralization bias will be discussed here: emotion resemblance, babyfacedness, fitness, and familiarity.

2.1.1 Emotion Resemblance: Facial expressions are used in social interactions to make judgements about a person's current affective state (Dimberg, \& Öhman, 1996). For example, parting of the lips may denote surprise or amusement, whilst raising the upper lip may indicate disgust (Namba, Makihara, Kabir, Miyatani, \& Nakao, 2017). Just like the warmth and competence judgments discussed in the previous chapter, judgments of affect occur quickly and spontaneously (Tracy \& Robins, 2008), trigger adaptive approach or avoidance responses (Willis, Palermo, \& Burke, 2011), and are, thus, functional. However, as well as providing cues to a person's affective state (which is subject to change), facial 
expressions may also be used to make stable trait inferences about the target person (Zebrowitz \& Montepare, 2008). For example, target individuals with happy or surprised facial expressions tend to be judged as possessing greater levels of dominant and affiliative traits (such as assertiveness or friendliness). Whereas target individuals with sad or fearful expressions tend to be judged as being low in dominant traits (Montepare \& Dobish, 2003).

This emotional-face overgeneralisation may also occur in circumstances where the target face bears a structural resemblance to a particular emotion. For example, Said, Sebe, and Todorov, (2009) asked participants to make trait related judgements of a set of neutral expression faces. They then used a computer program (designed to detect emotional patterns in facial structure) to examine the structure of the same neutral expression faces. It was found that faces judged by participants to be high in threat-related traits (those signalling avoidance) were classified by the computer program to (structurally) resemble anger. Furthermore, faces judged by the participants as being either positively or negatively-valenced were classified by the computer program as resembling happiness and sadness (respectively). These results suggest that our ability to recognise emotional expressions on faces (while adaptive) may then be overgeneralised to neutral faces that bear a structural resemblance to emotional expressions, resulting in inference of stable personality judgements.

2.1.2 Baby-facedness overgeneralisation effect. In adults, cues to baby-facedness (such as large eyes or small noses) prompt baby-related trait inferences such as warmth, helplessness, naivety and incapability (Cassidy, Zebrowitz, \& Gutchess, 2012; Zebrowitz, \& Montepare, 2005). As with emotion resemblance, biased responding to baby-faced adults is thought to be based in evolutionary adaptability. When the target individual is a baby or small child, these types of judgments facilitate functionally adaptive behaviors on the part of the perceiver, regarding the need to protect and care for one's offspring (Zebrowitz, \& 
Montepare, 2008); however, these responses are then overgeneralised to adults with baby-ish features.

The evolutionary explanation for the babyfacedness overgeneralisation effect is supported by cross-cultural similarity in response to infantile features (McArthur \& Berry, 1987; Zebrowitz, Montepare, \& Lee, 1993). For example, McArthur \& Berry (1987) found near perfect cross-cultural agreement (between Korean and American students) in judgements of facial maturity, as well as in attribution of more psychologically child-like traits to babyfaced individuals than to mature-faced individuals. Furthermore, correlations between facial maturity ratings and specific facial features were very similar for Korean and American students, suggesting that the same facial features are being used as the basis for maturity judgements across cultures.

Similarity in responding to baby-faced adult faces is also found between adults and young children. For example, Montepare and Zebrowitz-McArthur (1989) asked groups of younger children (aged 3-4) and older children (aged 4.5-6) to make judgements of 6 adult (male or female) stimuli faces in terms of babyfacedness. Half of the six adult stimuli photos had been previously rated by adults as being high in babyfacedness, and half as being high in maturity. It was found that when the stimuli photographs were male, the ability of children in both age groups to distinguish the baby-faced from the mature faced photos was above chance. However, when the stimuli photographs were female, only the older children were able to distinguish the baby-faced from the mature faced photos at above chance levels. The authors concluded that, whilst some perceptual experience may be necessary to distinguish babyish adult faces, their results demonstrate a similarity in facial maturity judgements between children and adults.

2.1.3 Fitness. Another common finding in first impression research is that perceivers have a tendency to rate attractive individuals more positively in a wide variety of dimensions 
(such as intelligence, health, likeability, and social competence), than less attractive individuals (Dion, Berscheid \& Walster, 1972; Feingold, 1992; Zebrowitz, \& Montepare, 2008a, 2008; Ambady, \& Skowronski, 2008). This effect (dubbed the 'attractiveness halo effect') is thought by some to originate in the functional use of appearance as an indicator of fitness.

Indeed, some research suggests that cues to attractiveness (such as facial averageness, and facial symmetry) are associated with evolutionary benefits such as increased fertility (Pflüger, Oberzaucher, Katina, Holzleitner, \& Grammer, 2012) and immune function (Scheib, Gangestad, \& Thornhill, 1999, as cited in Ambady \& Skowronski, 2008). Thus, sensitivity to these cues may be an evolutionary adaption, allowing for selection of more genetically desirable mates. This thesis is supported by the finding that a preference for attractive faces can emerge early on in infancy (Griffey \& Little, 2014; Slater et al., 2000; Slater et al.,1998), and that ratings of attractiveness remain consistent across cultures (Langlois, et al., 2000).

More recent research suggests that the attractiveness halo effect is driven by an aversion to unattractiveness rather than a preference for attractiveness per se - an effect dubbed anomalous face overgeneralisation (Zebrowitz, \& Montepare, 2015). For example, Zebrowitz and Rhodes (2004), selected target stimuli from a longitudinal data set, which included facial images of targets. Judgements pertaining to the attractiveness, perceived health, and perceived intelligence of these faces (obtained in previous studies) were compared to actual intelligence and health ratings of the target person (as recorded in the longitudinal study). For the sake of analysis, target faces were divided into two groups those below the median in terms of attractiveness ratings, and those above the median. Results showed that (for adult stimuli faces) whilst attractiveness predicted perceived intelligence and health for both the below and above median groups, attractiveness only predicted actual intelligence and health outcomes for the below median group. In other 
words, cues to attractiveness resulted in accurate impressions of health and intelligence but only for unattractive to averagely attractive individuals. Importantly, perceived intelligence and health ratings continued to be utilized for targets in the above median (attractiveness) group. Together, these findings support the anomalous face overgeneralisation hypothesis, in that aversion to unattractiveness (and possible genetic undesirability) is overgeneralised beyond the point of being valid.

2.1.4 Familiarity. The familiar face overgeneralisation hypothesis (Zebrowitz, Bronstad, \& Lee, 2007) states that our first impressions of others are influenced by the degree of similarity between the facial appearance of the target person and that of others one has been exposed to. As noted by Weigold, Weigold, Natera, and Russell, (2013; see also Peskin \& Newell 2004), this effect can be explained by reference to two different types of facial of familiarity: episodic familiarity (based on previous exposure to that face), and general familiarity (based on pre-existing cognitive prototypes). The former refers to familiarity due to perceived similarity between a novel target and a specific known individual (Peskin \& Newell, 2004). Research into episodic familiarity has shown that people prefer stimuli that they have previously been exposed to over those that they have not (Zajonc, 1968). Termed the mere exposure effect, this finding has been replicated more recently using facial stimuli (Rhodes, Halberstadt, \& Brajkovich, 2001; Zebrowitz \& Zhang, 2012).

For example, Rhodes et al (2001) demonstrated that repeated exposure to an individual target face is enough to increase perceived likeability. Participants were exposed to four groups of six faces that varied by sex and ethnicity between groups. Each face within a group was presented four times. Following this exposure phase, participants were asked to make trait judgements of various faces in terms of likeability. These faces (to be rated) included the previously seen faces, new faces, and two sets of composite faces made up of either the previously seen group faces or of new faces. Participants showed increased liking 
for the previously seen faces over those not included in the learning phase. Furthermore, it was found that averaged composites of facial stimuli that had been seen in the exposure phase were themselves more liked than average composites of unseen faces. These findings suggest that not only does the mere exposure effect apply to facial stimuli, but that liking for previously seen facial stimuli can also generalise to new stimuli that are representative of that group.

In a later study Zebrowitz et al (2007) demonstrated a similar general familiarity effect on judgements of other race faces. Black and White American college undergraduates rated photos of White and Black individuals on a number of dimensions including measures of likeability and familiarity. Both Black and White participants reliably rated own-race faces as both more familiar and more likeable than other-race faces; however, lower familiarity for own-race faces was found to partially mediate this in-group favouritism. Furthermore, unfamiliarity of other race faces contributed to greater levels of negative stereotyping. Again, consistent with familiar face overgeneralisation, these results indicate that target similarity to racial prototypes can affect perceived familiarity and stereotyping of that target.

As noted by Moreland and Topolinski (2010) current research is still deciphering the underlying mechanisms of familiarity effects such as those discussed above. One of the most popular theories posits that being exposed to a stimulus repeatedly increases the ease with which it can be processed - referred to as fluency. This increase in processing fluency then results in an increase in positive affect (Winkielman, \& Cacioppo, 2001; Harmon-Jones, \& Allen, 2001). A connection between repeated exposure to a stimulus and positive affect has been proposed by Zajonc (2001) in the context of classical conditioning; any conditioned stimulus (such as an unknown face) paired repeatedly with neutral or benign events (i.e. the unconditioned stimulus), will result in the attachment of an approach tendency (the conditioned response) to the conditioned stimulus, which in turn elicits a general positive 
affect. In relation to evolutionary adaptiveness, the lack of negative events following repeated exposure to a stimulus (and subsequent positive affect) may act as a signal that the stimulus is safe (Zajonc, 2001).

Whilst familiarity judgements of target stimulus have been found to increase based on mere exposure to that stimulus (or representative others), this is not the only route through which familiarity can influence first impressions. Another type of familiarity effect, called transference, influences first impressions through meaningful similarity between the target and a well-known individual. This effect will be discussed in depth below and provides a direct basis for the current thesis.

\subsection{The Transference Effect.}

There are a variety of salient cues that may be used as a basis for drawing inferences about the personality of a novel target. These may involve the use of perceivable target attributes such as facial features (Hugenberg \& Wilson, 2013), and voice features (McAleer, Todorov, \& Belin, 2014), or the use of perceivable aspects of the target's environment (Weisbuch, Unkelbach, \& Fiedler, 2008). In addition to things that can be directly perceived, there are numerous other sources of information cannot be directly perceived, yet still exert influence upon impression formation. In particular, the activation of a mental prototype is a good example of an information source that is not directly perceptible, yet still has an influence upon the formation of first impressions. This is because, once activated by environmental stimuli, the mental representation may act as a filter for all subsequent information. Thus, something not actually present at the time (and that may have only a tangential relationship to the current situation) may determine what impression is formed.

Based on research into category prototypes, Andersen and Cole (1990) examined the thesis that first impressions may be influenced by the activation of pre-existing 
representations pertaining to well-known others. That is, the degree to which a novel person (partially) matches the representation of a close other will have direct impact on how that novel person is perceived. Specifically, if a novel target resembles a significant other then they are more likely to be thought of as having similar characteristics to that significant other.

In their study, participants were asked to generate a number of features (in response to sentence-stem prompts e.g. “A person like Roger ...”) describing four categories of individuals: 1) a significant other, 2) a non-significant other, 3) a stereotype, and 4) a person whom embodies a specific trait (e.g. "neurotic"). Participants then ranked each feature based on relevancy and exclusivity to the category of individual described. Finally, participants were asked to select several descriptors that were irrelevant to each type of individual. Later, in an ostensibly unrelated experiment, participants were asked to read and remember multiple statements describing four fictional characters. Each fictional character description corresponded to one of the four social categories used at the beginning of the experiment (i.e., significant other, non-significant other, trait, and stereotype). Of the statements used to describe each fictional character, slightly over half contained category relevant features, whereas the remaining contained information that the participant had previously selected as category-irrelevant. After a filler task designed to disrupt short term memory, participants completed a recognition memory test in which they indicated their confidence about whether or not a series of statements had been included in the fictional character descriptions. Some of the new items matched the features of the category type (e.g., significant other, stereotype) that had not been paired with the novel target.

Results demonstrated that the activation of significant-other representations resulted in significantly more false-positive recognition errors than activation of any other category. In other words, when the concept of their significant other was activated (compared to any of the other representations), participants were more likely to "recognise" additional significant- 
other relevant features as having been presented - even when these were not included in the novel target descriptions. For example, if someone described their significant other as being "honest, intelligent, gregarious, funny, intense, and generous,", and was then presented with a target description that included some (but not all) of these traits (e.g. honest, intelligent, gregarious, warm, and agreeable), they would be more likely to falsely recall that a generousrelevant feature had been presented. Andersen and Cole (1990) refer to this effect as "transference" because content that is characteristic of the activated representation gets "transferred" to the new individual. This leads the perceiver to respond to the individual in a similar way as they would to their significant other.

Anderson and Baum (1994) extended this research by looking into the role of transference in affective judgements of novel stimuli (rather than just the incorporation of positive character traits). In an initial session, participants provided feature lists describing both positive and negative features of two significant others, one whom they felt very positively about and the other whom they felt very negatively about. Two weeks later (in an ostensibly unrelated experiment) participants were brought back to the lab and told that they would be joined by another participant. Before meeting the person, participants read and were asked to remember a set of descriptors pertaining to the other alleged participant. In reality the descriptors were manipulated to either resemble the participant's positive or negative significant other (a control group saw lists that resembled a different participant's positive or negative significant other). After reading the information, participants completed an evaluative measure of the target person, and a recognition memory test for target information. For the recognition memory test descriptors were either items included in the original target information, or items that had been included in the subject's own descriptions of each of their significant others. 
The results of this study showed that target resemblance to the participant's significant other (rather than an unknown other), resulted in significantly more false-positive errors on the recognition task (for representation consistent descriptors). In other words, as in Anderson and Cole (1990), when the concept of their significant other was activated, participants were more likely to falsely "recognise" significant-other relevant features as having been presented in the target description. It was also found that when the target resembled the participant's significant other (either positive or negative) participants expressed a greater magnitude of valence in their evaluative judgement of that target than when the target resembled an unknown significant other (positive or negative respectively). Specifically, greater liking was expressed for targets resembling the participant's own positive significant other (as compared to targets resembling a different participant's positive significant other), and less liking was expressed for targets resembling the participant's own negative significant other (as compared to targets resembling a different participant's negative significant other). Based on these results Anderson and Baum (1994) concluded that resemblance to significant others may trigger transference of both representation-consistent information (such as specific characteristics or descriptors of that person e.g. works hard), and of representation consistent evaluation (such as the degree of positive or negative feelings that one holds towards a significant other e.g. like or dislike).

2.2.1 How transference is triggered; faces? Anderson and Cole (1990) and Anderson and Baum (1994) demonstrated that transference can be triggered with written personalitybased descriptions of targets. More recently research has taken this one step further to see whether target facial similarity to significant others (conveyed through photographs) would be enough to trigger transference. For example, Kraus and Chen (2010) got participants to rate a wide range of photographs in terms of resemblance to a specific significant other. Participants also provided positive, negative, and irrelevant attributes that described their 
significant other. At a later date participants returned to the lab and completed an (ostensibly) separate task in which they rated the photograph of a novel target. In fact, the "new" photograph was one previously rated as "highly similar" or "highly dissimilar" to their significant other. Participants were asked to rate the new photographs on critical attributes (derived from the participant's significant other descriptors) and non-critical attributes (taken from the participant's significant other-irrelevant descriptors). It was found that participants in the "highly similar" condition rated the new photograph as more similar to their significant other than participants in the "highly dissimilar" condition. In other words, supposing that all participants rated their significant other as trustworthy, participants in the "highly similar" condition would be far more likely than those in the "highly dissimilar" condition to also rate the new photograph as trustworthy. These results suggest that subjective similarity to a significant other is enough to trigger transference as evidenced through representationconsistent content (Kraus \& Chen, 2010).

2.2.2 How transference is triggered; subjective versus objective similarity. Kraus and Chen (2010) provided initial evidence for transference as triggered by subjective similarity between a novel target and the perceiver's significant other. However, Günaydin and colleagues (Günaydin, Zayas, Seluk, \& Hazan, 2012) critiqued their findings, noting that the transference effect found in Kraus and Chen (2010) does not allow for inferences to be made about the effect of objective facial resemblance on transference. That is, the transference effects found in Kraus and Chen (2010) are based upon participant judgements of similarity (i.e., between the stimuli materials and the significant other), and thus, are likely to be affected by individual-level biases; such as the tendency to rate significant others as more attractive than they actually are (see Barelds-Dijkstra \& Barelds, 2008). Günaydin and colleagues argue that more objective measures of similarity would better support the argument that transference is triggered by feature-based similarities. 
In order to investigate the role of feature-based resemblance in triggering transference effects Günaydin et al., (2012) conducted a study using morphing techniques to combine significant-other (i.e., romantic partners) photographs with novel person photographs (compiled from databases: Minear \& Park, 2004; Tottenham et al., 2009). Participants were required to make snap judgements about a number of novel faces, half of which were morphed with the participant's significant-other photo (participants were unaware that the photographs had been morphed), and half of which were morphed with a novel (nonsignificant) other. Snap judgements consisted of "yes" or "no" answers to trait related questions, e.g. "Is this person trustworthy" (Günaydin et al., 2012, p.351).

Based on previous research suggesting that people automatically evaluate their partners positively (Zayas \& Shoda, 2005), Günaydin et al., (2012) hypothesised that transference would occur in the sense that the partner-morphed stimuli would be evaluated more positively by participants making snap judgements than the non-partner -morphed stimuli. The results partially supported their hypothesis, with female participants in general rating significant-other-morphed photos as more positive that the non-significant-othermorphed photos. These results suggest that feature-based similarity to a significant other can provide the basis for transference of significant other related information onto novel targets.

Summary: From the research discussed thus far it has been established that certain adaptive responses to target information often become overgeneralised, affecting our first impressions of new people. Once such overgeneralisation (transference) occurs when the mental representations that we hold for significant others are activated and subsequently integrated into our first impressions of a novel target. Transference can be triggered by written descriptions, as well as photographs that bear either a subjective or objective resemblance to a the significant other. The next section will examine the merits of the suggestion that transference can be applied to the self (as a significant other). 


\subsection{The Self and Transference}

As discussed in the previous section, transference as triggered by facial stimuli occurs in three stages wherein: 1) The target face resembles (either objectively or subjectively) the face of someone who is significant to the perceiver, 2) A mental representation of the significant other becomes activated in response to this stimulus, 3) The subsequent judgement of the target stimulus incorporates both the valence and contents of the significant other representation. The current section will work through the three stages of transference outlined above and evaluate the possibility that self-similar facial stimuli can trigger transference. During this section transference as triggered by self-similar stimuli will be referred to as selfsimilar transference (to allow for concision).

2.3.1 Stage 1: Target face resembles significant other. There are two conditions that need to be met in order for the first stage of self-similar transference to be possible. First, the target face must resemble the self. As far as self-similar stimuli are concerned a photograph of a participant would be adequately similar to that participant in order to trigger transference (as defined above). This assertion is based on the common laboratory technique of using mirrors (i.e. reflections of the self-face) as an effective means to increase a subject's private self-awareness (see Fejfar \& Hoyle, 2000 for a review). Morphing techniques (such as those used in Günaydin et al., 2012) used to combine these participant-similar photographs with novel person photographs would allow for the creation of objectively self-similar stimuli.

Second, the "self" must act as a significant other. In so far as a significant other is defined as "any individual who is or has been deeply influential in one's life and in whom one is or once was emotionally invested" (Anderson \& Chen, 2002 p. 619), the current thesis asserts that an individual may act as significant to themselves in the same way. That is, the self-concept is a mental representation of a significant individual that is both deeply 
influential and highly motivating to the individual, and for which there is great emotional investment.

In research that would seem to support this contention, Anderson, Glassman, Gold, and Kruglanski (1998) conducted a study examining the similarity between mental representations of the self and significant/ non-significant others. Participants were asked to: 1) list features describing themselves, a significant other, and a non-significant other, 2) rank the four most important private and the top four public features in each list in terms of how well they described each individual, 3) Finally, Participants were asked to rate how descriptive each of the four public aspects was of each of the four private aspects and vice versa.

The results of this study suggested differences in accessibility, availability, and distinctiveness of memory representations for the self and others. Accessibility was operationalised as the speed (retrieval latency) with which featural aspects were provided for each target. Private aspects of the self were retrieved significantly faster than private aspects of non-significant others, but not faster than significant-other representations. The authors concluded that self-other perspective differences may drive some of the difference in mental representation accessibility, but that emotional and motivational importance to the self can also have an important impact. The similarity in accessibility of self and significant other featural aspects in this study supports the notion that the self could trigger transference in a similar way as the self-representation is as readily accessible as the significant other representation.

Availability was operationalised as the number of private and/or public features provided by participants for each target. It was found that self-representations included a greater number of private featural aspects e.g. "often anxious" than public featural aspects e.g. "walks fast", a difference not found for other targets. Comparing across targets, the 
greatest number of private featural aspects were listed for the self, followed by the significant other, and finally the non-significant other. The authors concluded that the emphasis upon private featural aspects for the self (but not for other targets) again speaks to the influence of self-other perspective differences in shaping mental representations. However, the fact that a greater number of private aspects were listed for the significant other than for the nonsignificant other suggests that (as with accessibility) emotional and motivational factors also have an important influence on mental representations.

Distinctiveness was operationalised as the degree to which private featural aspects of the target are rated as descriptive of public featural aspects and vice-versa. Participants rated public featural aspects of the self as more descriptive of private aspects than vice-versa. A similar (although non-reliable) trend was found for the significant other target, whilst a reliable reversed pattern was observed for the non-significant target (i.e. for non-significant other targets participants rated private featural aspects as more descriptive of public featural aspects than vice-versa). The authors concluded that our mental representations of the self are characterised by private featural aspects, as these are the aspects that stand out in our memory, whilst mental representations of non-significant others are characterised by public featural aspects. Furthermore, the difference between the trend for the significant other and the reliable pattern of data for the non-significant other, suggests a role for emotional and motivational significance in distinctiveness of private features in memory representations.

Overall the results of Anderson, et al. (1998) suggest similarities in the way that we access and conceptualise our mental representations of the self and significant others. Differences in emotional and motivational significance to the self play an important role in creating these similarities in that the more significant a target is to the self the more similar the mental representation of that target will likely be to the mental representation of the self (in terms of accessibility, availability, and emphasis upon private vs. public featural aspects). 
These findings support the notion that transference of the self-representation to a novel target is likely to occur much in the same way that activation of a significant other leads to such transference.

\subsubsection{Stage 2. A mental representation of the significant other becomes activated}

in response to the self-similar stimulus. In order to assert that the second stage of selfsimilar transference is likely to occur the mental representation of the self must be shown to meet the necessary requirements for activation (as similar to significant-other mental representation activation). In previous research Anderson, Glassman, Chen, and Cole (1995) investigated the necessary factors required for individual representation activation, and found that both chronic accessibility and transient accessibility of the representation determine the likelihood that it will become activated.

These authors describe chronic accessibility as the frequency with which a construct is activated. A construct that is activated more frequently is more chronically accessible and thus more primed or "ready" to become activated in future. Whilst it is difficult to argue that the self-concept is not chronically accessible, the nature of self-concept may determine which types of self-knowledge are most accessible at any one time. Rather than being one stable mental representation, the self-concept is thought to be a multi-faceted and flexible construct (Markus \& Wurf, 1987). Termed "working self-concept", the facet (or facets) of self-concept that is (are) active at any one moment can differ depending on the context and the perceiver's inner psychology. So, with regards to chronic accessibility, working self-concept is constantly-activated and therefore can be thought of as chronically accessible. Howeverwhich aspects of working self-concept are most accessible may differ dependent upon how often each aspect is activated (Markus, \& Wurf, 1987).

Previous research has already found that specific aspects of working self-concept can be activated in first impressions with others. Hinckley and Anderson (1996) found that, upon 
meeting someone new who resembled a significant other, people's relational self (i.e. the aspects of one's self that are related to who they are then they are with that significant other) become activated. Furthermore, there is much research to suggest that the content of one's self-concept overlaps with mental representations of significant others (Aron, Aron, Tudor, Nelson, \& Miller, 1991; Mashek, Aron, \& Boncimino, 2003; Smith, Coats, \& Walling, 1999). The fact that aspects of self-concept are activated in response to significant-other similar targets suggests that activation of self-concept based on self-similar targets should also occur (given the relative importance to the self of the self versus the significant other).

Assuming self-concept is chronically accessible, the second factor required for individual representation activation is transient activation (Anderson \& Chen, 2002), described as environmental cues that are relevant to the mental representation and therefore act as triggers for activation. In the current research a self-similar face will act as the transient cue for activation of the self-concept. In so far as significant-other transference has been successfully triggered using significant-other faces as stimuli (Günaydin et al, 2012) it is expected that self-similar facial stimuli will be adequate to trigger activation of self-concept in the current study.

\subsubsection{Stage 3: The subsequent judgement of the target stimulus incorporates the} contents and/ or valence of the significant other representation. It is necessary to meet one condition in this stage in order to argue that transference of a mental representation has occurred: the valence and/ or contents of the mental representation is integrated into target judgements. The likelihood that these conditions will be met as triggered by self-similar facial stimuli will be discussed below and alternative explanations will be explored.

\subsubsection{Transference of the Contents/Valence of Self-Similar Judgements: Self-}

Esteem in Self-Transference. According to the theory of transference we would expect self- 
similar stimuli to be judged in accordance with the way the perceiver views themselves. That is, if the perceiver views themselves positively we would expect them to judge the selfsimilar stimuli positively (i.e., positively valenced transference). Likewise, if the perceiver views themselves negatively we would expect them to judge the self-similar stimuli negatively (i.e., negatively valenced transference). Based on this reasoning any research examining transference as triggered by self-similar stimuli would need a way to measure the valence of a perceiver's self-concept. This could be done through gauging the relative weight assigned by that participant to positive versus negative self-descriptors (i.e. specific contents of a person's self-representation) in self-evaluations, or by measuring more general positivity towards the self, such as self-esteem.

Self-esteem. Put simply, self-esteem is an evaluation of the self along a positivitynegativity dimension (Leary \& MacDonald, 2003); however, there exist a number of conceptualisations as to what comprises self-esteem. Brown Dutton, and Cook, (2001) identify three main ways in which self-esteem is defined in the existing literature including: global self-esteem, domain-specific self-esteem (referred to as self-evaluations in Brown et al., 2001), and state self-esteem (referred to as feelings of self-worth in Brown et al., 2001). To argue for an appropriate measure of self-esteem in assessing self-similar transference, consideration must be given to how we would expect these different conceptualisations of self-esteem to operate.

Global Self-Esteem (a.k.a., trait self-esteem) can be described as one's attitude towards the self as a whole (Rosenberg, Schooler, Schoenbach, \& Rosenberg, 1995; Brown Dutton, \& Cook, 2001). Global self-esteem is a general self-evaluation, rather than a focus on an individual's feelings regarding specific personality traits or aspects of their self-concept (e.g. creativity or academic performance). Previous research suggests that this type of selfesteem remains relatively stable over time (Trzesniewski, Donnellan, \& Robins, 2003; 
Roberts \& DelVecchio, 2000; Kuster, \& Orth, 2013). In contrast to global self-esteem, domain specific self-esteem represents an individual's attitudes regarding specific aspects of their personality or self-concept. These domain-specific self-evaluations have been found to fall under four main categories: academic, emotional, social, and physical (Shavelson, Hubner, \& Stanton, 1976). Domain specific self-esteem is thought by some to act as a basis for one's global self-esteem (von Soest, Wichstrøm, \& Kvalem, 2016), and is thought to remain relatively stable over time (Rentzsch, \& Schröder-Abé, 2018). In this hierarchical approach to self-esteem, global self-esteem acts as the sum of multiple domain-specific selfevaluations. Finally, state self-esteem refers to an individual's transient emotions regarding the self, often in response to positive (e.g., receiving a promotion) and negative (e.g., failing an assessment) life events (Brown Dutton, \& Cook, 2001). State self-esteem is often viewed as "noise", that is, temporary fluctuations in self-esteem that can occur moment to moment, but that always hover around an average baseline self-esteem (Heatherton, \& Polivy, 1991).

The general nature and stability of the self-esteem conceptualisations above have different ramifications for the likelihood to be assessable in judgements of self-similar others. At any one point in time all three self-esteem conceptualisations may be transferred as they are all acting upon the valence of an individual's self-concept. However, global self-esteem transference or trait self-esteem may be more fruitful to measure when attempting to assess self-similar transference, as it seems to be regarded as the most stable over time. This stability is of practical value in the current research as it increases the likelihood that participant self-esteem is consistent between initial measurement and subsequent evaluation of self-similar stimuli. Whilst it is theoretically possible for state self-esteem to be transferred onto self-similar stimuli, the practical measurement of it would be harder, as the participant would need to be in the same state of mind when reporting their own self-esteem as when making evaluations of self-similar stimuli. 
Implicit versus Explicit Self-Esteem. One further conceptualisation of self-esteem must be considered here, and that is the distinction between implicit and explicit self-esteem. Greenwald and Banaji, (1995) define implicit self-esteem as "the introspectively unidentified (or inaccurately identified) effect of the self-attitude on evaluation of self-associated and selfdissociated objects" (p. 11). This conceptualisation of self-esteem is predicated on the notion that our self-attitudes are reflected at a non-conscious level (rather than at the conscious level apparent in explicit self-reported self-esteem). Without conscious awareness these selfattitudes then guide our evaluation of self-relevant stimuli in a way that is similar to our selfattitude (when stimuli are associated with the self) or dissimilar to our self-attitude (when stimuli are dissociated from the self).

There is no consensus in the literature as to whether implicit self-esteem is a separate construct to explicit self-esteem and methods used to assess implicit and explicit self-esteem are necessarily very different. As noted by Tafarodi, Ho, and Hadjistavropoulos, (2006) explicit measures of self-esteem require individuals to actively reflect upon and report their own beliefs about their self-worth. An example of a such a measure is The Rosenberg Self Esteem Scale (RSE; Rosenberg, 1965, as cited in Robins, Hendin \& Trzesniewski, 2001) which requires participants to rate their agreement with positively or negatively valenced statements such as "On the whole, I am satisfied with myself" on a scale of 1 "Strongly Agree" to 4 "Strongly Disagree". These ratings are then added up (with negatively valenced items reverse-scored) to provide a numerical indicator of self-esteem level.

Implicit measures of self-esteem do not involve self-report as this reflection would bring the participant's self-evaluations into conscious awareness. Therefore, they are designed to assess an individual's self-evaluations by measuring that individual's attitude towards stimuli that are evaluatively consistent (or evaluatively inconsistent) with the self (Greenwald \& Banaji, 1995). A common measure used to assess implicit self-esteem is the 
Implicit Association Test (IAT; Greenwald, McGhee, Schwartz, \& Kruglanski, 1998). When used to measure self-esteem this test requires participants to respond to concept-attribute pairs including "self" and "other" as concepts, paired with one of two valenced attributes such as "pleasant" and "unpleasant". The speed with which a participant responds to the pairing reflects the associative strength between the concept and valence in the mind of the participant. For example, if the participant is faster responding to "self + pleasant" pairings than to "self + unpleasant" pairings, it would indicate that the association between the self and positive valence is stronger than that between self and negative valence. That is, it would indicate positive implicit self-esteem.

Despite the methodological differences in the measures themselves, if they were measuring the same base concept we would expect participant scores on implicit and explicit measures to correlate. Bosson et al (2000) examined the reliability and validity of both implicit and explicit self-esteem measures, as well as the strength of the relationship between the two types of measure. Participant self-esteem levels were assessed (using a range of explicit and implicit measures) at two time points, with a test re-test interim of four weeks. The resulting analysis (using average scores across time points) found no relationship between explicit and implicit self-esteem measures, suggesting that these measures were tapping in to different base concepts.

However, as noted by Oakes, Brown, and Cai (2008) the lack of correlation between implicit and explicit measures of self-esteem doesn't necessarily pose an issue when considered in conjunction with a split-level view of attitude representation. Research suggests that attitudes can be processed at both conscious and unconscious levels (see Gawronski, Bodenhausen \& Cooper 2006). Oakes et al (2008) point out that these levels of processing are thought to be distinct and can lend themselves towards divergent predictions. The fact that 
these levels of processing appear to be distinct would allow for a lack of correlation between implicit and explicit measures of self-esteem to be theoretically feasible.

If self-esteem is indeed processed at two different levels (both conscious and unconscious) then the use of measures for both levels of processing would be useful in the current research. Implicit self-esteem may be argued to have more likelihood of transference to self-similar stimuli given the nature of transference as a non-conscious process (and one that would supposedly be operating at a similar level to unconscious attitude judgements. Although any predictions regarding this claim would be largely speculative. It should be noted, however that test-retest reliabilities for implicit tests have been found to be low (such as with the IAT) or below acceptable levels (Bosson et al, 2000). These authors explain that the instability in IAT scores may be due to the nature of implicit self-esteem as being situationally dependent and prone to moment-to-moment changes. This may be problematic in the current research because (as noted by Bosson et al, 2000) a measure that is unstable from one time-point to the next (regardless of the reason for the instability) cannot be relied upon to predict specific research outcomes. In the current research we could not rely upon the IAT as an implicit measure of self-esteem to predict the positivity of judgements of selfsimilar targets. This means that whilst it is prudent to include an implicit measure of selfesteem in the current research, inclusion of a more stable measure of self-esteem (such as the RSE) is a priority.

Research regarding the self-face and self-esteem. Previous research examining the effect of subliminal self-face priming suggests that judgements of the self-face are affected by self-esteem (Tao, Zhang, Li, \& Geng, 2012). These researchers were specifically interested in the modulation of self-esteem in self- and other-evaluations primed by subliminal and supraliminal faces. Participants completed a self-esteem measure followed by a computer task. During the computer task participants were subliminally presented with 
repeated images of either their own face or the face of a same-sex stranger (a control group were supraliminally presented with the same types of images). Following each face presentation a positive or negative valenced personality trait would be shown on screen. Participants were asked to respond as quickly as possible by categorising the word as positive or negative (reaction times were measured).

After viewing the self-face participants with high self-esteem were found to respond significantly faster to positive trait words than to negative trait words; this effect disappeared for valence judgements made after viewing the other-face. On the other hand, participants with low self-esteem were found to respond only marginally faster to positive trait words than to negative trait words, a pattern that became significant following exposure to the non-selfface. The pattern of results in this study suggest that the valence of our self-concept (i.e. level of self-esteem) influences our judgement of the self-face in a self-concept consistent manner. This suggests that inclusion of self-similar stimuli may trigger transference of self-concept valence to that stimuli - however this effect will likely be influenced by the extent to which the stimuli resembles the self. That is, there may be a threshold of self-similarity below which transference effects do not take place.

Previous research using morphed facial stimuli has examined the effect of selfsimilarity on valenced judgements. For example, DeBruine, 2002 examined how participants would interact in a trust-based game with self-resembling others. Participants were told that they would be taking part in an online computer game with 16 other people (off-site at different universities) and were shown photographs of the other players. In reality they were playing against a computer program, and the photographs they were shown had been manipulated (using computer morphing techniques) to look like either themselves or like an unknown other. The results showed that participants trusted self-resembling players to a greater extent than non-self-resembling players; as evinced by making a greater number of 
pro-social game decisions in favour of self-resembling players (a pattern of behaviour not found for matched control subjects using the same stimuli as participants).

This study was purposefully designed to account for some alternative explanations. For example, in order to rule out familiarity effects a control group participated in the same experiment but with famous and non-famous stimuli faces taking the place of self and novelother faces (morphed at 50\% with novel-other faces to produce famous-similar and nonfamous-similar facial stimuli). Furthermore, in order to rule out the attractiveness halo effect - all stimuli faces were judged in terms of attractiveness by independent raters. Results of the famous-non-famous control group showed no significant effect by stimuli type, indicating that the results of the experimental conditions were not likely to be due to familiarity effects. Results also showed no significant difference in attractiveness ratings for self vs. other morphed stimuli, indicating that the results of the experimental conditions were not due to the attractiveness halo effect.

The results of DeBruine (2002) may be argued to indicate integration of selfrepresentation-consistent judgements into self-similar target judgements (transference effect) but DeBruine provides a different explanation by way of inclusive fitness theory. According to Inclusive fitness theory (Hamilton, 1964) cues to kinship will somewhat dictate a perceiver's behaviour towards, and treatment of, a target; as a function of the adaptive value of such behaviours. DeBruine argues that self-similarity acts as a cue to kinship resulting in more prosocial behaviour towards that target - explaining the greater levels of trust placed in self-similar stimuli by participants in her study.

In so far as judgements of the self are positive, transference of the self-concept may produce theoretically similar results to those found in Debruine (2002). That is, we would expect to see more positive judgements for self-similar faces. However, this explanation 
would only hold up if perception of the self is positively valenced. if judgements of the self were negatively valenced then a transfer of self-concept consistent valence to self-similar faces would result in similarly negative target evaluations. Therefore, the results of DeBruine (2002) may support the argument for transference as triggered by self-similarity, but because participant self-concept was not measured in this study no specific conclusions can be drawn regarding the role of transference.

Although there is yet to be a consensus in the literature as to what comprises selfesteem, all self-esteem concepts or types discussed above would theoretically be transferable as triggered by self-similarity. The plausibility of this theory is supported by previous research that has found a relationship between self-esteem and self-face judgements, and between the self-face and positive evaluation. As previously noted, the current research would likely benefit from using a global self-esteem measure (due to its stability over time), and from including a measure for implicit self-esteem.

\section{Overall Summary}

The research outlined above suggests that 1) the self is a mental representation that is built and functions in a way consistent with a significant other representation, 2) this selfrepresentation is (at least) as accessible as a mental representations of a significant other, and 3) judgements of facial stimuli that either fully or partially include the self-face (and therefore pertain to one's self-representation) have been found to elicit more positive reactions and/or judgements from perceivers than stimuli that do not include the self-face. of the available self-esteem Collectively these points form a convincing rationale for the argument that selfsimilar transference is possible. Chapter 3 draws upon the information outlined in the current chapter to form specific hypotheses with regards to self-similar transference, details the studies conducted to test these hypotheses, and presents the results of the current research. 


\section{Chapter 3: The Current Research}

Although there are numerous studies examining the various mechanisms through which transference of significant other representations can occur (Andersen \& Berk, 1998; Andersen \& Cole, 1990; Andersen, \& Baum, 1994; Günaydin et al., 2012; Kraus \& Chen, 2010), we are aware of no research examining the possibility that the self-concept can be transferred in a similar way. The current thesis aimed to extend prior research in the area of transference by examining the possibility that objective target similarity to the perceiver (in the form of facial stimuli) may activate the perceiver's self-representation, resulting in transference of self-concept to the target. Thus, the current work provides a novel combination of concepts that have the potential to contribute to both the person perception and self-related literatures.

If transference is triggered by self-similar facial stimuli, the current research should find that judgements of self-similar targets will be more consistent with the perceiver's selfrepresentation than judgements of other (non-self-similar) targets. If transference is not triggered by self-similar facial stimuli, the current research should find that judgements of self-similar targets will be as consistent (or less consistent) with the perceiver's selfrepresentation than judgements of non-similar targets.

\section{Overview and hypotheses}

\section{Study 1}

In study 1 participants were asked to make trait-based judgements of self-similar and non-self-similar similar faces in a forced-choice paradigm. These judgements were then examined for evidence of self-similar preference and were compared to participant judgements of themselves (provided in an ostensibly separate study conducted at an earlier date). 
Specifically, it is hypothesised that:

1. If the valence of a participant's self-representation is negative, then self-morphed stimuli in the current research will be judged more negatively than non-selfmorphed stimuli. This would be demonstrated by a decreased selection of selfsimilar faces compared to non-self faces when asked to select between them on a positive trait (e.g., trustworthiness, intelligence, etc.).

2. If the valence of a participant's self-representation is positive, then self-morphed stimuli in the current research will be judged more positively than non-selfmorphed stimuli. This would be demonstrated by an increases selection of selfsimilar faces compared to non-self faces when asked to select between them on a positive trait.

\section{Participants and Design}

Participants for this study were recruited from a 100-level psychology undergraduate classes at Victoria University of Wellington as part of their research participation requirement. The design of this study necessitated participants not knowing that sessions 1 and 2 were related (see session 2 for full explanation). No limit was put on enrolment in order to increase the chances that enough students would enrol to participate in session 2. A total of 88 participants $(\mathrm{F}=67, \mathrm{M}=21)$ enrolled in and competed sessions 1 and 2 of the current study. $\mathrm{N}=88$,). This moderate sample size was used in order to obtain sufficient statistical power ${ }^{1}$. Participants were awarded course credit upon completion of each experimental session.

Footnote 1: The sample size was chosen based on a power analysis conducted using $G^{*}$ Power $\left(G^{*}\right.$ Power Version 3.1 Faul, Erdfelder, Buchner, \& Lang, 2009). Using a moderate effect size of 0.30 (based on previous research by DeBruine), with an alpha level of 0.05 , the analysis recommended a sample size of 82 in order to achieve $80 \%$ power. 


\section{Measures and Procedure.}

Session 1. In the first session, participants posed for a "neutral expression" headshot (hair secured out of face, facial accessories, make-up, and jewellery removed), against a white background. Participants were informed that the photos were being compiled to form a face database for use in future research but were not led to believe that it would be used in the current study. Following this, participants completed two measures of self-esteem: the Rosenberg Self-Esteem Scale (RSE; Rosenberg, 1965, as cited in Robins, Hendin \& Trzesniewski, 2001), and an implicit association test (IAT; see Greenwald \& Farnham, 2000). During this session participants also completed two measures of personality (NEO-5 Domains [NEO-5]; Costa \& McCrae, 1992), and the Ten Item Personality Inventory (TIPI; Gosling, Rentfrow, \& Swann, 2003). Finally, participants completed two tasks designed to examine self-evaluation (the Me Not Me [MNM] task, and a Self-Descriptive/Self Irrelevant task). All of the instructions were presented and measures were completed on a computer running InQuisit experimental software (Millisecond Software, 2016).

Self-esteem. In order to examine the effect of self-evaluation on self-similar transference the current study included multiple measures of participant self-esteem. According to Greenwald and Farnham (2000) it is important to distinguish between implicit and explicit functioning of the self when measuring concepts such as self-esteem. There is a distinct possibility that the self may function differently in these two modes (Greenwald, \& Farnham, 2000), and therefore relate differently to other processes and concepts (such as selfsimilarity driven transference). Based on this reasoning, the current study used both explicit (RSE; Rosenberg, 1965, as cited in Robins, Hendin \& Trzesniewski, 2001) and implicit (IAT; see Greenwald \& Farnham, 2000) measures to examine participant self-esteem. Self-esteem 
was used as a conceptual analogue to the relationship quality measure used by Günaydin et al., (2012).

$R S E$. For the RSE participants marked agreement with 10-items (e.g. "On the whole, I am satisfied with myself") using a 4-point Likert scale (1- strongly agree, to 4- strongly disagree). Total scores for the RSE were calculated by summing the participant responses for all items, with higher scores representing higher levels of positive self-esteem (for all items and instructions, see Appendix A).

IAT. The implicit association test has been used to measure self-esteem by examining the extent to which people automatically associate the category of "self" with other categories of either positive or negative valence (Greenwald \& Farnham, 2000). The IAT used in the current study examined the extent to which participants associated the categories "pleasant" and "unpleasant", with the categories "self" and "other" (for all stimuli and instructions, see Appendix B). Accordingly, the more positive one's self-esteem, the easier it should be for that person to pair self-related terms with other pleasant words than to pair self-related terms with unpleasant words (see Greenwald, \& Banaji, 1995). The IAT consisted of five distinct phases (for a table categorising the different blocks for the IAT procedure, please see Figure 1).

In the first block, participants were presented with single words (taken from Greenwald \& Farnham, 2000) in the middle of the screen (e.g. "joy"), which they then categorised as PLEASANT (by pressing the "A" key on the computer keyboard) or UNPLEASANT (by pressing the "L" key). The category names remained on the screen ("PLEASANT" on the top left, and "UNPLEASANT" on the top right) to serve as a reminder for participants. This phase consisted of 26 randomly-selected trials from a list of 13 pleasant and 13 unpleasant words. Incorrect categorisations would cause a red cross to appear in the middle of the screen until the participant selected the correct category. 
In the second block, participants followed the same procedure as the previous block, but with a different set of category labels ("SELF" or "OTHER") and a new set of words ("I", "me”, "my", "mine", and "self” for $S E L F$, or "they", "them", "theirs", "their", and "other" for OTHER). The category labels appeared at the top of the screen on the appropriate side. This phase consisted of 20 randomly-selected trials from a list of the 5 "SELF" words and the 5 “OTHER” words.

Block 3, combined the previous blocks so that multiple categories were associated with a shared response; in this case the pairing of "PLEASANT or SELF" and “UNPLEASANT or OTHER". This combined block included 64 randomly-selected trials from the lists of self, other, pleasant, and unpleasant terms used in the previous phases. In IAT terms, this combined block represents self-esteem congruent pairings such that self is paired with pleasant.

For block 4, participants followed the same procedure as in the second block, with the position of the category labels switched (the category label "OTHER" appeared on the top left of the screen, and the category label "SELF" appeared on the top right of the screen). This block served to re-map the self-other responses.

For block 5, participants followed the same procedure as in block 3 (i.e., the selfesteem congruent block), but now with the pairings of "PLEASANT or OTHER" and "UNPLEASANT or SELF". Again, in IAT terms, this combined block represented selfesteem incongruent pairings because it requires that self-related terms be paired with unpleasant terms.

The final IAT measure was calculated by measuring the difference in RT latency between the compatible block (block 3) and the incompatible block (block 5). High selfesteem would be indicated by faster reactions times in the compatible block (i.e., self + pleasant) as compared with the incompatible block (i.e., self + unpleasant). As in Greenwald 
and Farnham (2000) the order of presentation for blocks 2-3 and 4-5 was counterbalanced to avoid order effects for compatible versus incompatible blocks. The d-algorithm was used to create d-scores for each participant based on their IAT responses (Nosek, Bar-Anan, Sriram, Axt, \& Greenwald, 2014). Higher d-scores imply greater ease of pairing self-related terms with positive terms than with negative terms. That is, higher scores theoretically indicate higher implicit self-esteem.

\begin{tabular}{|l|c|c|c|}
\hline Block Number & Category Label 1 & Sample Item & Category Label 2 \\
\hline \multicolumn{5}{|c|}{ PLEASANT } & & UNPLEASANT \\
\hline Block 1 (26 trials) & $\bigcirc$ & diamond & $\bigcirc$ \\
\hline & 0 & vomit & OTHER \\
\hline Block 2 (26 trials) & SELF & me & $\bigcirc$ \\
\hline & 0 & they & 0 \\
\hline
\end{tabular}

\begin{tabular}{|c|c|c|c|}
\hline $\begin{array}{c}\text { Block 3/ Compatible } \\
\text { block (26 trials) }\end{array}$ & PLEASANT or SELF & UNPLEASANT or OTHER \\
\hline & 0 & me & $\bigcirc$ \\
\hline & 0 & diamond & $\bigcirc$ \\
\hline & $\bigcirc$ & they & 0 \\
\hline
\end{tabular}

\begin{tabular}{|c|c|c|c|}
\hline Block 4 (26 trials) & OTHER & & SELF \\
\hline & $\bigcirc$ & me & 0 \\
\hline & 0 & they & $\bigcirc$ \\
\hline
\end{tabular}

\begin{tabular}{|c|c|c|c|}
\hline $\begin{array}{c}\text { Block 5/ Incompatible } \\
\text { block (26 trials) }\end{array}$ & PLEASANT or OTHER & UNPLEASANT or SELF \\
\hline & 0 & me & \\
\hline & 0 & diamond & $\bigcirc$ \\
\hline & 0 & they & $\bigcirc$ \\
\hline & $\bigcirc$ & vomit & \\
\hline
\end{tabular}

Figure 1: Table categorising the IAT procedure into blocks. Category labels and sample items are provided. Filled-in circles indicate the correct answer for each sample item. If a participant selects an incorrect item response (as indicated by the empty circles) a red cross would appear, this cross would remain on-screen until the participant had chosen the correct 


\section{Self-Concept.}

Me-Not Me Task. For this task, participants were presented with 36 positive and 36 negative traits on a computer screen (e.g. "Affectionate", or "Cowardly"; for full lists, see Appendix C), and were asked to judge whether or not that trait generally describes them by responding "A" (describes me) or "L" (does not describe me) using the keyboard (keys were counterbalanced between participants). Total scores for the MNM were calculated by counting the number of "describes me" responses for positive and negative words, and then by subtracting the total responses for negative words from the total responses for positive words. Higher scores represent a more positive self-evaluation.

Self-Descriptive/ Self-Irrelevant task. For the self-descriptive/ self-irrelevant task, participants were presented with 60 traits (mostly positive) that fall along both interpersonal warmth (e.g. "Friendly") and competence (e.g. "Industrious") dimensions (for full list of terms, see Appendix F). These 60 traits were presented in concert (4 rows of 15) on the computer screen. Participants were asked to choose the six traits that are most important to how they define themselves. Finally, participants noted the importance of each of these six traits to how they view themselves (and how they think about other people) using a 7-point Likert scale (1- not at all, to 4- moderately, to 7-extremely). This final step was repeated a second time with participants selecting the 6 traits that were most irrelevant (rather than important) to how they define themselves, and by noting the importance of each of these six traits to how they view themselves (and how they think about other people).

\section{Personality.}

NEO-5. For the NEO-5 participants noted the extent to which they agreed with 100items (e.g. "I make friends easily.") using a 5-point Likert scale (1- strongly disagree, to 5strongly agree). The 100 items of this scale capture the 5 personality dimensions (openness, conscientiousness, extraversion, agreeableness, and neuroticism), with 20 items per domain. 
Of the 20 items per domain, half were reverse coded (e.g. the item "I retreat from others" as a reverse coded item for extraversion). Indices were calculated by averaging together the 20 items (for instructions and full scale, see Appendix D)

TIPI. For the TIPI (Ten-Item Personality Inventory), participants noted the extent to which they agreed with 10-items (e.g. "I view myself as extraverted, enthusiastic.") using a 7point Likert scale (1- Disagree Strongly, to 4- Neither Agree nor Disagree, to 7-Agree Strongly). The 10 items of this scale capture the 5 personality domains (openness, conscientiousness, extraversion, agreeableness, and neuroticism), with 2 items per domain (for instructions, scoring, and items, see Appendix E). Total scores for the TIPI were calculated by averaging the response for the two items corresponding to each personality domain.

\section{Creation of Materials}

Materials for the second session were created during the delay (approximately two weeks) between the first and second session.

Photo preparation. Participant photos (taken in session 1) were mirrored (i.e., flipped along the vertical axis) so as to best represent the participants face as viewed in a mirror. Participant (and database) photos were standardised in Adobe Photoshop CC 2015 to include a white background and pre-prepared neck and shoulders (with skin toned adjusted to match that of the subject). Any obvious skin blemishes, stray hair strands, or jewellery that was missed when the participant photo was taken, was also removed at this stage (see Figure 2 for an example of the photo preparation procedure).

Stimulus creation. An important question that was considered during stimuli creation was - how similar could a stimuli photograph be to the self before they become consciously aware of the similarity? A 50\% inclusion of the significant other was used in the research conducted by Günaydin et al (2012) as adequate to trigger transference but not conscious 
awareness. Based on the results of Anderson et al., (1998) suggesting the similarity between accessibility of self vs. significant other representations it would be reasonable to assume that a similar threshold could be used for self-similar stimuli in the current research. Furthermore, other research into the effect of self-face similarity on first impression judgements has used $50 \%$ morphs of the self-face (with a novel face) wherein the majority of participants did not consciously recognise the resemblance (DeBruine, 2005). In another study DeBruine used a 40\% morph (DeBruine 2002). However, pilot testing revealed that a large number of participants recognised themselves in stimuli materials at a 50\% morph rate so we dropped the morph percentage to $40 \%$ of the self-face ${ }^{2}$.

Using the computer program FantaMorph 5 (Abrosoft, 2013), the standardised photos were morphed (at $40 \%$ of self-face and $60 \%$ of other face) with six of twelve same-sex photos compiled from a pre-existing database (Ma, Correll, \& Wittenbrink, 2015) to create eight "self-morphed" photos. The remaining six database photos were used to create "othermorphed" stimuli (see Figure 3 for an example of morphed stimuli). Yoked pairs were created using same-sex participants, with the first individual in each pair using "yokedsimilar" photos as their "other-morphed" stimuli and vice versa. As in Günaydin et al., (2012), yoked pairs were used to control for stimuli peculiarities, since both partners in each yoked pair see the same faces. 


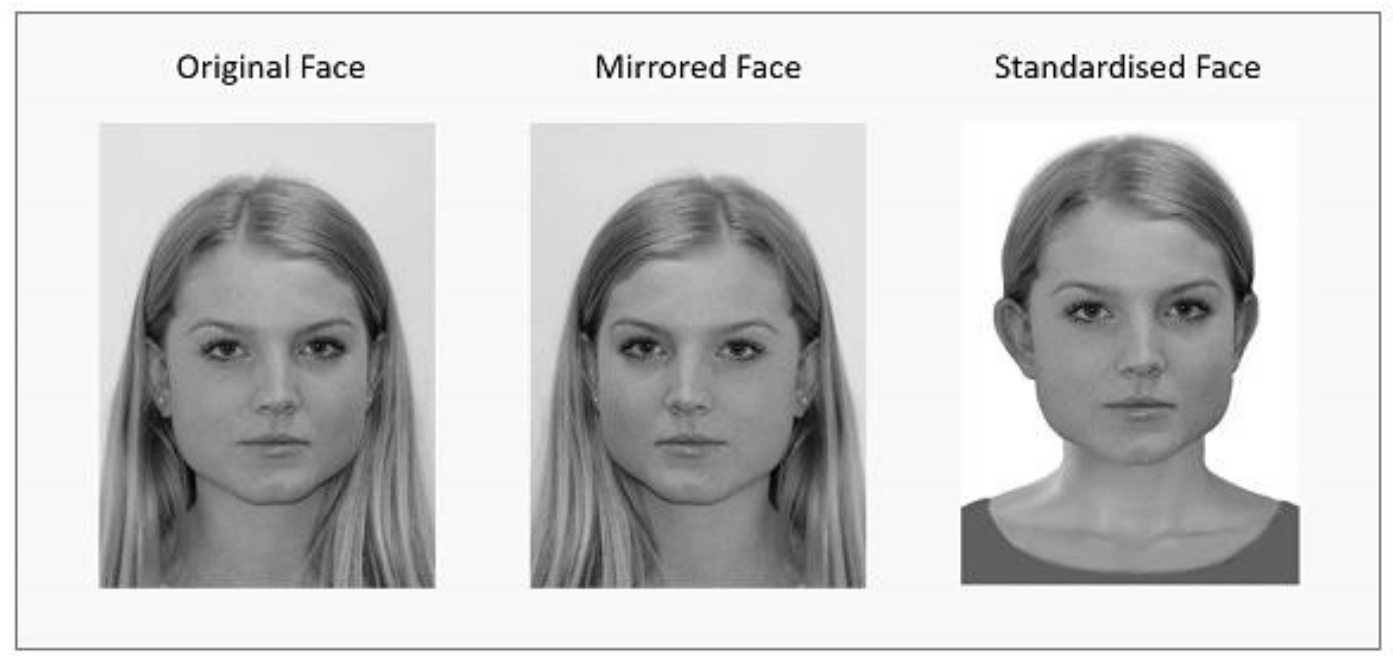

Figure 2. A visual depiction of the stages included in preparation of participant (and database) photos. Depicted (from left) is: An example of an original participant photograph (Original Face), an example of the same participant's face mirrored (Mirrored Face), and an example of the same participant's face standardised (Standardised Face).

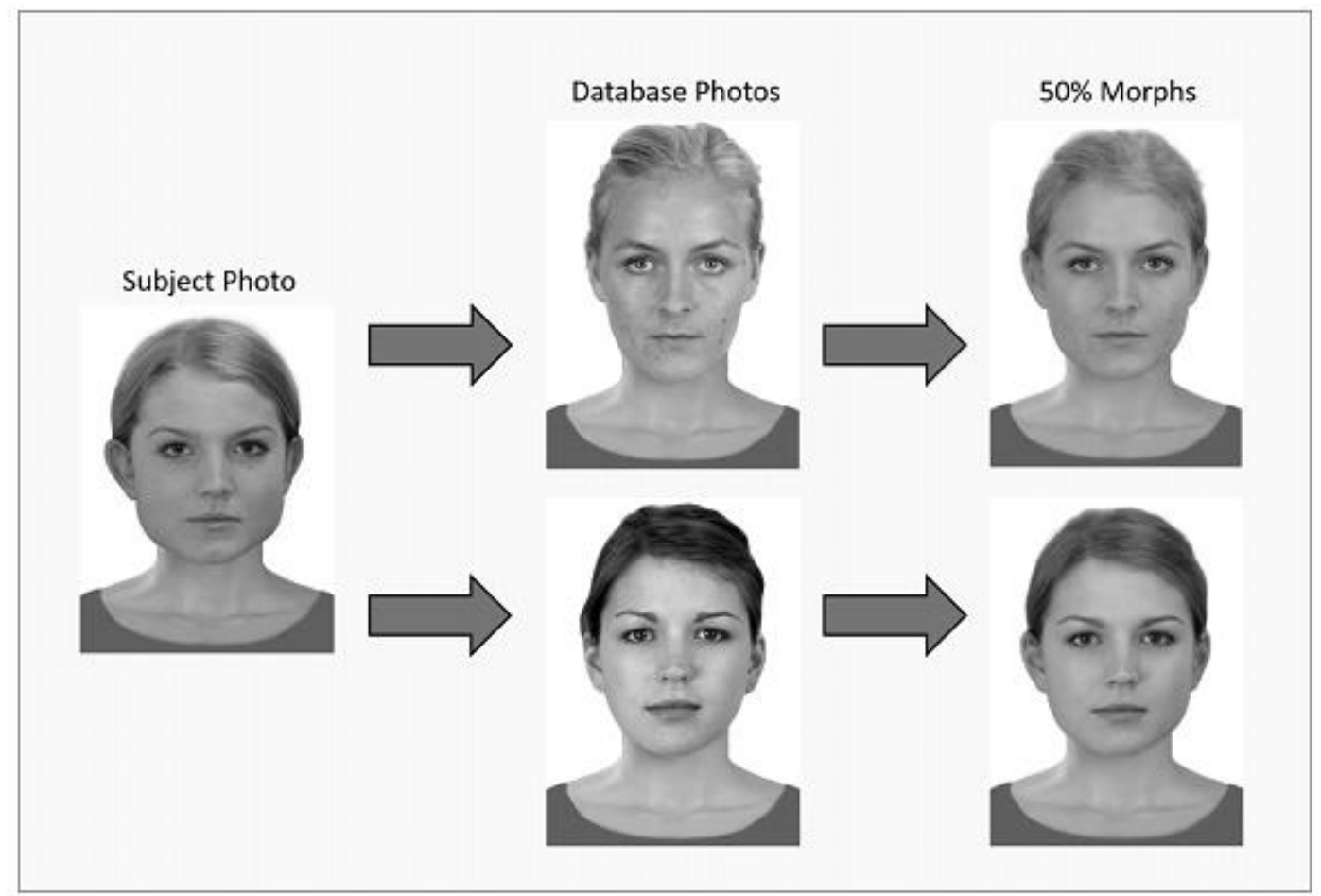

Figure 3. A visual depiction of two $40 \%$ morphs (far right) between the subject photo (far left) and two database photos of the same gender (middle). 


\section{Session 2.}

The second session was conducted approximately two weeks after the first session. Participants in Session 2 comprised a sub-set of those participants who had completed Session 1 as an ostensibly unrelated study. Specifically, only participants who had completed the first session were able to view (and sign up) for the second session even though they had different experiment numbers. This was done in order for participants not to relate their photograph being taken (in session 1) with the face evaluations included in session 2 . The entirety of this session took place at a computer with all instructions and tasks presented using InQuisit experimental software (Millisecond Software, 2016). During this session participants completed a forced-choice trait judgment task, as well as an affective misattribution procedure (AMP; Payne, Cheng, Govorun, \& Stewart, 2005) task. As in Günaydin et al., (2012) participant awareness of the resemblance between themselves and self-morphed stimuli was measured following completion of the trait judgement task. Participants were asked to report whether any of the stimuli resembled anyone they knew, and if yes then whom. Following the subjective measure, participants were debriefed; this included an explanation of the goals of the current research and made participants aware that their own photograph (taken in a previous IPRP session) was included in the stimuli that they had evaluated during session 2.

Trait judgements. Participants made snap judgements of each novel face on eight traits: trustworthy, friendly, sincere, helpful, intelligent, competent, confident, and creative. The specific traits used in the current study differ slightly from the exact traits used in Günaydin et al., (2012). This is because the traits used in Günaydin et al. were related to judgements of partner similar stimuli (e.g. supportive and caring) and thus were replaced with more self-related terms. These terms were selected from the dimensions of "interpersonal 
warmth" and "competency", as these dimensions have been shown to be fundamental to basic-level social cognitions (Fiske, Cuddy, \& Glick, 2007).

In a forced-choice paradigm adapted from DeBruine (2005) participants were shown a pair of stimuli faces (always one participant-morphed and one other-morphed) and were asked to select the face that best represented the relevant trait (trustworthy, friendly, sincere, helpful, intelligent, confident, competent, or creative). Levels of self- transference in this task are indicated by the percentage of times the participant chose a self-morphed photograph over a yoked-other photograph. Higher levels of transference are indicated by an (above-chance, i.e., .50) tendency for participants to choose the self-morphed face.

This task consisted of 8 blocks (one block per trait, 12 trials per block), which were completed in random order. Participant-morphed faces appeared an equal number of times on the left and on the right across each block. Each trial consisted of a fixation cross (500ms), followed by a trait question e.g. "Which person looks more COMPETENT?" and a reminder of which keys to respond with ("D = Left $\|$ Right $=$ K"). After 2000ms the response reminder disappeared and was replaced with two stimuli faces. The faces and trait question remained on the screen until the participant had responded (with "D" or "K") Pairings of self-similar and yoked-similar faces were randomly selected, however no one pairing was repeated within that block. The stimuli faces and the judgement question e.g. "Which person looks more CREATIVE?" remained on screen until the participants had made their decision. (see Figure 4 below for a visual depiction of one trial). 
$\boldsymbol{A M P}$. The AMP is a task designed to implicitly assess attitudes (Payne et al., 2005). This task operates by requiring subjects to make affective judgements about a stimulus following exposure to a prime (which they are told to ignore). Research has demonstrated that the prime (even when presented at speeds below conscious awareness) has a significant effect upon the valence of the judgement made by the subject. Specifically, when the prime is considered pleasant by the subject then the judgements of the stimuli following the prime tend to be more positive, and when the prime is negative, judgements of the stimuli following the prime tend to be more negative (Greenwald, Smith, Sriram, Bar-Anan, \& Nosek, 2009). The current study utilised the AMP to implicitly assess participant's attitudes (positive or negative valence) towards self-morphed versus other-morphed stimuli.

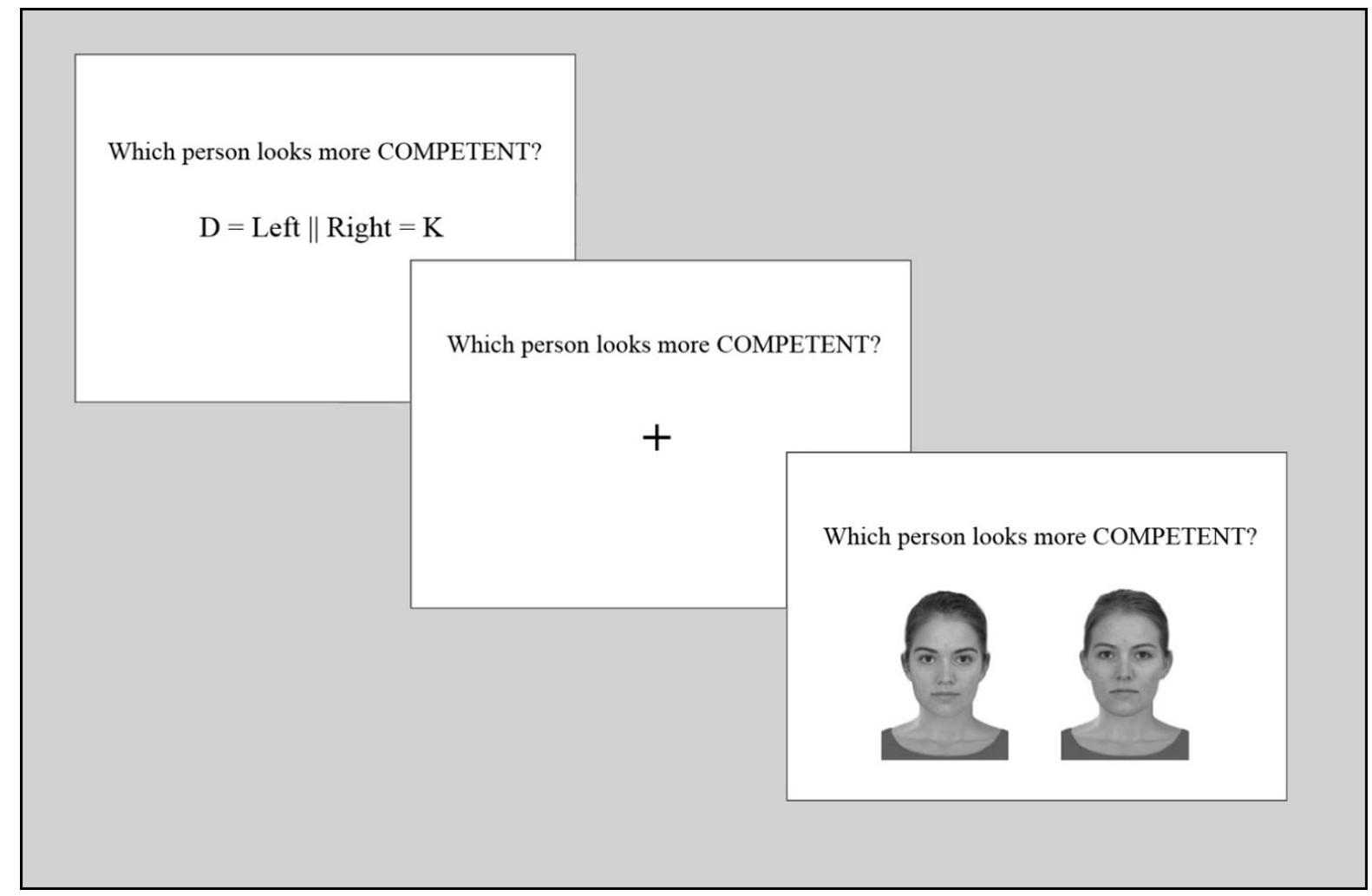

Figure 4. A visual depiction of the stages included in one trial of the trait judgement procedure. The trial runs from left to right, the length that each stage is presented for is noted beneath the relevant depiction. From left to right is depicted: a fixation cross (stage 1), a stimuli face (stage 2), a trait-related statement and Likert scale (stage 3). 
There were a total of 88 trails over 3 blocks (20 trials block 1, 20 trials block 2, 48 trials block 3). All trials required participants to make judgements of "pleasant" or "unpleasant" for each of 20 words (blocks 1 and 2) or for each of 48 words (block 3). For blocks 1 and 2 (see Figure 5 below) participants were presented with a mask (a row of X's) followed by a positive or negative word (500ms in block $1,250 \mathrm{~ms}$ in block 2$)$, and then another mask (remained on screen until the participant had make their pleasantness judgement).

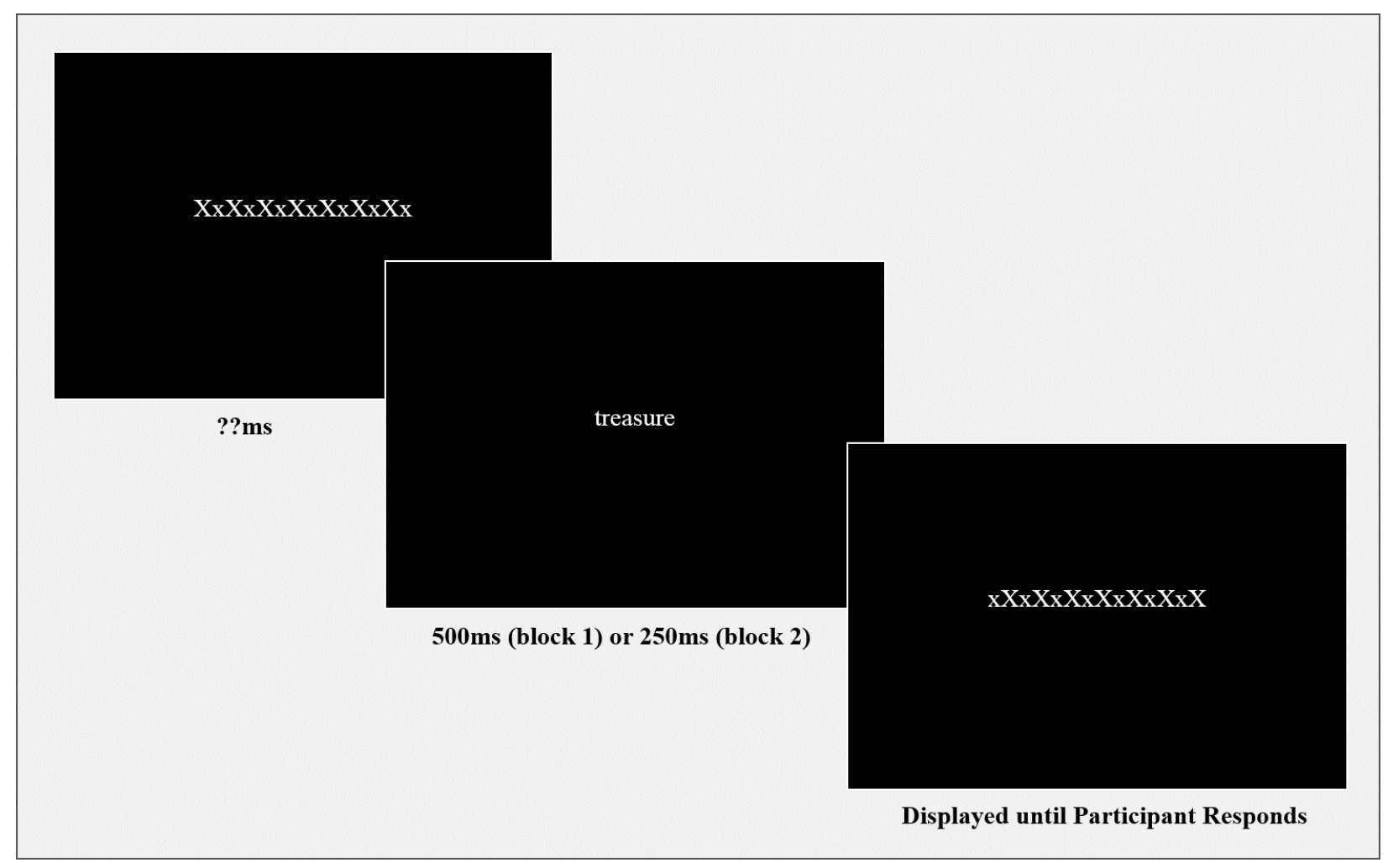

Figure 5. A visual depiction of the stages included in one trail of the AMP task procedure. The trial runs from left to right, the length that each stage is presented for is noted beneath the relevant depiction. From left to right is depicted: a mask (stage 1), a positive or negative word (stage 2), and a second mask (stage 3).

followed by a face $(700 \mathrm{~ms})$, a nonsense word $(750 \mathrm{~ms})$, and finally a mask (a row of X's) which remained on screen until the participant had make their pleasantness judgement. 
Subjective awareness measure. As in Günaydin et al., (2012) participant awareness of the resemblance between themselves and self-morphed stimuli was measured following completion of the trait judgement task. For the subjective awareness task all participants were asked to report whether they recognised any of the stimuli faces, and if so then whom did they recognise. Following the awareness measure participants were debriefed.

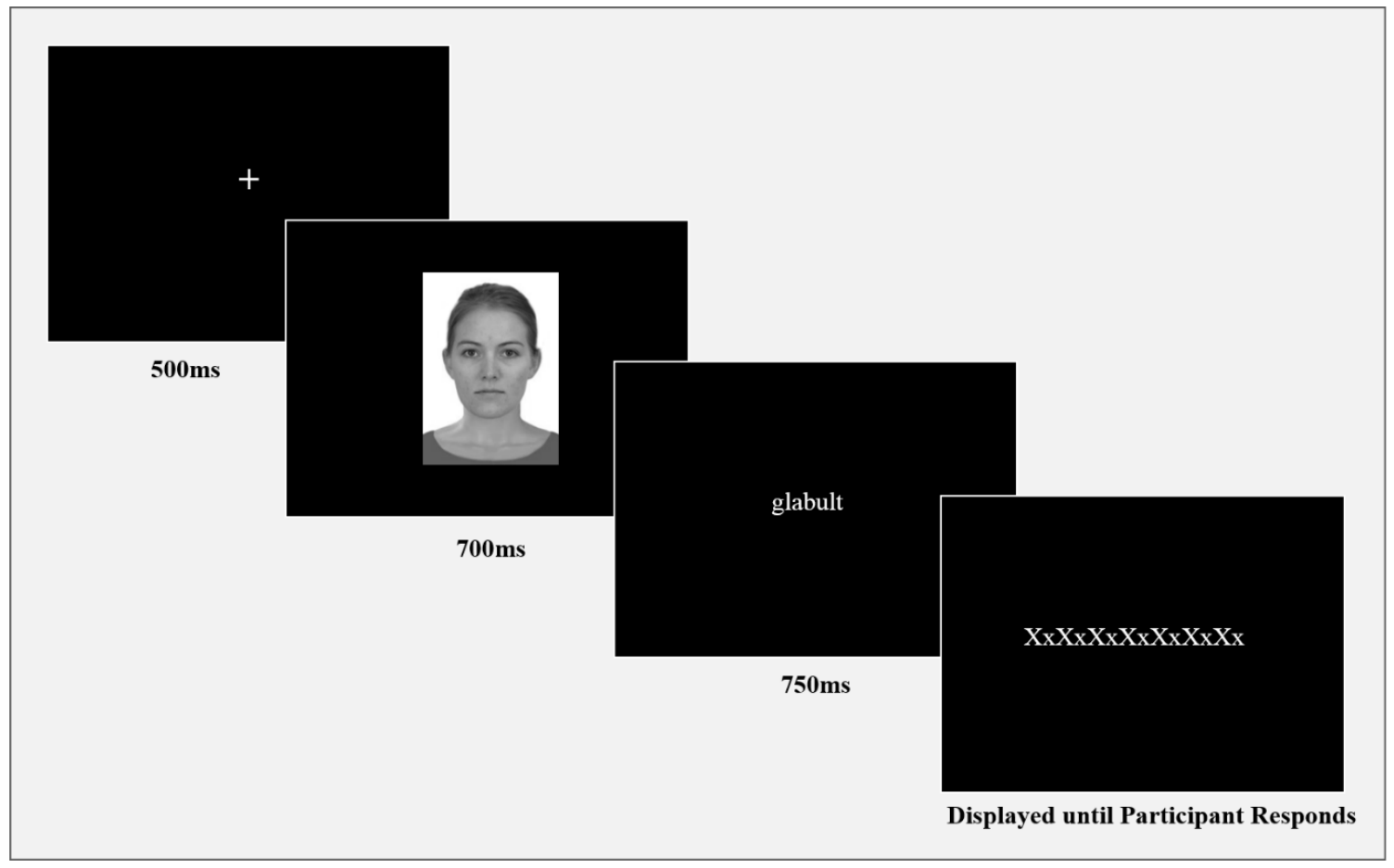

Figure 6. A visual depiction of the stages included in one trail of the AMP task procedure (block 3). The trial runs from left to right, the length that each stage is presented for is noted beneath the relevant depiction. From left to right is depicted: a fixation cross (stage 1), a face (stage 2), a nonsense word (stage 3 ), and a mask (stage 4). 


\section{Results}

Exclusions and Data Reduction. Eighty-eight participants $(\mathrm{M}=21, \mathrm{~F}=67)$ completed both sessions 1 and 2 of the current study. No participants were excluded from the data analysis. A reliability analysis was conducted examining the internal consistency of "Warmth" traits (sincere, friendly trustworthy and helpful), and "Competence" traits (confident, competent, creative, and intelligent). Cronbach's alpha for the warmth traits was 0.74 suggesting that the warmth trait category had high internal consistency. Cronbach's alpha for the competence traits was 0.45 , with no improvement with any individual item excluded, indicating that the competence trait category had relatively low internal consistency. The low internal consistency of the Competence Index is surprising given the wealth of literature suggesting that these traits tend to fall together in first impression judgements (Fiske et al., 2007), and in judgements of faces specifically (Oosterhof and Todorov, 2008).

Due to the relatively weak reliability of the competence dimension, we also ran an Exploratory Factor Analysis (Orthogonal with Varimax rotation) on self-selection scores. Only one factor with an Eigenvalue greater than 1.0 emerged. This factor comprised the four warmth-relevant traits with competence also loading moderately. The factor structure and component loadings for all four studies are presented in Appendix G. As can be seen from examining across the studies, no consistent pattern emerges other than the four warmthrelevant traits always load strongly on the single factor that emerges. Due to the lack of a consistent factor structure, and because the selection of warmth and competence dimensions is theoretically driven, in all of the studies, the four warmth and the four competent items are combined and reliability, as measured by Cronbach's alpha are reported with the caveat that any effects involving competence should be considered somewhat sceptically. 
Self-Selection: Overall. It was hypothesised that transference would occur as indicated by participant selection of self-similar stimuli over other-similar stimuli. A onesample t-test was run to determine whether the average (positive) self-selection score for recruited subjects was significantly different to chance (i.e., 0.50). This score was calculated by averaging the percentage of trials on which participants selected the self-morphed target, collapsing across all of the trait dimensions. The mean self-selection score $(\mathrm{M}=0.50, \mathrm{SD}=$ 0.10) was not found to be significantly different to chance, with a mean difference of 0.00 $(95 \% \mathrm{CI}, 0.48$ to 0.53$), \mathrm{t}(88)=0.22, \mathrm{p}=0.83, \mathrm{~d}=.02$. In other words, collapsing across all of the trait dimensions in the current study, participants were not more likely to select the selfsimilar stimuli over other-similar stimuli as their responses were not significantly different from what would be expected by chance responding.

Self-Selection: Warmth \& Competence Traits. Similar one-sample t-tests were conducted to examine whether the average self-selection for traits that separately fall under the warmth (i.e., sincere, helpful, friendly, and trustworthy) and competence (i.e., confident, competent, creative, and intelligent) dimensions was significantly different to chance. This analysis was used to examine whether a self-similar transference effect (indicated by selection of self-similar over other similar stimuli) would emerge when traits were grouped by the two major categories of first impression judgements (see Fiske, Cuddy, \& Glick, 2007). Neither analysis was found to be significant. Specifically, neither the proportion of self-selection responses for warmth $(\mathrm{M}=0.51, \mathrm{SD}=0.14)$, nor competence $(\mathrm{M}=0.50, \mathrm{SD}=$ 0.11 ) were found to be significantly different to chance (both $t<1.0$, smallest $p=.51$ ), In other words, participants were not more likely to select the self-similar stimuli over othersimilar stimuli when making warmth or competence judgements.

Self-Esteem \& Self-Selection. Even though an overall pattern of self-similar transference was not observed in the responses, this may be due to the impact of self-esteem on how self- 
similar targets are perceived. Recall that it was predicted that self-transference of positive traits should occur more strongly for high self-esteem individuals. That is, if high self-esteem individuals show heightened self-selection and low self-esteem individuals show decreased self-selection, then the overall pattern would fail to show an overall effect. The next series of analyses examine the effect of self-esteem on the selection of self-similar over other-similar faces in the trait judgment task.

As can be seen in Table 1, scores on the RSE were positively correlated with IAT scores and negatively correlated with scores on the Me/Not-me (MNM) task. The IAT and MNM were not correlated. We suggested that if self-esteem served a valence matching function, then self-esteem should correlate with the percentage of self-selection responses made in the trait judgment task. This, however, was not the case. None of the self-esteem measures correlated significantly with self-selection, either overall, or within the warmth or competence dimensions.

\section{TABLE 1}

\begin{tabular}{|c|c|c|c|c|c|c|}
\hline & Overall & Warmth & Competence & IAT & RSE & MNM \\
\hline Overall & -- & $0.88 * *$ & $0.81 * *$ & 0.13 & -0.08 & 0.12 \\
\hline Warmth & & -- & $0.43 * *$ & 0.08 & -0.10 & 0.07 \\
\hline Competence & & & -- & 0.16 & -0.02 & 0.07 \\
\hline IAT & & & & -- & $0.27 *$ & -0.19 \\
\hline RSE & & & & & -- & $-0.50 * *$ \\
\hline MNM & & & & & & -- \\
\hline
\end{tabular}

Footnote 2: We also examined Self-esteem (RSE) as a categorical variable to examine differences between different bands $(2,3$, or 4$)$ of self-esteem. None of the analyses produced significant differences. 


\section{Affective Misattribution Procedure.}

Participants were not more likely to respond that a nonsense word was positive when it followed a self-similar $(\mathrm{M}=.52, \mathrm{SD}=.170)$ compared to a non-self similar $(\mathrm{M}=.54, \mathrm{SD}$ $=.172)$ face, $\mathrm{t}(86)=-0.71, \mathrm{p}=.48$. That is, the AMP was not able to differentiate, in terms of valence carry-over, between faces that were or were not similar to the participant. In terms of the other self-esteem measures, only the number of positive traits that were selected as "describing me" correlated with the likelihood of responding that a word was positive after a face was presented. However, the relationship was the same for both self-similar $(r=.224, p$ $=.037)$ and non-self $(\mathrm{r}=.262, \mathrm{p}=.014)$ and likely reflects an individual level tendency to respond to positive stimuli. The percentage of times that participants responded that a nonsense word following a self-similar face was positive was not related to likelihood of selecting self-similar faces over non-self faces in the forced-choice trait judgment task.

\section{Summary}

Taken together, the results of Study 1 did not support the hypotheses. Participants were not more likely to select self-similar faces than non-self faces in the forced-choice trait judgment task. This lack of an effect is not due to the effect of self-esteem (i.e., that high selfesteem and low self-esteem differences might be masking self-similar transference), as none of the self-esteem measures related to self-selection bias. There was also no evidence of an implicit evaluative generalisation from self-similar faces to ambiguous/nonsense word stimuli in the Affective Misattribution Procedure. 


\section{Overview}

\section{Study 2}

Following the largely null findings in Study 1, Study 2 was altered slightly in order to explore the question of whether self-similar transference may be more likely for only very rapid impressions - rather than impressions involving greater deliberation. As noted in the introduction, first impressions of functionally significant traits (such as those being assessed in the current study) are likely to be fast and implicit (Bar, Neta \& Linz, 2006; Rule \& Ambady, 2008; Rule, Ambady \& Hallett, 2009). However, it is possible that the fast and implicit judgements that we tend towards can be altered with conscious deliberation (Wilson \& Schooler 1991). That is, if self-similar transference relies on the misattribution of fluency, then it may be the case that allowing unlimited time to process the faces means that participants are "overwriting" that initial reaction. To examine this, the faces in Study 2 were presented for a much briefer period of time (i.e., 750ms) with the decision required while the faces are no longer present on the screen. By only presenting the faces for $750 \mathrm{~ms}$ we are hoping to capture the very initial participant judgements rather than deliberative ones.

\section{Participants and Design}

Participants for this study were recruited from a 100-level psychology undergraduate classes at Victoria University of Wellington as part of their research participation requirement. As in study 1 the design of this study necessitated participants not knowing that sessions 1 and 2 were related. No limit was put on enrolment in order to increase the chances that enough students would enrol to participate in session 2. A total of 85 participants (58 women, and 27 men) enrolled in and completed sessions 1 and 2, and thus were counted as participants for Study 1*. This moderate sample size was used in order to obtain sufficient statistical power. Participants were awarded course credit upon completion of each experimental session. 
Photo preparation. Participant and database photos were standardised in Adobe Photoshop CC (Adobe Systems Incorporated, 2011) to include the inner features of the participant's face, with the rest of the face obscured by a white foreground (rather than including a neck and full head as in Study 1). This change was made to make the stimuli materials easier to morph successfully (e.g., morphs that involve hair involve a certain level of image distortion), whilst only including participant features (rather than a standard neck that was Photoshopped in). See Figure 7 for an example of the standardisation process for Study 2 .

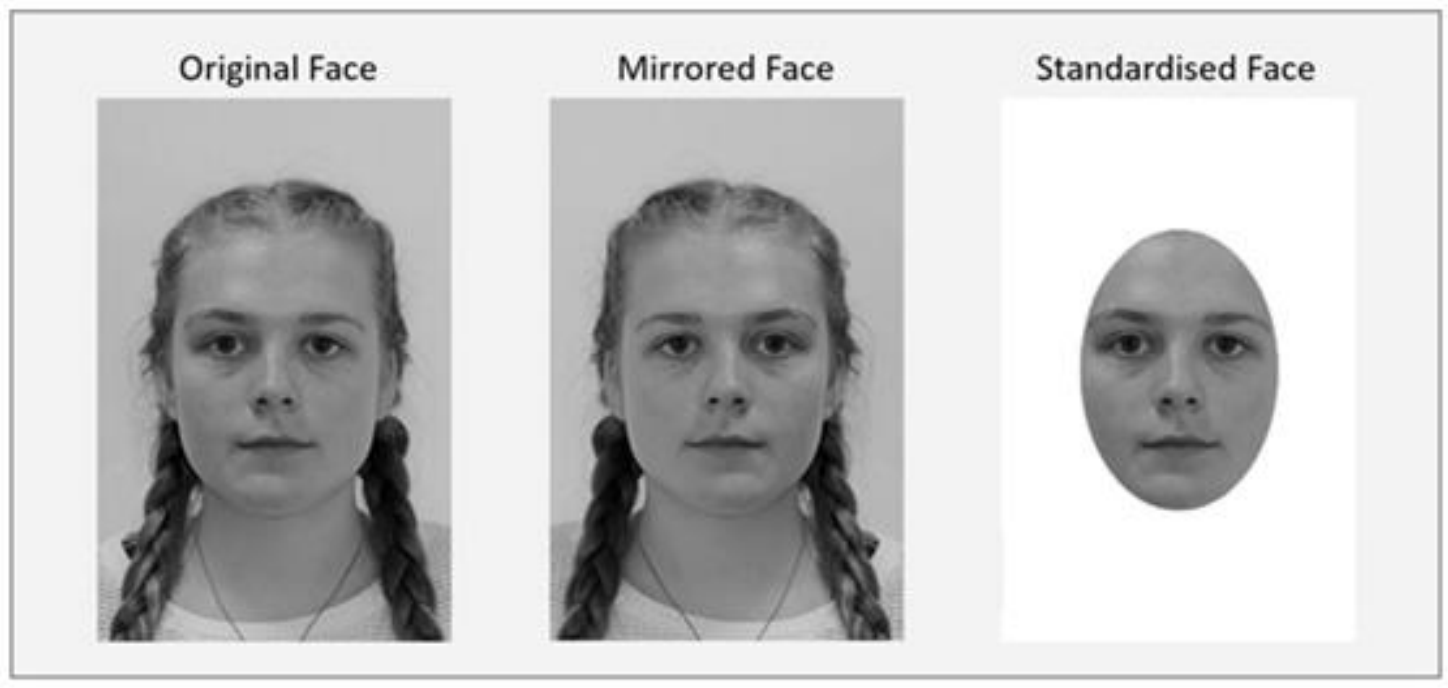

Figure 7. A visual depiction of the stages included in preparation of participant (and database) photos. Depicted (from left) is: An example of an original participant photograph (Original Face), an example of the same participant's face mirrored (Mirrored Face), and an example of the same participant's face standardised (Standardised Face).

Session 2: Trait judgements/Computer task procedure. As in study 1 participants were shown a pair of stimuli faces (always one participant-morphed and one other-morphed) and were asked to select the face that best represented the relevant trait (trustworthy, friendly, sincere, helpful, intelligent, confident, competent, or creative). As distinct from Study 1, 
faces were displayed for only 750ms (see Figure 8 below for a visual depiction of the trials with Study 2 Stimuli).

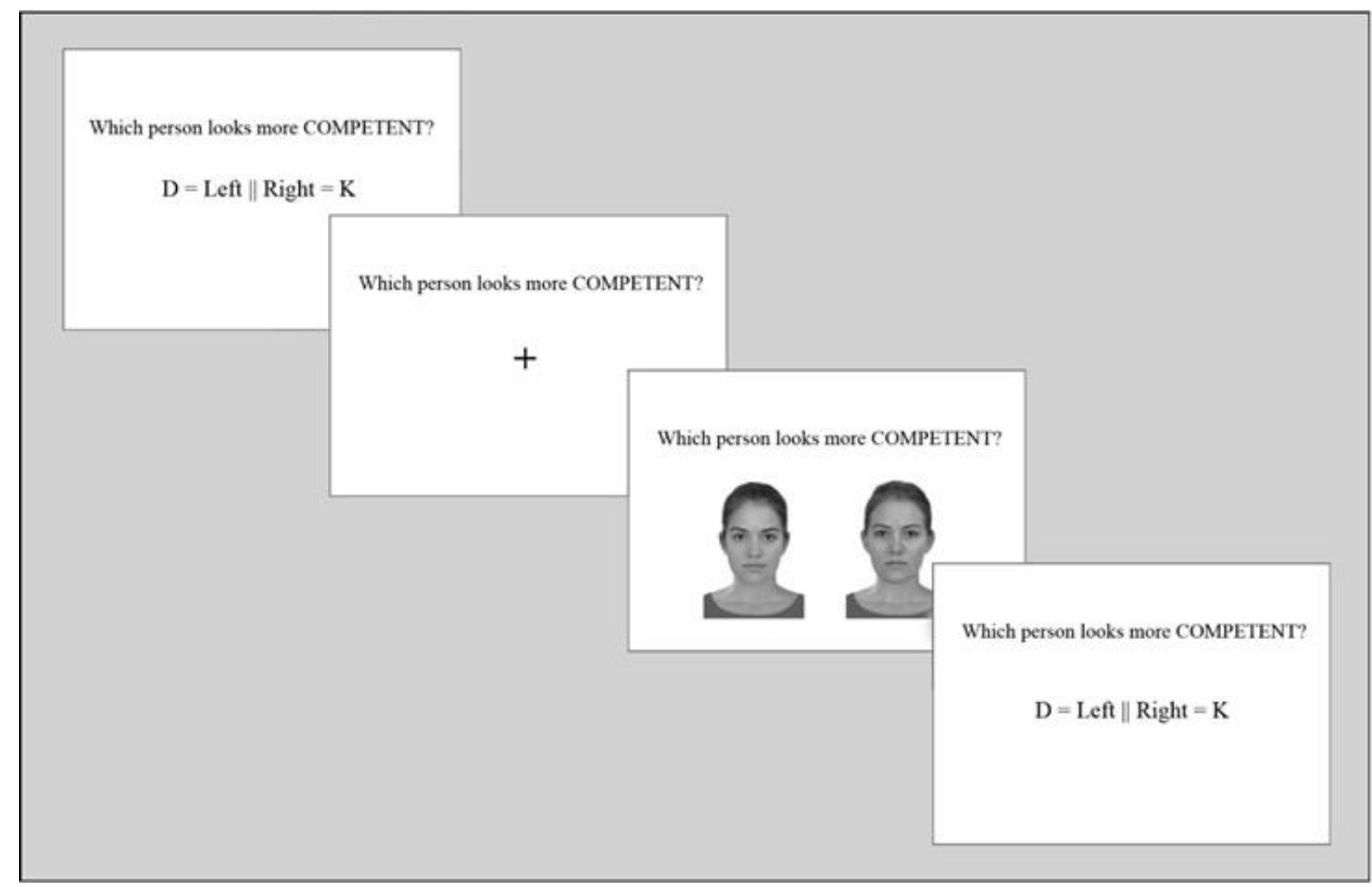

Figure 8. A visual depiction of one trial of the trait judgment procedure. Times were as follows: reminder question remained on screen for $2000 \mathrm{~ms}$, followed by a $500 \mathrm{~ms}$ fixation cross, two faces were presented for $750 \mathrm{~ms}$, and replaced with the reminder screen until a choice was made. 


\section{Study 2 Results}

Exclusions \& Data Reduction. No participants were excluded from the data analysis for this study leaving a total $\mathrm{N}$ of $85(\mathrm{M}=27, \mathrm{~F}=58)$. Based on the extensive literature on warmth and competence dimensions as primary in person perception, the four interpersonal warmth traits (sincere, friendly, trustworthy, and helpful) were combined into a Warmth index and the four competence traits (confident, competitive, creative, and intelligent) were combined into a Competence index. Reliability analyses indicated that the Warmth index was adequately strong (Cronbach's $\alpha=0.77$ ), but that the Competence index was not (Cronbach's $\alpha=0.25$ ). Examination of alpha excluding each item separately indicated that it was not any one item that was resulting in low reliability (highest $\alpha=0.47$ ).

Self-Selection: Overall. A one-sample t-test was run to determine whether the average (positive) self-selection score was significantly different to chance (i.e., 0.50). The results showed that the mean self-selection score $(\mathrm{M}=0.52, \mathrm{SD}=0.10)$ was significantly different to what would be expected by chance, $t(84)=2.24, p=0.03, d=0.25$. In other words, participants were more likely to select the self-similar stimuli over other-similar stimuli when collapsing across all of the trait dimensions included in the study.

Self-Selection: Warmth \& Competence. One-sample t-tests were conducted to examine whether the average self-selection for Warmth and Competence indices were significantly different to chance. As in Study 1, this analysis was used to examine whether a self-similar transference effect (indicated by selection of self-similar over other similar stimuli) would emerge when traits were grouped by the two major categories of first impression judgements (see Fiske, Cuddy, \& Glick, 2007). The results showed that the mean self-selection score for the Warmth index $(\mathrm{M}=0.54, \mathrm{SD}=0.14)$ was significantly different to what would be expected by chance $t(85)=2.31, p=0.02, d=0.24$, whilst the mean selfselection score for the Competence index $(\mathrm{M}=0.51, \mathrm{SD}=0.10)$ was not significantly 
different to what would be expected by chance $t(85)=1.18, p=0.23, d=0.13$. In other words, participants were more likely to select the self-similar stimuli over other-similar stimuli when making warmth judgements but not when making competence judgements. As noted previously, this latter finding should be taken with some caution as the index of competence-related traits do not reliably cluster, indicating that the items making up that index are, for whatever reason, seemingly not measuring the theoretical construct (i.e., "competence"). Although not reported here in the main analysis section, analysis by individual trait dimension can be seen in APPENDIX $\mathrm{H}$.

Self-Esteem and Self-Selection. In order to examine whether transference of selfconcept consistent valence had occurred in Study 2, we once again examined the relationship between measured self-esteem and self-selection likelihood. Pearson correlations were run to determine the relationship between self-esteem relevant measures completed during session 1, and self-selection responses during the trait judgment tasks from Session 2. As can be seen in TABLE 2, correlations among the self-esteem measures indicated that the IAT did not correlate with either the RSE or the Me/Not-Me (MNM) task, but that the RSE and the MNM were negatively correlated.

Correlations between self-esteem and self-selection. As suggested in Study 1, if self-esteem served a valence matching function, then self-esteem should correlate with the percentage of self-selection responses made in the trait judgment task. As can be seen in TABLE 2, neither the RSE, nor the MNM task showed significant correlations with selfselection. The IAT was significantly correlated with the Warmth index indicating that participants with higher levels of implicit self-esteem were more likely to choose a selfsimilar face over a non-self face for judgements relating to Warmth. This result suggests that implicit self-esteem (as measured using the IAT) may have affected the likelihood of choosing a self-similar face over a non-self similar face for judgements of Warmth. 
Furthermore, as this effect was not apparent for either of the other self-esteem measures it may suggest that the effect is driven by implicit process that are only tapped into by the IAT.

TABLE 2

\begin{tabular}{|c|c|c|c|c|c|c|}
\hline & Overall & Warmth & Competence & IAT & RSE & MNM \\
\hline Overall & -- & $0.88 * *$ & $0.74 * *$ & 0.16 & 0.02 & -0.09 \\
\hline Warmth & & -- & $0.34 * *$ & $0.22 *$ & 0.05 & -0.07 \\
\hline Competence & & & -- & 0.00 & -0.03 & -0.08 \\
\hline IAT & & & & -- & -0.06 & -0.02 \\
\hline RSE & & & & & -- & $-0.41 * *$ \\
\hline MNM & & & & & & -- \\
\hline
\end{tabular}

Relation between AMP and self-selection. The percentage of times participants responded that a nonsense word following a self-similar face was positive was not significantly correlated with self-selection, either overall or related to warmth or competence dimensions.

\section{Summary}

The findings for Study 2 are generally more supportive of the original hypotheses. That is, participants did show a significant bias toward self-similar selection for warmthrelevant traits (which also resulted in an overall significant self-selection effect). Additionally, self-esteem - as measured by the IAT - did correlate positively with selfselection tendencies for those warmth-related traits. There was still no evidence of an evaluative self-similar bias as measured by the AMP. 


\section{Study 3}

\section{Overview}

The pattern of results for Study 2 is promising - that is, consistent with the initial theorising, participants did show a significantly greater likelihood of choosing self-similar over non-self faces, at least for warmth-relevant traits when exposure to the faces was limited. This suggests that self-similar transference may represent a relatively quick judgment that is attenuated rapidly with additional (visual) information. Additionally, the correlation between the IAT self-selection of these warmth-relevant traits also suggests that self-similar transference may be a relatively implicit effect.

Study 3 was conducted as a direct replication but with both the limited (Study 2) and the unlimited (Study 1) presentation times in a within-subjects design. Although Study 1 indicated a lack of any self-transference, it is not possible to directly compare the results between that study and Study 2. By including both presentation times in the same study, it will be possible to both replicate the findings of the second study (i.e., that significant selftransference occurs for warmth-relevant traits when faces are presented for a limited time period) and allow direct examination of presentation time as a boundary condition. Specifically, it is expected that participants will again show increased likelihood of selecting self-similar over non-self faces for warmth-relevant traits in the limited but not the unlimited exposure condition.

Participants. Participants for this study were recruited from a 100-level psychology undergraduate classes at Victoria University of Wellington as part of their research participation requirement. As in study 1 the design of this study necessitated participants not knowing that sessions 1 and 2 were related. No limit was put on enrolment in order to increase the chances that enough students would enrol to participate in session 2. A total of 
77 participants (68 women, and 9 men) enrolled in and completed sessions 1 and 2, and thus were counted as participants for Study $1 *$. This moderate sample size was used in order to obtain sufficient statistical power (see footnote 1 for details of power analysis). Participants were awarded course credit upon completion of each experimental session.

Session 2: Trait judgements/Computer task procedure. As in study 1 participants were shown a pair of stimuli faces (always one participant-morphed and one other-morphed) and were asked to select the face that best represented the relevant trait (trustworthy, friendly, sincere, helpful, intelligent, confident, competent, or creative). However, in Study 3, participants completed both unlimited time (i.e., as used in Study 1) and limited time blocks (i.e., as used in Study 2). That is, participants completed the eight blocks of traits with both faces remaining on screen until the decision was selected, and another eight blocks of traits with the faces having been presented for only $750 \mathrm{~ms}$. The order of completion of the limited versus unlimited presentation blocks was counterbalanced across participants.

Session 2: AMP Task. There was no significant effect found in the AMP task for Studies 1 and 2 (see exploratory analyses section later on), so it was removed for Study 3 to allow time for the second block of trait judgements described above.

\section{Study 3 Results}

Exclusions and Data Reduction. Two participants were excluded from the data analysis due to having more than ten percent of their responses under $250 \mathrm{~ms}$ (i.e., indicating anticipatory responding). This left a total $\mathrm{N}$ of $75(\mathrm{M}=9, \mathrm{~F}=66)$. As in the previous studies, the warmth-relevant traits were combined (Cronbach's $\alpha=0.80$ ) as were the competencerelevant traits (Cronbach's $\alpha=0.65$ ). The competence index shows minimal change with the exclusion of any of the four items. This again indicates that the warmth items make up a reliable index and that the competence items, unlike in previous studies, are at least within a low, but acceptable, range. 
Self-Selection: Overall. One-sample t-tests were conducted to determine whether the average (positive) self-selection score for recruited subjects was significantly different to chance (i.e., 0.50). When collapsing across all of the traits in the current study, these analyses found no significant self-selection effect in either the unlimited presentation condition $(\mathrm{M}=$ $0.49, \mathrm{SD}=.16 ; \mathrm{t}<1.0)$, or the limited presentation condition $(\mathrm{M}=0.47, \mathrm{SD}=0.14), \mathrm{t}(74)=-$ $1.69, \mathrm{p}=0.09$. In other words, participants were not more likely to select the self-similar stimuli over other-similar stimuli in either stimulus presentation condition. Analysis by individual item type is presented in APPENDIX I.

Self-Selection: Warmth \& Competence. A series of one-sample t-tests were also used to examine the selection of traits that fall under the warmth (sincere, helpful, friendly, and trustworthy) and competence (confident, competent, creative, and intelligent) for stimuli with limited presentation times, and for stimuli with unlimited presentation times. For stimuli with unlimited viewing time neither the mean selection score for warmth traits $(M=0.48, S D$ $=0.19)$ nor for competence traits $(\mathrm{M}=0.51, \mathrm{SD}=.16)$ was significantly different to chance (both $\mathrm{t}<1.0$, smallest $\mathrm{p}=0.34$ ). For the limited time presentation condition, the level of selfselection responses was not significantly different from chance for the mean selection score for Competence traits $(\mathrm{M}=0.48, \mathrm{SD}=0.16), \mathrm{t}(74)=-1.22, \mathrm{p}=0.23, \mathrm{~d}=-.14$. However, as distinct from the unlimited time condition, the level of self-selection responses was significantly different from chance for the mean selection score for Warmth traits $(M=0.46$, $\mathrm{SD}=0.17), \mathrm{t}(74)=-2.06, \mathrm{p}=0.04, \mathrm{~d}=.20$. What is especially surprising here, and counter to the predictions, is that participants were actually less likely to select self-similar compared to non-self faces in the limited time condition. That is, a significant difference emerged, but in the opposite direction of the effect from Study 2. 
Comparing Limited and Unlimited Stimuli Presentation. A 3 (Dimension:

Warmth, Competence, Overall) x 2 (Time: Unlimited vs. limited) repeated measures ANOVA was run to examine whether there was a significant difference in means of selfselection, warmth, and competence, between stimuli with limited presentation times versus stimuli with unrestricted presentation times. The analysis revealed only a marginally significant main effect for Time $(\mathrm{F}(1,64)=3.78, \mathrm{p}=.056)$ indicating that, overall, participants were less likely to select the self-similar images in the limited time condition (M $=.47)$ compared to the unlimited time condition $(\mathrm{M}=.50)$.

Self-Esteem \& Self-Selection. A Pearson correlation was run to determine the relationship between self-ratings/measures completed during session 1 (the RSE and the Me/Not me Task), and average self-selection (positivity) scores from Session 2 (as well as self-selection for warmth and competence traits). As in Study 1, this analysis was used to examine whether transference of self-concept consistent valence had occurred in Session 2. If so, we would expect the data to show a correlation between participant levels of self-esteem and selection of self-similar stimuli. Similar to what was found in Study 2, the RSE did not correlate with the IAT, but was significantly correlated with the MNM.

As can be seen in TABLE 3, self-esteem as measured by the RSE and the IAT did not correlate with self-selection tendencies in the unlimited presentation time condition. Scores on the Me/Not-me (MNM) task were negatively correlated with overall self-selection and warmth index indicating that the more positive than negative traits that people say are selfdescriptive is related to lower self-selection in the trait-based task. The only significant correlation that emerged in the limited presentation time condition was that self-esteem as measured by the RSE was significantly correlated with the Competence index. Thus, the 
significant correlation between scores on the IAT and self-selection likelihood for warmthrelated traits that was seen in Study 2 was not replicated in this study.

TABLE 3

\begin{tabular}{lllllll}
\hline & Overall & Warmth & Competence & IAT & RSE & MNM \\
\hline Overall & -- & $.92^{* *}$ & $.88^{* *}$ & .13 & .15 & -.22 \\
Warmth & $.88^{* *}$ & -- & $.61^{* *}$ & .13 & .12 & $-.24^{*}$ \\
Competence & $.86^{* *}$ & $.51^{* *}$ & -- & .11 & .16 & -.15 \\
IAT & .05 & .01 & .09 & -- & -.08 & .02 \\
RSE & .19 & .08 & $.24 *$ & -.08 & -- & $-.51^{* *}$ \\
MNM & -.15 & -.17 & -.08 & .02 & $-.51^{* *}$ & - \\
\hline
\end{tabular}

NOTE: $*=<.05 ; * *=<.001$. Coefficients in the upper right portion of the table $=$ unlimited time condition; coefficients in the lower left portion of the table $=$ limited time condition.

\section{Overview}

\section{Study 4}

The results of Study 3 were somewhat surprising and counter to what had been hypothesized. That is, the finding that participants were more likely to select self-similar faces for Warmth-relevant traits that was found in Study 2 did not replicate in the current study. In fact, Study 3 showed a significant effect in the opposite direction. Participants were less likely to select self-similar faces compared to non-self faces when the trait judgment to be made was related to interpersonal warmth. The patterns for self-esteem and self-selection, similarly, did not replicate the previous pattern. The failure to replicate either effect is disappointing, but certainly indicates the importance of replication within a research program. 
At this point in the project, we were particularly concerned with the fact that not only were the patterns of findings not supporting the theorised phenomenon, but - crucially - the studies were not replicating an established finding. Specifically, DeBruine (YEARS) had demonstrated that faces that had been morphed with her participants' faces were viewed as more trustworthy than targets that had been morphed with someone else's face. Given the basic similarity in design (i.e., self-morph vs other-morph, forced-choice, trustworthiness judgment), the failure to replicate at least those findings was somewhat confounding. This led us to go back to the previously published DeBruine articles and try to narrow down any meaningful differences that existed between her paradigm and the current work.

Study 4, then, was an attempt to eliminate the primary difference that was identified between the current and the previous work. In particular, DeBruine (YEARS) presented the exact same faces differing only in whether they were morphed with the self or with an unknown other. For example, if the face that was used as the "base" of the morph could be labelled "Face A," participants would be presented with "Face A(self) vs. Face A(other)" during the forced-choice task. The only difference being self vs. other. In the previous three studies in this thesis, the pairing of the faces presented were not controlled in this manner. That is, on each trial, participants were randomly presented with a self-similar and a non-self face, but the "base" face could have been any of the faces used from the database. This is likely to have introduced additional noise, potentially masking a subtle effect, to the judgment context.

In Study 4, then, participants were presented with either unmatched pairs (i.e., randomly paired self and other photos) or with matched pairs (i.e., self and other photos with the same base face). If the introduction of noise due to greater differences between the faces is masking the self-transference - or even just the self-similarity trustworthiness effect 
demonstrated by DeBruine - then we should expect to see self-transference in the matched pairs, but not the unmatched pairs condition.

\section{Methods}

Participants. Participants for this study were recruited from a 100-level psychology undergraduate classes at Victoria University of Wellington as part of their research participation requirement. As in study 1 the design of this study necessitated participants not knowing that sessions 1 and 2 were related. No limit was put on enrolment in order to increase the chances that enough students would enrol to participate in session 2. A total of 83 participants (65 women, and 18 men) enrolled in and completed sessions 1 and 2, and thus were counted as participants for Study 1. This moderate sample size was used in order to obtain sufficient statistical power (see footnote 1 for details of power analysis). Participants were awarded course credit upon completion of each experimental session.

Session 2: Trait judgements/Computer task procedure. As in study 3 participants were shown a pair of stimulus faces (always one participant-morphed and one othermorphed) and were asked to select the face that best represented the relevant trait (trustworthy, friendly, sincere, helpful, intelligent, confident, competent, or creative). Again, as in Study 3, participants completed two blocks of trait judgement trials, however the conditions of these blocks differed from those used in Study 3. The two blocks in Study 4 consisted of: one condition wherein the two to-be-judged faces were morphed using the same base database face, and a second condition wherein two to-be-judged faces were morphed using a different base database face (see Figure 9 below for a visual depiction of the judgement trial stimuli for each block during Study 4). 


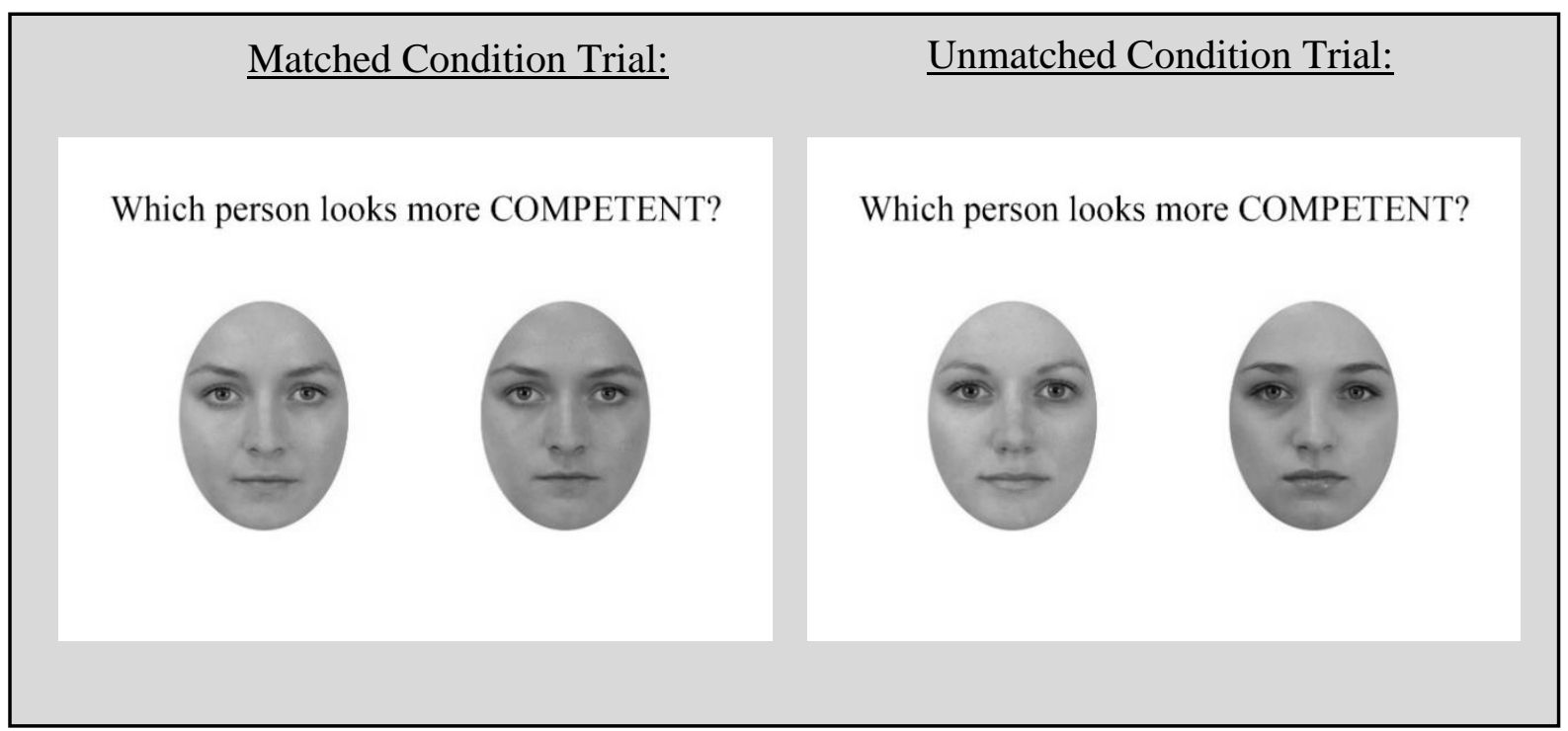

Figure 9. A visual depiction of one judgement trial from each condition (Matched or Unmatched) in Study 4. In the Matched condition the left-hand face is a morph consisting of $50 \%$ Subject $50 \%$ and Database 1, and the face on right is a morph consisting of $50 \%$ yoked subject and 50\% database 1 . In every Matched condition the Database face used for the selfmorph and other morphed faces will be the same.

In the Unmatched condition the left-hand face is a morph consisting of 50\% subject and $50 \%$ Database 2, and the face on right is a morph consisting of 50\% yoked subject $50 \%$ Database 5. For every trial in the Unmatched condition the database face used for the selfmorph and other morphed faces will be the different.

\section{Results}

Exclusions and Data Reduction. Six participants were excluded from the data analysis for this study leaving a total $\mathrm{N}$ of $77(\mathrm{M}=18, \mathrm{~F}=59)$. Specifically, three participants were excluded from data analysis due to having greater than ten percent of their responses below $250 \mathrm{~ms}$ (i.e., indicating anticipatory responding), and three were excluded due to computer error in assignment of stimuli. The four warmth-related traits were combined and showed good reliability (Cronbach's $\alpha=0.83$ ). Consistent with the previous studies, the competence-related items did not show adequate reliability (Cronbach's $\alpha=.50$ ) with minimal improvement with the exclusion of intelligent. 
Self-Selection: Overall. A series of one-sample t-tests was run to determine whether the average (positive) self-selection score for recruited subjects was significantly different to chance (0.5). Participants in the Unmatched condition did show an overall bias toward selection of self-similar faces over non-self faces $(\mathrm{M}=0.53, \mathrm{SD}=0.13 ; \mathrm{t}(76)=2.33, \mathrm{p}=$ $0.02, d=.27)$. Even though the mean level of self-selection was equivalent, this pattern did not reach significance in the Matched condition $(\mathrm{M}=0.53, \mathrm{SD}=0.16 ; \mathrm{t}(76)=1.77, \mathrm{p}=0.08$, $\mathrm{d}=.20$ ). In other words, participants were only slightly more likely to select the self-similar stimuli over other-similar stimuli in either the matched or the unmatched condition.

Self-Selection: Warmth \& Competence. When stimuli were unmatched, the mean self-selection score for warmth traits $(\mathrm{M}=0.52, \mathrm{SD}=0.16)$ was not found to be significantly different to chance, $\mathrm{t}(76)=1.65, \mathrm{p}=0.10, \mathrm{~d}=.19$; however, self-selection on Competence traits $(\mathrm{M}=0.53, \mathrm{SD}=0.13)$ was significantly different from chance, $\mathrm{t}(76)=2.63, \mathrm{p}=.01, \mathrm{~d}$ $=.30$. When stimuli were matched, the mean self-selection score for warmth traits $(\mathrm{M}=0.54$, $\mathrm{SD}=0.23$ ) was not found to be significantly different to chance, $\mathrm{t}(76)=1.40, \mathrm{p}=0.17, \mathrm{~d}$ $=.16$. However, self-selection on Competence traits $(\mathrm{M}=0.53, \mathrm{SD}=0.15)$ did show a trend toward self-selection bias, $\mathrm{t}(76)=1.63, \mathrm{p}=0.11 ; \mathrm{t}(69)=1.75, \mathrm{p}=.08, \mathrm{~d}=.20$. In other words, participants were more likely to select the self-similar stimuli over other-similar stimuli in either the matched condition or (marginally so) in the unmatched condition when making competence judgments but not when making judgments along the Warmth dimension.

Comparing Unmatched and Matched Stimuli. A 3 (Dimension: Warmth, Competence, Overall) x 2 (Trial type: Matched vs. Mismatched) repeated measures ANOVA was run to examine whether there was a significant difference in self-selection likelihood across the different dimensions. The analysis revealed no significant main effects or interactions (all Fs < 1.0). Counter to expectations, participants did not show different levels 
of self-selection when pairs were matched for original database image than when these images were unmatched.

Self-Esteem \& Self-Selection. As can be seen in TABLE 4, scores on the IAT were not correlated with either the RSE or the Me/Not-me (MNM) task. The RSE and MNM were, again, negatively correlated. In the Unmatched stimuli condition (upper-right portion of the table), scores on the MNM task were negatively correlated with self-selection for both warmth-related and competence-related indices, as well as for overall levels of self-selection. That is, participants who selected more positive than negative terms as self-descriptive showed decreased self-selection in this condition. This pattern was mostly shown in the Matched stimuli condition with MNM scores negatively related to overall self-selection as well as for warmth-related, but not competence-related, indices. Neither the IAT nor the RSE correlated with self-selection in either condition.

TABLE 4

\begin{tabular}{lllllll}
\hline & Overall & Warmth & Competence & IAT & RSE & MNM \\
\hline Overall & -- & $.92 * *$ & $.87 * *$ & -.09 & .16 & $-.32^{*}$ \\
Warmth & $.90^{* *}$ & -- & $.59 * *$ & -.12 & .11 & $-.26^{*}$ \\
Competence & $.75 * *$ & $.39 * *$ & -- & -.02 & .18 & $-.32^{*}$ \\
IAT & -.10 & -.13 & -.01 & -- & .06 & -.01 \\
RSE & .03 & .00 & .08 & .06 & -- & $-.48^{* *}$ \\
MNM & $-.28 *$ & $-.27 *$ & -.18 & -.01 & $-.48 * *$ & - \\
\hline
\end{tabular}

NOTE: $*=<.05 ; * *=<.001$. Coefficients in the upper right portion of the table $=$ unmatched stimuli condition; coefficients in the lower left portion of the table $=$ matched stimuli condition. 


\section{Exploratory Results}

\section{Self-Selection and NEO-5 Personality Traits.}

Given the consistency in methodology applied across all studies it was thought reasonable to collapse the data into a single set for exploratory analysis. Because all four studies included the same eight trait judgments, we included all 325 participants in the following analyses. That is, data for each participant included all of the personality scales from Session 1 as well as self-similarity selection percentages for each of the eight traits.

A series of Pearson correlations were run to determine the relationship between selfratings/measures completed during Session 1 (the NEO-5 personality measure for the traits of: openness, conscientiousness extraversion, agreeableness, and neuroticism), and average self-selection for all traits (as well as self-selection for warmth and competence traits separately), in Session 2 (collapsing across studies.in each study). The correlations between the different dimensions of the NEO-5 and the TIPI are shown in Table 5.

\section{Correlations between personality dimensions and self-similar target selection}

Neo-5. As can be seen in Table 6, with the exception of Neuroticism being positively correlated with self-selection likelihood for judgments of sincerity and creativity, none of the dimensions (e.g., Openness, Conscientiousness, Extraversion, or Acceptance) as measured by the NEO-5 were correlated with a tendency to select self-similar faces over other-similar faces on any of the trait dimensions we examined. Neuroticism did correlate positively with both the competence and overall self-selection indices, and showed a trend toward a positive relationship with the warmth index (see Table 7). That is, as neuroticism increased, the likelihood of selecting self-similar faces over non-self faces increased.

TIPI. Personality dimensions as measured by the TIPI, on the other hand, did show some significant correlations with self-similar selection tendency. As can be seen in Table 6, both Openness and Agreeableness were negatively correlated with self-selection along some 
of the trait dimensions. These subscales also, thus, correlated negatively with level of selfselection for the warmth dimension index (see Table 7). Emotional Stability as measured by the TIPI was negatively correlated with creativity. None of the other subscales of the TIPI correlated with either individual or combined indices of self-selection.

Overall, the pattern of results does not provide a very coherent story. The best predictor for the NEO-5 seems to be Neuroticism as it showed the most consistent pattern. Specifically, higher Neuroticism related to increased self-selection likelihood overall. For the TIPI, both Openness and Agreeableness showed the most consistent patterns with higher levels of either being related to decreased self-selection likelihood for warmth-related traits. Any attempt for a theoretical explanation for these results would be speculative at best and, given the general lack of a self-selection bias overall, would probably be inappropriate. 


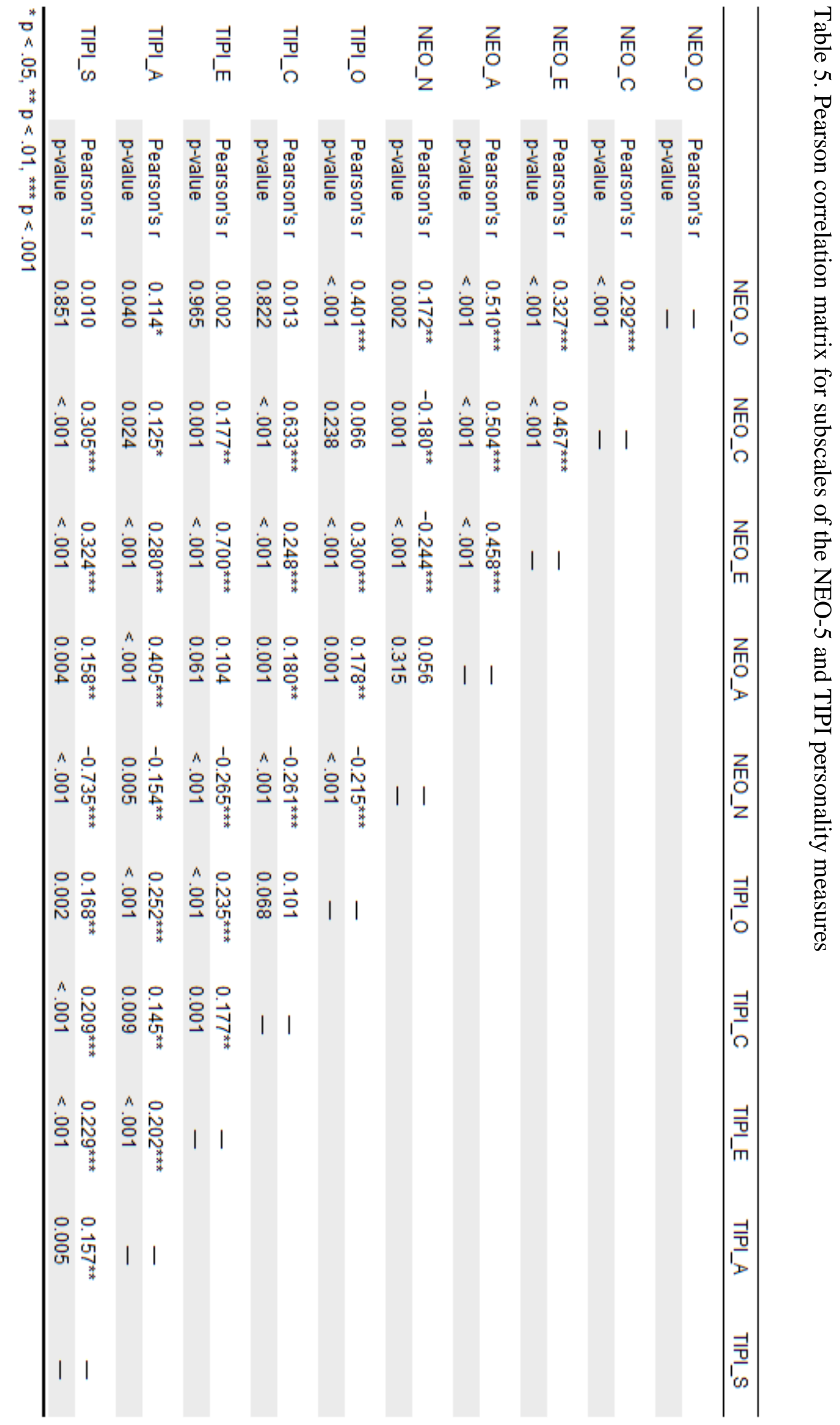




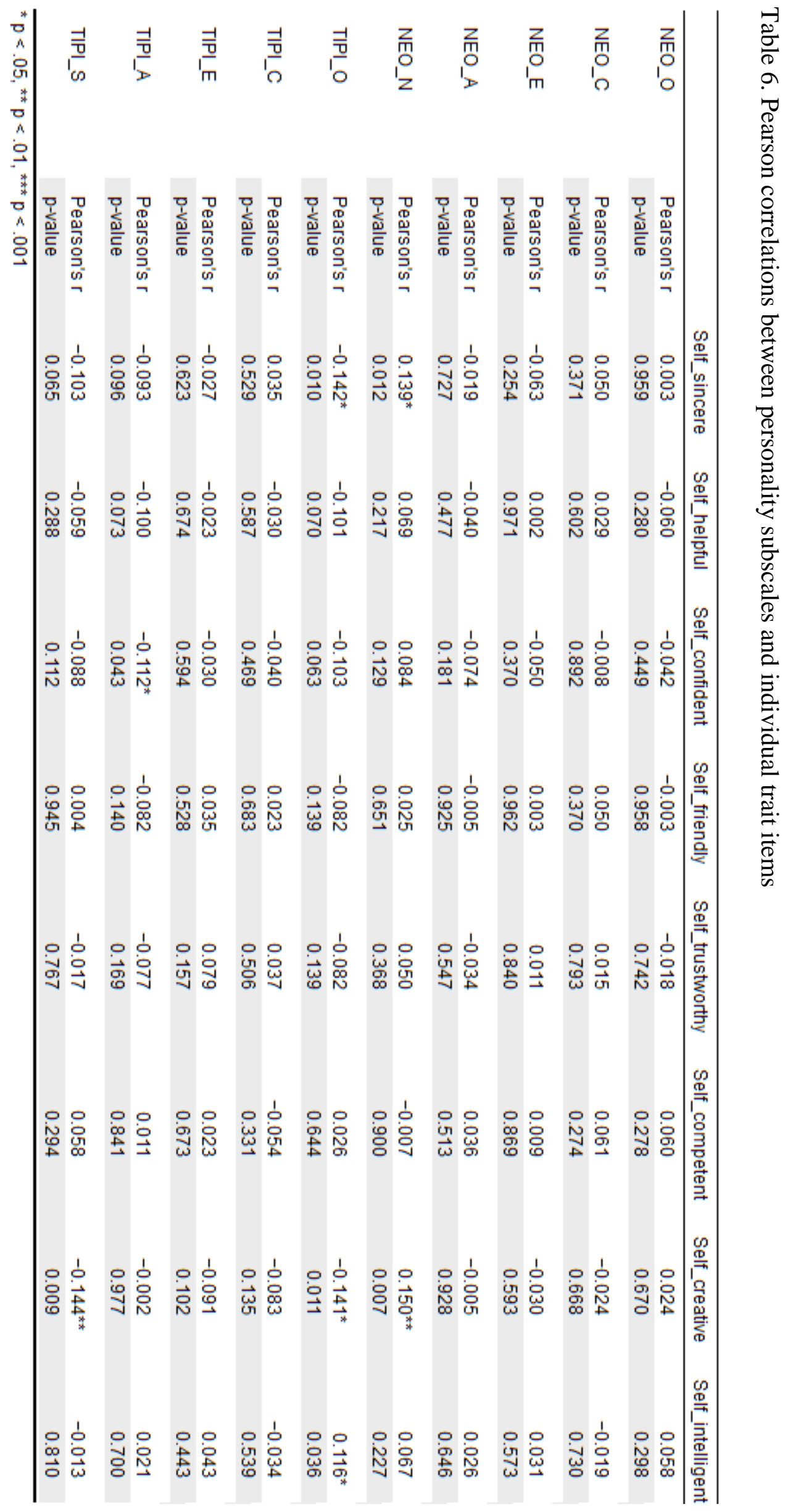


Table 7. Pearson correlations between personality subscales and trait indices

\begin{tabular}{|c|c|c|c|c|}
\hline & & Warmth & Competence & Positivity \\
\hline \multirow[t]{2}{*}{ NEO_O } & Pearson's r & -0.021 & 0.042 & 0.007 \\
\hline & p-value & 0.711 & 0.450 & 0.896 \\
\hline \multirow[t]{2}{*}{ NEO_C } & Pearson's r & 0.039 & -0.002 & 0.024 \\
\hline & p-value & 0.490 & 0.970 & 0.665 \\
\hline \multirow[t]{2}{*}{ NEO_E } & Pearson's r & -0.020 & -0.022 & -0.024 \\
\hline & $\mathrm{p}$-value & 0.723 & 0.696 & 0.671 \\
\hline \multirow[t]{2}{*}{ NEO_A } & Pearson's r & -0.031 & -0.010 & -0.025 \\
\hline & p-value & 0.577 & 0.864 & 0.653 \\
\hline \multirow[t]{2}{*}{ NEO_N } & Pearson's r & 0.095 & $0.124^{*}$ & $0.124^{*}$ \\
\hline & $\mathrm{p}$-value & 0.088 & 0.025 & 0.026 \\
\hline \multirow[t]{2}{*}{ TIPI_O } & Pearson's r & $-0.126^{\star}$ & -0.040 & -0.102 \\
\hline & $\mathrm{p}$-value & 0.023 & 0.468 & 0.066 \\
\hline \multirow[t]{2}{*}{ TIPI_C } & Pearson's r & 0.015 & -0.086 & -0.033 \\
\hline & p-value & 0.792 & 0.123 & 0.556 \\
\hline \multirow[t]{2}{*}{ TIPI_E } & Pearson's r & 0.018 & -0.021 & 0.002 \\
\hline & $\mathrm{p}$-value & 0.749 & 0.713 & 0.978 \\
\hline \multirow[t]{2}{*}{ TIPI_A } & Pearson's r & $-0.116^{\star}$ & -0.042 & -0.097 \\
\hline & p-value & 0.037 & 0.449 & 0.082 \\
\hline \multirow[t]{2}{*}{ TIPI_S } & Pearson's r & -0.060 & -0.080 & -0.079 \\
\hline & p-value & 0.280 & 0.150 & 0.156 \\
\hline
\end{tabular}

\section{Summary}

Main Hypotheses. In the current research it was hypothesised that transference of self-concept to judgements of self-similar stimuli would occur, operationalised as: 1) selfselection of self-similar images (over other similar images), and 2) a positive relationship between self-esteem and self-selection. The results of studies one through four largely disconfirmed these hypotheses in that: 1) self-similar selection was not found to significantly differ from chance in the vast majority of analyses, and 2) self-similar selection was not found to be significantly correlated with self-esteem in the vast majority of cases.

In order to get an overall estimate of effect size, we conducted a mini meta-analysis (using Meta-Essentials Version 1.4 [computer software]; Suurmond, van Rhee, \& Hak, 2017) 
combining the effects for each study. As can be seen in Figure 10, the analysis revealed an overall effect size of .05 for self-selection of Warmth-based trait judgments. As the $95 \%$ confidence interval (LL -.01, UL .11) contains zero, the estimated effect size, perhaps unsurprisingly, is not significant. A similar meta-analysis examining Competence-related trait judgments revealed an effect size of .05 (see Figure 11) with a 95\% confidence interval again containing zero (LL -.02, UL .11). That is, overall, there is no reliable evidence that selfsimilar faces were selected at a higher rate than other-similar faces in these studies.

Figure 10: Meta-analysis of Warmth-related traits across the four studies.

\begin{tabular}{|c|c|c|c|c|c|c|c|c|c|c|c|c|c|}
\hline \multirow{2}{*}{$\#$} & \multirow{2}{*}{ Study name } & \multirow{2}{*}{ Effect size } & \multirow{2}{*}{ CI Lower limit } & \multirow{2}{*}{ CI Upper limit } & \multicolumn{9}{|c|}{ Effect Size } \\
\hline & & & & & -0.40 & -0.30 & -0.20 & -0.10 & 0.00 & 0.10 & 0.20 & 0.30 & 0.40 \\
\hline 1 & Trustworthy & 0.05 & 0.01 & 0.09 & & & & & & & & & \\
\hline 2 & Trustworthy & 0.10 & 0.07 & 0.14 & 1 & & & & & & & & \\
\hline 3 & Trustworthy & -0.17 & -0.22 & -0.11 & $\begin{array}{l}2 \\
3\end{array}$ & & & & & & & & \\
\hline 4 & Trustworthy & -0.08 & -0.13 & -0.03 & 3 & & & & & & & & \\
\hline 5 & Trustworthy & 0.26 & 0.22 & 0.30 & $\begin{array}{l}4 \\
5\end{array}$ & & & & & & & & \\
\hline 6 & Trustworthy & 0.23 & 0.17 & 0.29 & $\begin{array}{l}3 \\
6\end{array}$ & & & & & & & & \\
\hline 7 & Sincere (S1) & 0.04 & 0.01 & 0.08 & 7 & & & & & & & & \\
\hline 8 & Sincere (S2) & 0.07 & 0.03 & 0.11 & 8 & & & & & & & & \\
\hline 9 & 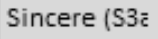 & -0.11 & -0.16 & -0.05 & $\begin{array}{l}0 \\
9\end{array}$ & & & & & & & & \\
\hline 10 & Sincere (S3t & -0.09 & -0.13 & -0.05 & $\begin{array}{r}9 \\
10\end{array}$ & & & & & & & & \\
\hline 11 & Sincere ( $S 4 \bar{c}$ & 0.06 & 0.01 & 0.10 & 11 & & & & & & & & \\
\hline 12 & Sincere (S4k & 0.07 & 0.01 & 0.13 & 12 & & & & & & & & \\
\hline 13 & Helpful (S1) & 0.14 & 0.10 & 0.18 & 13 & & & & & $\longmapsto$ & & & \\
\hline 14 & Helpful (S2) & 0.26 & 0.21 & 0.30 & 14 & & & & & & & & \\
\hline 15 & Helpful (S3i & -0.01 & -0.07 & 0.05 & 15 & & & & & & & & \\
\hline 16 & Helpful (S3t & -0.31 & -0.36 & -0.25 & 16 & -1 & & & & & & & \\
\hline 17 & Helpful (S4i & 0.05 & 0.00 & 0.10 & 17 & & & & & & & & \\
\hline 18 & Helpful (S4t & 0.20 & 0.13 & 0.26 & 18 & & & & & & & & \\
\hline 19 & Friendly ( $\mathrm{S1}$ & -0.03 & -0.06 & 0.01 & 19 & & & & & & & & \\
\hline 20 & Friendly (S2 & 0.20 & 0.16 & 0.24 & 20 & & & & & & $\longmapsto$ & & \\
\hline 21 & Friendly (S3 & 0.01 & -0.05 & 0.07 & 21 & & & & & & & & \\
\hline 22 & Friendly ( $\mathrm{S3}$ & -0.13 & -0.18 & -0.08 & 22 & & & - & & & & & \\
\hline 23 & Friendly ( $\$ 4$ & 0.26 & 0.21 & 0.31 & 23 & & & & & & & $\longrightarrow$ & \\
\hline 24 & Friendly (S4 & 0.04 & -0.02 & 0.11 & 24 & & & & & & & & \\
\hline $\begin{array}{l}25 \\
76\end{array}$ & & & & & $\begin{array}{l}25 \\
26\end{array}$ & & & & & & & & \\
\hline
\end{tabular}


Figure 11: Meta-analysis of Competence-related traits across the four studies.

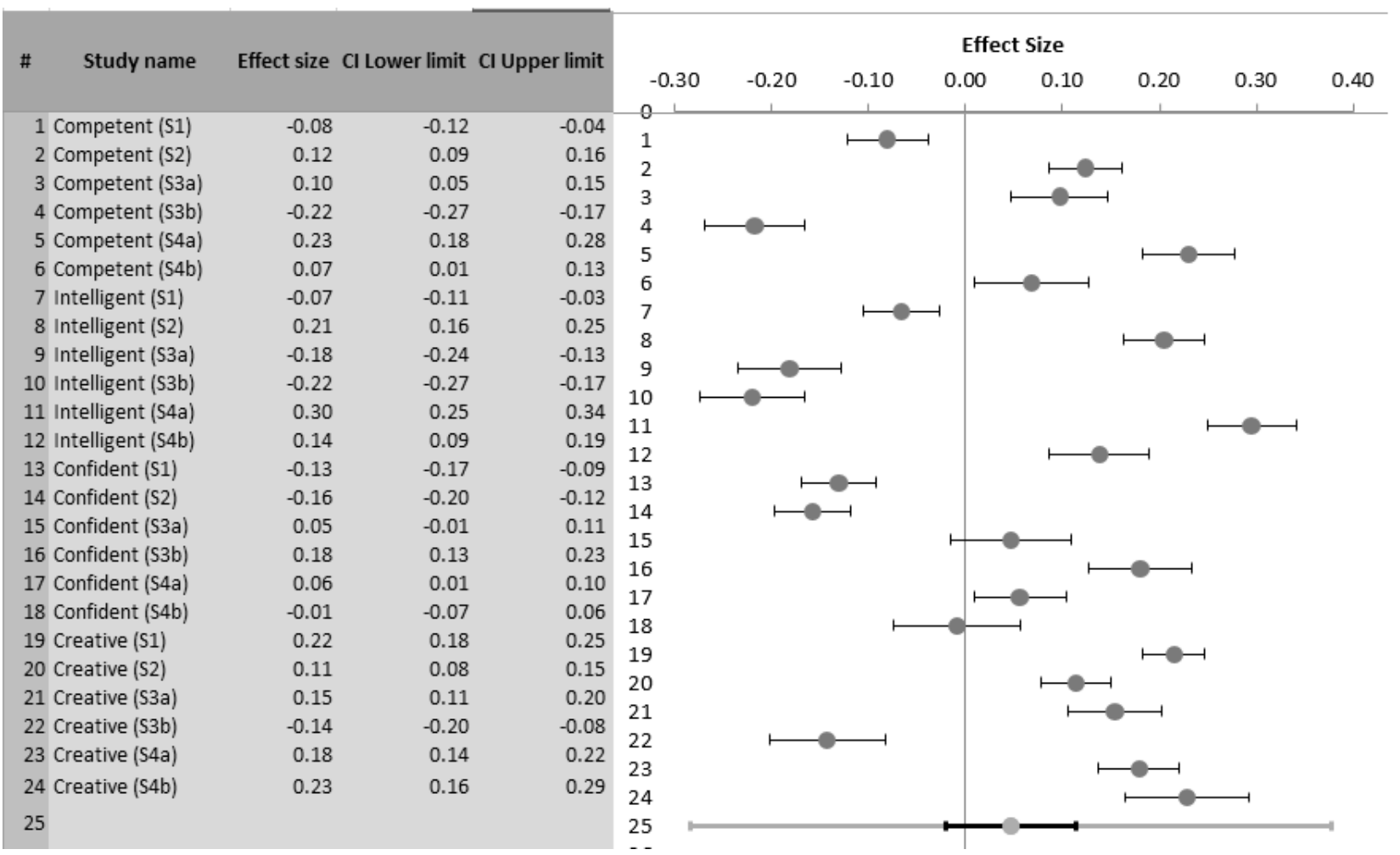

In terms of self-esteem, the RSE did not correlate with self-similar choices in any of the studies. Collapsing across the studies, the RSE correlations were: Warmth, $r=.034, \mathrm{p}$ $=.563$; Competence, $\mathrm{r}=.059, \mathrm{p}=.310$; and Overall, $\mathrm{r}=.051, \mathrm{p}=.384$. The IAT fared slightly better, but still showed no reliable pattern. Again, collapsing across the four studies, the IAT correlations were: Warmth, $\mathrm{r}=.098, \mathrm{p}=.091$; Competence, $\mathrm{r}=.094, \mathrm{p}=.107$; and Overall, $\mathrm{r}=.107, \mathrm{p}=.064$. The most reliable predictor of self-selection bias was the number of negative self-descriptive traits selected in the Me/Not-me task. The correlation of this variable, collapsing across studies was: Warmth, $r=.114, p=.050$; Competence, $r=.103, p$ $=.075 ;$ Overall, $\mathrm{r}=.122, \mathrm{p}=.035$. Although technically significant, the effect is quite small and did not emerge in a consistent pattern across the studies. 
Presentation Time: The current research also considered presentation time as a factor that may affect rate of self-similar transference (Study 2). The results disconfirmed this notion in that: 1) largely no difference was found in rate of self-similar selection between stimuli with limited and unlimited presentation times, 2) self-esteem was (largely) not found to be related to self-similar selection for either limited or unlimited presentation times.

Noise Reduction: Additionally, the current research attempted to clean up any noise that may have masked transference effects in Studies 1-3, by utilising matched versus unmatched stimuli (Study 4). The results disconfirmed this notion in that: 1) largely no difference was found in rate of self-similar selection between matched stimuli or unmatched stimuli, and 2) self-esteem was (largely) not found to be related to self-similar selection for either matched or unmatched stimuli. 


\section{Chapter 4: General Discussion}

Previous research has demonstrated that our first impressions of others are influenced by their appearance. Facial similarity between a novel target and one's significant other has been found to result in transference; a first impression bias wherein the mental representation of a 'significant other' becomes activated in memory, causing evaluations of a novel target to be assimilated to that representation. The current thesis aimed to extend previous research in the area of transference by investigating whether transference of a self-representation is possible, using self-similar facial stimuli.

Based upon previous research it was hypothesised that:

1. If the valence of a participant's self-representation is negative, then self-morphed stimuli in the current research will be judged more negatively than non-selfmorphed stimuli.

2. If the valence of a participant's self-representation is positive, then self-morphed stimuli in the current research will be judged more positively than non-selfmorphed stimuli.

The four experiments reported in this thesis found minimal evidence to support either hypothesis. From the results of the current research it can be inferred either that either: 1) self-similar transference is either not possible or (if possible) acts in a way that is different to significant-other transference, or; 2) assuming self-similar transference is possible, the methods used in the current research may not have been sufficient to demonstrate the effect. The remainder of this thesis will focus on the merit of each of the above inferences with reference to previous research. 


\section{1 Why no Self-Similar Transference?}

For lack of any reliable evidence for transference in the current studies reflects either a failure to detect an effect (if one exists), a failure to produce the conditions necessary to trigger self-similar transference, or suggests that the idea of self-similar transference is not viable. This discussion will be structured in such a way as to examine the findings of this study in relation to transference theory. In order to do this the findings will be assessed as they relate to the three stages of transference outlined in the introduction. To recap, the three stages of transference are as follows:

1) The target face resembles (either objectively or subjectively) the face of someone who is significant to the perceiver,

2) A mental representation of the significant other becomes activated in response to this stimulus

3) The subsequent judgement of the target stimulus incorporates both the valence and contents of the significant other representation.

4.1.1 Stage 1: Target face resembles significant other. As mentioned in the introduction, there are two conditions that need to be met for the first stage of self-similar transference to be possible. Firstly, the "self" must be significant to the individual, and secondly, the target face must resemble the self.

Possibility 1: The self-concept does not qualify as a significant other. In the introduction we argued that one's self fulfils the description of a significant other as "any individual who is or has been deeply influential in one's life and in whom one is or once was emotionally invested" (Anderson \& Chen, 2002 p. 619), and posited that an individual may act as significant to themselves in the same way. That is, the self-concept is a mental representation of a significant individual that is both deeply influential and highly motivating 
to the individual, and for whom there is great emotional investment. Given that mental representations of the self are conceptualised in a similar way to mental representations of significant others (Anderson et al., 1998) it is unlikely that the self does not meet the criteria of being a significant individual (in one's own life). Therefore, if the fault in finding transference in the current study occurred at this stage is possibly more likely to be due to the extent to which the stimuli resembled the self.

\section{Possibility 2: The picture of the "Self" doesn't match the way they see themselves.}

When creating the stimuli photographs for the current study we used frontal images of the participant, which were then flipped on the horizontal axis (to resemble the self as seen in a mirror) and were morphed at $40 \%$ with a database photograph. Morphing with another face was required in order for the participant not to overtly recognise themselves in the stimuli face. As previously mentioned a morphing percentage of $40 \%$ was chosen due to the results of pilot testing in which faces morphed at $50 \%$ were recognised at a reasonably high rate, and previous research in which a facial morph of $40 \%$ self was used without participant recognition (and with significant effects of inclusion of self on subsequent judgements; DeBruine, 2002).

The high degree of familiarity that people have with their own face (it is assumed) may mean one of two things regarding the stimuli in the current research: 1) a lower morph percentage (such as $40 \%$ ) can be used whilst still activating the self-representation (because we are so familiar with our own face that we recognise it at lower percentages), or 2) Our memory for our own face is so accurate (because we know it so well) that the stimuli face needs to be more like the self-face for the self-representation to be activated. In support of using a lower morphing percentage, face perception research has demonstrated that recognition for faces that we are personally familiar with should be much more resistant to disruption of the facial characteristics (e.g. through lighting, expression, angle, and/or 
rotation; see Carbon, 2008; Herzmann, Schweinberger, Sommer, \& Jentzsch, 2004). This is because we have more experience in viewing these faces in a variety of contexts and conditions.

Whilst the research cited above suggests that a lower morphing percentage can be used whilst still activating self-concept, it can't be inferred that there is no baseline level of self-face inclusion below which self-concept is not activated. Perhaps dropping the morph percentage to $40 \%$ in the current research dropped the inclusion of self-face beyond the point that self-representation is likely to be triggered. It is possible when dealing with facial stimuli (a stimuli type that we as humans are arguably particularly sensitive to) that dropping the morph percentage by only a few percent (say to $48 \%$ or $46 \%$ ) would have been sufficient to reduce overt recognition whilst still achieving activation of self-mental representation.

However, even if the morph percentage used in the current study was too low to trigger the self-representation, it should still have been high enough to trigger other reported effects using self-similar stimuli morphed at that same percentage. For example, in her 2002 study involving trait judgements DeBruine used a morph percentage of $40 \%$ self, and $60 \%$ unknown other to create stimuli avatars (ostensibly of real people) that participants interacted with in a social game. Participants demonstrated markedly greater trust of self-morphed faces over other stimuli faces (not morphed with their own face). However, the current research found little to no effect of self-similarity on ratings of trustworthiness across all four studies (despite having the same percentage of self-face included in the stimuli faces).

It may also be argued that the standardisation method used for facial stimuli in the current research affected the results of the studies. For studies 2 through to 4 only the inner features of the face were integrated into the stimuli materials. Other studies that have found an effect of self-face similarity on first impression judgements (such as DeBruine 2002), used full-face morphs as stimuli materials (including face-shape information). Some research 
suggests that the outer features of the face (e.g. face shape, hair style) are more heavily relied upon than the inner features of the face (e.g. eyes, nose, mouth) for accurate facial recognition (Nachson, \& Shechory, 2002; Bruce et al., 1999). This would suggest that masking the outer facial features of the stimuli in the current research may have resulted in the removal of important self-face-information necessary for triggering self-similar transference.

However, greater reliance upon outer-facial features for recognition only tends to apply to unfamiliar faces (or not at all); whereas recognition for highly familiar faces (such as the self-face) relies more heavily upon information from the inner facial features (Ellis, Shepherd, \& Davies, 1979; Clutterbuck \& Johnston, 2005; Campbell, 1999; Henderson, Williams, \& Falk, 2005). Furthermore, Study 1 of the current research included stimuli with both inner and outer facial features, yet near-to no effect was found of self-face similarity. Taken together, this evidence would suggest that the stimuli used in the current research included sufficient information to trigger self-concept transference (were such an effect possible); and that failure to produce this effect is likely due to a factor other than focus upon internal facial features.

\subsubsection{Stage 2: A mental representation of the significant other becomes activated} in response to the self-similar stimulus. In order to assert that the second stage of selfsimilar transference is likely to occur the mental representation of the self must be shown to meet the necessary requirements for activation (as similar to significant-other mental representation activation). As discussed in the introduction the criteria required for selfconcept activation (chronic accessibility and transient accessibility; see Anderson et al., 1995) are likely to be have been fulfilled in the current research.

Possibility 1: The self-concept is not chronically accessible. The assertion that selfconcept qualifies as a chronically accessible mental representation is difficult to find fault 
with. Chronic accessibility specifically refers to the frequency with which a social construct is used (Anderson et al., 1995). As explained by Anderson et al (1995) the activation of a construct (such as one's mental representation of a significant other) has a cumulative effect upon the accessibility of that construct in future. That is, the more frequently a construct is activated, the more ready it is to be activated in future in response to relevant stimuli.

Previous research as far back as the 1970's has demonstrated that the self-concept is a construct to which chronic accessibility can be applied. For example, it was found by Davis and Brock (1975) that, when presented with a live image of themselves on a screen (or seated in front of a mirror), participants demonstrated greater attention to self in a subsequent exercise (greater use of first-person pronouns in a word task). Furthermore, transference theory itself (Anderson et al., 2002) proposes the activation of relational selves during transference of significant other representations. In other words, when you are making a judgement of someone that looks like your significant other, the knowledge of yourself that is linked to that particular significant other (i.e. who you are when you are around that person) becomes activated. If our self-concept (or at least one of our relational selves) is activated when we are presented with significant other similar stimuli, it seems very likely that one of our "selves" ought to be activated when presented with self-similar stimuli. However, the notion of multiple selves does pose a problem at the third stage of transference, as will be described below.

\subsubsection{Stage 3: The subsequent judgement of the target stimulus incorporates the} contents and/ or valence of the significant other representation. As mentioned in the introduction, for the final stage of transference to occur the valence and/ or contents of the mental representation (in the case of our research the "self") must be integrated into target judgements of the stimuli (in the case of our research, self-similar stimuli). So, assuming that 
participant self-concept was activated during the current research (i.e. Stage 2 of transference was achieved), why might we have found no evidence of self-similar transference?

Possibility 1 Chronic Activation of the Self-Concept. One argument for the lack of difference between judgements of self -similar and other-similar targets is the chronic accessibility of the self. That is, perhaps the self is so chronically accessible that it is always activated -whether or not a self-similar target is present- causing us to constantly transfer personal self-concept information onto any novel target encountered. If this were the case, self-concept consistent information would simply act as an idiosyncratic baseline that is pushed around depending on the activation of additional mental representations. If the self is always activated then we may not find differences in judgements of self-similar stimuli versus other similar stimuli due to a ceiling effect. That is, because the self-concept is always activated, you are already getting transference of self-concept for everyone you make judgements of (i.e. some kind of a self-baseline), or if you do happen to get a slight increase in activation of the self-concept for self-similar stimuli it may not be enough to make a significant (or measurable) difference to target judgements.

The notion that the self-concept is used as a baseline from which to rate unknown others is consistent with the assimilation hypothesis of social perception, in which our perceptions of others are coloured by our self-knowledge (Green, \& Sedikides, 2001). It is also consistent with the theory of social projection, a judgemental heuristic that is thought to be central to social cognition and involves the expectation that others will be similar to the self (Krueger, 2007). Both of these theories involve filtering judgement of others through the lens of our own self-concept; a feat that would not be possible without some activation of self-concept (even if outside of conscious awareness). 
Possibility 2: Differential activation of Multiple Selves. An alternate explanation for the current findings involves the notion of multiple selves. As mentioned during the "Stage 2" discussion (above) Anderson et al (2002) suggest that different relational selves become activated in response to relevant significant other similar stimuli. This idea of multiple selves has been examined more recently in research on the composition of self-concept. In development of his Multiple Self-Aspects Framework McConnell (2011) suggests that multiple selves (termed self-aspects in his research) make up each individual's self-concept and differ in content and activation by that person's experiences. Importantly, self-aspects are idiosyncratic in nature, reflecting the most meaningful aspects of each individual's life. It is entirely possible for one individual to not share a single self-aspect with another individual. However, whilst differing in nature these self-aspects fall under four broad categories: goals (such as approach and avoidance; see Higgins, 1997) private versus public selves (e.g. "I am honest" versus "people think I am honest"; see Triandis, 1989), roles (e.g. son, teacher), and relational and collective identities (e.g. My family thinks I'm funny, or “My prayer group thinks I'm introverted"; see Triandis,1989). Each self-aspect is associated with multiple personal attributes (e.g. "honest" or "aggressive") that are activated as the self-aspect they fall under is activated (and vice versa).

An important feature of the Multiple Self-Aspects Framework (McConnell, 2011) is that each self-aspect does not exist and function as separate from the other self-aspects. Rather, activation of one self-aspect may determine the activation of another, and so forth. McConnell explains the structure of self-concept as a distributed series of interconnected nodes. This associated network allows spreading activation from one aspect to another via their relationship in the network. For example, let's say a person has an "academic" self aspect and a "parent" self-aspect and under each self-aspect is contained the trait "hardworking". If the "academic" self-aspect is activated it will cause the trait "hard-working" to 
become activated, which (through spreading activation) will lead to activation of the "parent" self-aspect. Similarly, if the trait "hard-working" is activated, both the "academic" and "hard working" self-aspects will become activated. This spreading activation system of self-concept function can thus result in a vast array of possible patterns of self-concept activation.

The notion of multiple selves that function in this way poses a methodological problem for the current thesis: if we have the capacity for multiple self-aspects to become active (or remain inactive) dependent upon environmental triggers, how do we know that the "self" that was active during personality testing (Session 1) is the same "self" that was active during the stimuli judgements (Session 2)? For example, perhaps completion of a self-report scale in Session 1 of the current research (by asking participants to rate themselves on statements like "I am honest") activated the "private" self, whilst making judgements of facial stimuli in Session 2 activated the "goals" self (i.e. involved approach and avoid selftendencies). If the personal attributes associated with each participant's "private" and "goal" self-aspects are different, then we would have no frame of reference for determining whether transference of personality traits has occurred in Session 2 of the study. Given the complexity of the way in which self-concepts are composed and function under the Multiple Self-Aspects Framework, future research would ned to include a complex assessment of participant selfconcept, and an equally complex examination of stimuli judgements.

Possibility 3: Self-Other Distinction in Transference. As mentioned in the introduction, Anderson et al., (1998) found that the more significant a target is to the self, the more similar the mental representation of that target will be to the mental representation of the self (in terms of accessibility, availability, and emphasis upon private vs. public featural aspects). Indeed, it has been argued that close relationships are by their very nature defined by a blurring of the lines between "self" and "other" (Aron, Aron, \& Smollan, 1992). In the introduction it was argued that these findings suggest that self-similarity would be as-likely if 
not more likely to trigger transference than similarity to a significant other. However, the results of this study (i.e. little-to-no self-similar transference) suggests that this is not, necessarily, the case. How then can we reconcile Anderson et al's theory of transference with the results of the current research?

One argument may be that self-concept is not sufficiently similar to significant other mental representations to qualify as candidate for transference. However, whilst there are most definitely some important differences between the two, these differences largely work in favour of the prediction (for self-similar transference) made in the current thesis. For example, Anderson and Cole (2002) argue that significant others are significant because of the self-regulatory function that they serve. It is the degree to which these individuals impact the self's emotions and motivations that qualifies them to be a significant other (and therefore more likely to be triggered in transference). Based on this reasoning we would expect the self-concept, which serves a greater self-regulatory function (in terms of its impact on emotional and motivational impact on the self) than a significant other representation, to be more likely than a significant other representation to be triggered in transference.

Furthermore (as previously mentioned) extensive research in the area of social psychology suggests that people expect others to be, think, and act, in a similar way to themselves (Krueger, 2007). This phenomenon (referred to as projection) appears to operate outside of conscious awareness, and (importantly) is thought to be the default lens through which people navigate the social world (Krueger, 2007). Arguably, this suggests that application of self-knowledge to a novel self-similar target is more fundamental to human nature than application of other-knowledge (even significant-other knowledge) to a novel other-similar target. It then follows that (in so far as projection can be compared to selfsimilar transference) self-similar transference is more primed to occur (by default) than significant-other-similar transference. 


\subsection{Lack of Transference of Valence of Self-Concept (Self-Esteem).}

The other feature of transference that we were looking for in the current research is transference of self-concept-valence (rather than contents per se). We expected to find that the valence of judgements for self-similar stimuli were related to participant levels of selfesteem (as an indication of self-concept valence). Indeed, previous research suggested that this would be the case (see Tao, Zhang, Li, \& Geng, 2012). However, self-esteem (as measured by the RSE, IAT, and Me/Not-me trait ascription) in the current research did not seem to relate to levels of self-similar-selection. Two potential explanations for these results are that: (1) self-esteem as measured in session 1 does not relate to self-concept as activated in session 2, and/or (2) transference did not occur in the current research.

Possibility 1: At first glance the claim that self-esteem as measured in session one does not relate to the self-concept activated in session two seems counter-intuitive. Indeed, self-esteem is defined as the attitude that we hold with regards to our self-concept or selfknowledge (Baumeister, 2003) and therefore theoretically not separable from the selfconcept. As noted in the introduction, the RSE is a measure of global self-esteem and has been shown to be very stable over time and across various situations. Given the high level of stability of global self-esteem, a major fluctuation between sessions 1 and 2 seems relatively unlikely. However, the previously discussed research on multiple self-aspects may shed some light on the current (lack of) findings.

Supposing that individuals have multiple selves that may or may not be active at any one point in time (McConnell, 2011), and taking into account the fact that that self-esteem serves as an intrinsic feature of self-concept (Baumeister, 2003), it is possible that we possess multiple "self-esteems" that shift into activation alongside the related self-concept. The notion of multiple self-esteems is consistent with research suggesting that self-esteem is 
multi-faceted and can be broken down into distinct context-dependent categories such as peer relationships, academic achievement, and physical appearance (Shavelson, Hubner, and Stanton 1976; Marsh, \& O'Mara, 2008).

Indeed, one of the underlying principles of the self (as considered in the Multiple Self Aspects Framework; McConnell, 2011) pertains to self-evaluation in the sense that one's affect at any one time is determined by the overall evaluation across multiple self-concepts. Importantly, the evaluation of each multiple self will contribute to the total self-evaluation dependent upon level of activation. For example, consider a scenario where a person's academic-self is activated a lot, their romantic self is activated a small amount, and their piano-player self is hardly activated at all. Based on the theory behind the Multiple SelfAspects Framework we would expect the evaluation of one's academic self to be weighted most heavily in the person's total self-evaluation, followed by the romantic self, with the piano player self-evaluation contributing least.

This means that we cannot be sure that the same facets of self-esteem that were active during session one were also active during session two (i.e. the same issue that was encountered with the possibility of multiple self-concepts). Importantly, none of the measures of self-esteem that we used are designed to specifically assess multi-faceted self-esteem. As noted above, the RSE serves as a global measure of self-esteem and may not be sensitive to changes in specific aspects of self-concept activation. Although the IAT might be a better measure of situationally-dependent self-esteem, the fact that it was not measured in the same session as the self-selection task could be problematic. Specifically, changes that occur between sessions could mean that the relationship between self-esteem as measured by the IAT and self-selection may be too noisy to see an effect. 
Possibility 2: Assuming that self-esteem measurement was not an issue in the current study leaves us with the possibility that the lack of relationship between self-similar selection and self-esteem is due to lack of transference. The current study also used the AMP (in Studies one and two) to implicitly assess participant's attitudes (positive or negative valence) towards self-morphed versus other-morphed stimuli. The results showed negligible effects of both the IAT and the AMP, suggesting that implicit attitudes towards novel targets that resemble the self do not significantly differ from implicit attitudes towards targets that are not self-similar. That is, in the context of the current research, the implicit attitudinal component of self-concept is not being transferred to the self-similar target.

An alternative explanation for this finding is that nature of implicit self-esteem as constantly in flux, reflecting self-attitudes that are very sensitive to anything that influences the psychology of the individual (see Bosson, Swann, \& Pennebaker, 2000). This would make it difficult to be sure that any implicit attitude that was measured during session one. Another alternative explanation for this finding (related specifically to the AMP) is that the AMP is not a viable measure of implicit attitudes. Teige-Mocigemba, Becker, Sherman, Reichardt, and Klauer (2017) assessed implicit attitudes towards Turks (as a minority group in Germany) using the AMP. As noted by Teige-Mocigemba et al, a range of previous research conducted in the same country had already examined implicit attitudes towards the Turks (using measures other than the AMP). When compared with the results of this previous research the effect size of the AMP results found by Teige-Mocigemba et al (2017) were much smaller, only reaching a Cohen's d of 0.17. These authors suggest that the AMP may be only weakly sensitive to some implicit attitudes (such as prejudice towards minority group members), perhaps due to participant's reluctance to intentionally rate the primes. Whilst the current research does involve making judgements of others it is not socially sensitive in the same way that prejudice against minorities is. Coupled with the similar results of the IAT 
(showing no relationship with self-similar selection) it is more likely that the negligible AMP effects in the current study were due to lack of self-similar transference.

\section{Summary}

Examination of the current research findings in relation to the three stages of transference theory suggests that (in the current research):

- It is unlikely that the self-concept operates in a qualitatively different way than that of a close other. That is, the significance and importance of the self to the individual, if anything, is likely to be greater than that of another individual. Similarly, the activation of the self should be just as likely as the activation of a close other with the appropriate similarity present in the novel stimulus.

- The activation of the self-concept may not have occurred due to too low an inclusion percentage of the self-face in the stimulus materials. This, however, also seems unlikely given the prevalence of findings using the same level of self-inclusion.

- Most likely, in our view, is that the activation of the self did not influence the judgments of the novel stimuli in any predictable pattern. We have discussed several possibilities as to why this may be the case (e.g., ceiling effects due to chronic activation of self-concept, activation of different self-aspects across sessions).

\subsection{Improving Upon the Current Research}

Potential weaknesses in the current research (as identified in the preceding summary) could be rectified as follows.

Stimulus materials. As noted above, the most likely issue with the stimulus materials used in the current research was the low percentage of "self" included in the morphed faces. Future research could determine the threshold at which conscious recognition of the self-face 
occurs, then include a percentage of self-face that only just undercuts that threshold. This would maximise the potential to trigger self-similar transference whilst minimising the likelihood of conscious self-recognition. In a series of studies (not included in this thesis) we created morph videos of either a stranger morphing into the participant or the participant morphing into a stranger. Participants were asked to stop the video when the image on screen "is clearly your face" versus "is clearly no longer your face," respectively. Across two studies, when moving either from stranger to self, or self to stranger participants stopped the video when the self was included at about $65 \%$. This, of course, involved participants actively looking for themselves in the image and deciding when the image was "clearly/(no longer)" the self. That said, this is probably a reasonable estimate of the very upper limit.

Utilising previous research as a methodological template may also prove useful in examining the possibility of methodological versus theoretical error in the current research. For example, Debruine (2002) found that self-similar stimuli are judged to be significantly more trustworthy than other-similar stimuli in a trust game, using only 20 participants. Our study used four times the number of participants yet found no effect of target self-similarity on judgements of trustworthiness. One interpretation of this mis-match is that the stimuli in the current research was improperly prepared. A close replication of DeBruine's methodology using both stimuli prepared using the same standardisation process as DeBruine (2002) as well as stimuli prepared using the standardisation process from the current research would provide insight into the viability of the stimuli themselves, as well as having implications for the effect of self-similarity on target judgements in general (including the theory of transference and kin recognition).

Measurement of self-similar transference. In the current studies, we specifically selected the forced-choice procedure because it had been used in previous work by DeBruine $(2002,2005)$ and produced reliably large effect sizes. It is possible that this decision was 
problematic. For example, in an earlier pilot study, participants rated self- and other-morphed individuals on the traits used by Günaydin and colleagues (2012). In that study, we found an overall greater positivity across the ratings of self-morphed faces compared to other-morphed faces $(\mathrm{t}(43)=2.276, \mathrm{p}=.028)^{3}$. Future research should involve different types of measures to examine the conditions under which self-transference does or does not occur (assuming, of course, that it happens at all). That is, it may not emerge in tasks that require comparison between individuals (but see DeBruine), or may show a stronger effect for judgments that require less deliberation (e.g., Gunyadin et al. 2012; "Is this person ? Yes/no" task).

\section{Other considerations.}

Ceiling effects of Self-Concept Activation. As mentioned in the previous section, one of the possible issues with the third stage of transference is a ceiling effect of self-concept activation. Assuming that self-concept is unitary and maximally activated at all times it would be expected that no significant difference would be found between ratings of selfsimilar and other similar stimuli (as was found in the current study). Teasing apart this issue would involve determining that self-concept is maximally activated thus affecting self-similar and other-similar target judgements equally. To do this would involve (ethical!) manipulation of participant self-concept to examine whether target evaluations shifted accordingly. For example, false feedback on a task has been shown to have significant effects on how one views the self, at least temporarily, and can influence subsequent judgments and actions. The way in which target judgements shift in response to a self-concept manipulation would give valuable insight into the viability of self-similar transference as conceptualised in the current research. 
For example:

- If neither self-similar nor other-similar judgements move in accordance with selfconcept manipulation: the failure to find transference in the current study is not related to ceiling effects of self-concept activation.

- If both self-similar and other-similar target judgements move in accordance with selfconcept manipulations: self-concept is driving all target evaluations

- If self-similar target judgements move in accordance with shift in self-concept but other-similar judgements do not: Transference effects become constrained to selfsimilar targets directly following an alteration in self-concept

- If other-similar judgements move but self-similar judgements do not: Evidence against self-similar transference (as conceptualised in the current thesis).

Activation of Multiple Self-Concepts. If the self-concept consists of multiple selves then future research needs to ascertain that the same self-concept is activated during completion of the self-report measure, and completion of target judgements. One simple way to try this would be to get participants to complete the self-report measure and target judgements in the same session. A difficulty here would be the nature of multiple-self activation. If it different selves are activated quickly and easily (rather than being relatively stable and slow to activate) then differential activation could possibly occur as related to the type of task the participants are undertaking at any one time (e.g. self-reflective or other reflective). In an effort to offset this possibility self-awareness could be manipulated (e.g. through use of a mirror) with an aim to keeping the participant's self-reflective self-concept activated during target evaluations. 
Another way of improving upon the current research is to further tease apart the possibility of either methodological error or problems with the underlying theory. One way to do this would be to conduct a couple-study, run in a very similar way to the current research but involving trait judgements of self-similar targets, significant other-similar targets, and other-similar targets. The pattern of trait judgements by target type would provide valuable information as to whether self-similar transference is possible or not. For example:

- If transference was found for the significant-other stimuli but self-similar and othersimilar stimuli judgements remained at chance it would suggest that the methodology for the current research was relatively sound, but that the theory is unviable.

- If judgements of all target stimuli remained at chance then it would suggest that there is a problem with the current methodology (or a greater problem with theory of transference i.e. no replication found for significant-other-similar transference).

\section{Conclusion.}

In conclusion, the first impressions that we form of others are not always accurate and are subject to a number of biases. Transference is one such bias which occurs when the mental representation of a 'significant other' becomes activated in memory, causing evaluations of a novel target to be assimilated to that representation. The current research proposed that the self-concept as activated by self-similar stimuli can act in a similar fashion. Specifically, it was proposed that activation of the self-concept may trigger transference of self-conceptrelated evaluations and attitudes to the novel other. This prediction was tested by comparing participant judgements of own self-concept and self-esteem with trait-related judgements about novel targets, half of which were modified to resemble the perceiver. Specifically, it was hypothesised that transference of self-concept to judgements of self-similar stimuli would occur, operationalised as: 
1) Self-selection of self-similar images (over other similar images), and

2) A positive relationship between self-esteem and self-selection.

The results of four studies largely disconfirmed these hypotheses in that: a) Self-selection was not found to significantly differ from chance in the vast majority of analyses, and; b) Self-selection was not found to be significantly correlated with self-esteem in the vast majority of cases (at least not in any consistent pattern).

The notion that self-similar transference is not possible is a surprising one given the similarity of the self-concept to significant other mental representations. As with significant other representations, self-concept: is highly motivating to the self, is a construct in which we are highly emotionally invested, and is chronically accessible. Furthermore, although interpreted from a kin-recognition perspective, previous research has already found selfsimilar faces to be judged more positively than other-similar faces (DeBruine, 2002, 2005).

Several possible explanations were put forward for the null results of the current research. Largely these related to the nature of self-concept and self-esteem i.e. that self-concept and self-esteem may exists as multiple facets that were differentially activated across sessions. This would mean that: a) transference may still have occurred but was not captured using the current methodology, or that b) transference did not occur in the current research. Which of these two options occurred in the current research is not determinable without future research to a) address the possible methodological issues (to be more sure that null results can be related to the underlying theory), and b) examine transference using multiple measures of self-esteem and self-concept. Overall, the current research found no convincing evidence for self-similar transference. 


\section{References}

Abrosoft, 2005. FantaMorph 5 [Computer Software]. Retrieved from: www.fantamorph.com

Adobe Photoshop CC. ADOBE, Adobe Systems Incorporated, 2011, Retrieved from: www.adobe.com/products/photoshop/photoshop/.

Ahs, F., Davis, C. F., Gorka, A. X., \& Hariri, A. R. (2014). Feature-based representations of emotional facial expressions in the human amygdala. Social Cognitive and Affective Neuroscience, 9(9), 1372-1378. Retrieved from http://search.proquest.com.helicon.vuw.ac.nz/docview/1647034324?accountid=14782

Ambady, N., \& Skowronski, J. J. (2008). First impressions. New York: Guilford Press.

Anders, S., Lotze, M., Erb, M., Grodd, \& W., Birbaumer, N. (2004) Brain activity underlying emotional valence and arousal: a response-related fMRI study, Hum. Brain Mapp., Vol. 23, 2004, 200-209

Andersen, S. M., \& Baum, A. (1994). Transference in interpersonal relations: Inferences and affect based on significant-other representations. Journal of Personality, 62(4), 459497. Retrieved from http://search.proquest.com/docview/618635810?accountid=14782

Andersen, S. M., \& Berk, M. S. (1998). The social-cognitive model of transference: Experiencing past relationships in the present. Current Directions in Psychological Science, 7(4), 109-115. Retrieved from http://search.proquest.com/docview/619428959?accountid=14782

Andersen, S. M., \& Chen, S. (2002). The relational self: An interpersonal social-cognitive theory. Psychological Review, 109(4), 619-645. doi:http://dx.doi.org/10.1037/0033295X.109.4.619

Andersen, S. M., \& Cole, S. W. (1990). "Do I know you?” The role of significant others in general social perception. Journal of Personality and Social Psychology, 59(3), 384399. doi:http://dx.doi.org/10.1037/0022-3514.59.3.384

Andersen, S., Glassman, N., Chen, \& S., Cole. (1995). Transference in Social Perception: The Role of Chronic Accessibility in Significant-Other Representations. Journal of Personality and Social Psychology, 69(1), 41-57.

Andersen, S., Glassman, N., Gold, D., \& Kruglanski, Arie W. (1998). Mental Representations of the Self, Significant Others, and Nonsignificant Others: Structure and Processing of Private and Public Aspects. Journal of Personality and Social Psychology, 75(4), 845861.

Anzellotti, S., \& Caramazza, A. (2014). The neural mechanisms for the recognition of face identity in humans. Frontiers in Psychology, 5, 6. Retrieved from https://searchproquest-com.helicon.vuw.ac.nz/docview/1640006357?accountid=14782

Aron, Arthur, Aron, Elaine N., Tudor, Michael, Nelson, Greg, \& Miller, Norman. (1991). Close Relationships as Including Other in the Self. Journal of Personality and Social Psychology, 60(2), 241-253. 
Aron, Arthur, Aron, Elaine N., Smollan, Danny, \& Miller, Norman. (1992). Inclusion of Other in the Self Scale and the Structure of Interpersonal Closeness. Journal of Personality and Social Psychology, 63(4), 596-612.

Axelrod, V., \& Yovel, G. (2015). Successful decoding of famous faces in the fusiform face area. PLoS ONE, 10(2), 20. Retrieved from http://search.proquest.com.helicon.vuw.ac.nz/docview/1729372445?accountid=14782

Baars, B. J., Gage, N. M. (2010). Cognition, Brain, and Consciousness (Second Edition): Introduction to Cognitive Neuroscience. doi: http://dx.doi.org/10.1016/B978-0-12375070-9.00006-1

Ballew, Charles C. II, \& Todorov, A. (2007). Predicting political elections from rapid and unreflective face judgments. Proceedings of the National Academy of Sciences of the United States of America, 104(46), 17948. Retrieved from https://search-proquestcom.helicon.vuw.ac.nz/docview/201306829?accountid=14782

Bar, M., Neta, M., \& Linz, H. (2006). Very first impressions. Emotion, 6(2), 269-278. Retrieved from http://search.proquest.com.helicon.vuw.ac.nz/docview/621350657?accountid=14782

Barelds-Dijkstra, P., \& Barelds, D. P. H. (2008). Positive illusions about one's partner's physical attractiveness. Body Image,5(1), 99-108. doi:http://dx.doi.org/10.1016/j.bodyim.2007.07.004

Baudouin, J., \& Brochard, R. (2011). Gender-based prototype formation in face recognition. Journal of Experimental Psychology: Learning, Memory, and Cognition, 37(4), 888-898.

doi:http://dx.doi.org.helicon.vuw.ac.nz/10.1037/a0022963de

Baudson, T. G., Weber, K. E., \& Freund, P. A. (2016). More than only skin deep: Appearance self-concept predicts most of secondary school students' selfesteem. Frontiers in Psychology, 7, 14. Retrieved from https://search-proquestcom.helicon.vuw.ac.nz/docview/1845628221 ?accountid=14782

Baumeister, R. (2003). Does high self-esteem cause better performance, interpersonal success, happiness, or healthier lifestyles? Psychological Science in the Public Interest., 4(1), 1.

Baumeister 1998, Baumeister, R. F. (1998). The self. In D. T. Gilbert, S. T. Fiske, \& G. Lindzey (Eds.), Handbook of social psychology (4th ed., pp. 680- 740). New York: McGraw-Hill. Retrieved from: https://psy.fsu.edu/ baumeisterticelab/Baumeister\%20(1998)\%20The\%20Self\%20ch p15.pdf

Becker, D. V., Kenrick, D. T., Neuberg, S. L., Blackwell, K. C., \& Smith, D. M. (2007). The confounded nature of angry men and happy women. Journal of Personality and Social Psychology, 92(2), 179-190. doi:http://dx.doi.org.helicon.vuw.ac.nz/10.1037/00223514.92.2.179

Beer, J. S. (2012). This time with motivation: The implications of social neuroscience for research on motivated self- and other-perception (and vice versa). Motivation and Emotion, 36(1), 38-45. doi:http://dx.doi.org.helicon.vuw.ac.nz/10.1007/s11031-0119259-0 
Beer, J. S., \& Hughes, B. L. (2010). Neural systems of social comparison and the "aboveaverage" effect. NeuroImage, 49(3), 2671-2679. Retrieved from https://searchproquest-com.helicon.vuw.ac.nz/docview/621984021?accountid=14782

Behrmann, M., Scherf, K. S., \& Avidan, G. (2016). Neural mechanisms of face perception, their emergence over development, and their breakdown. WIREs Cognitive Science, 7(4), 247-263. Retrieved from http://search.proquest.com.helicon.vuw.ac.nz/docview/1803817992?accountid=1478

Birkás, B., Dzhelyova, M., Lábadi, B., Bereczkei, T., \& Perrett, D. I. (2014). Cross-cultural perception of trustworthiness: The effect of ethnicity features on evaluation of faces' observed trustworthiness across four samples. Personality and Individual Differences, 69, 56-61. Retrieved from http://search.proquest.com.helicon.vuw.ac.nz/docview/1699504800?accountid=14782

Bosson, J. K., Swann, W. B., Jr., \& Pennebaker, J. W. (2000). Stalking the perfect measure of implicit self-esteem: The blind men and the elephant revisited: Journal of Personality and Social Psychology, 79(4), 631-643. doi:http://dx.doi.org.helicon.vuw.ac.nz/10.1037/0022-3514.79.4.631

Brédart, S. (2003). Recognising the usual orientation of one's own face: The role of asymmetrically located details. Perception, 32(7), 805-811. doi:http://dx.doi.org.helicon.vuw.ac.nz/10.1068/p3354

Brown, J. D., Dutton, K. A., \& Cook, K. E. (2001). From the top down: Self-esteem and selfevaluation. Cognition and Emotion, 15(5), 615-631. doi:http://dx.doi.org.helicon.vuw.ac.nz/10.1080/02699930143000004

Bruce, V., Henderson, Z., Greenwood, K., Hancock, P. J. B., Burton, A. M., \& Miller, P. (1999). Verification of face identities from images captured on video. Journal of Experimental Psychology: Applied, 5(4), 339-360. doi:http://dx.doi.org.helicon.vuw.ac.nz/10.1037/1076-898X.5.4.339

Bruyer, R., Laterre, C., Seron, X., Feyereisen, P., Strypstein, E., Pierrard, E., \& Rectem, D. (1983). A case of prosopagnosia with some preserved covert remembrance of familiar faces. Brain and Cognition, 2(3), 257-284. doi:http://dx.doi.org/10.1016/02782626(83)90014-3

Calder, A. J., \& Young, A. W. (2005). Understanding the recognition of facial identity and facial expression. Nature Reviews. Neuroscience, 6(8), 641-51. doi:http://dx.doi.org/10.1038/nrn1724

Campbell, R. (1999). When does the Inner-face Advantage in Familiar Face Recognition Arise and Why? Visual Cognition, 6(2), 197-215.

Cantor, N., \& Mischel, W. (1977). Traits as prototypes: Effects on recognition memory. Journal of Personality and Social Psychology, 35(1), 38-48. doi:http://dx.doi.org/10.1037/0022-3514.35.1.38

Carbon, C.C. (2008). Famous faces as icons. The illusion of being an expert in the recognition of famous faces. Perception 37, 801-806.

Carney, D. R., Colvin, C. R., \& Hall, J. A. (2007). A thin slice perspective on the accuracy of first impressions. Journal of Research in Personality, 41(5), 1054-1072. doi:http://dx.doi.org/10.1016/j.jrp.2007.01.004 
Carré, J. M., McCormick, C. M., \& Mondloch, C. J. (2009). Facial structure is a reliable cue of aggressive behaviour. Psychological Science, 20(10), 1194-1198. doi:http://dx.doi.org/10.1111/j.1467-9280.2009.02423.x

Cassidy, B. S., Zebrowitz, L. A., \& Gutchess, A. H. (2012). Appearance-based inferences bias source memory. Memory \& Cognition, 40(8), 1214-1224. doi:http://dx.doi.org/10.3758/s13421-012-0233-1

Chen, J., Yuan, J., Feng, T., Chen, A., Gu, B., \& Li, H. (2011). Temporal features of the degree effect in self-relevance: Neural correlates. Biological Psychology, 87(2), 290295. http://dx.doi.org.helicon.vuw.ac.nz/10.1016/j.biopsycho.2011.03.012

Chen, Y., Dammers, J., Boers, F., Leiberg, S., Edgar, J. C., Roberts, T. P. L., \& Mathiak, K. (2009). The temporal dynamics of insula activity to disgust and happy facial expressions: A magnetoencephalography study. NeuroImage, 47(4), 1921-1928. Retrieved from http://search.proquest.com.helicon.vuw.ac.nz/docview/621984183?accountid=14782

Clutterbuck, R., \& Johnston, R. (2005). Demonstrating how unfamiliar faces become familiar using a face matching task. European Journal of Cognitive Psychology, 17(1), 97-116.

Collins, J. A., \& Olson, I. R. (2014). Beyond the FFA: The role of the ventral anterior temporal lobes in face processing. Neuropsychologia, 61, 65-79. Retrieved from https://search-proquestcom.helicon.vuw.ac.nz/docview/1696221894?accountid=14782

Comfort, W. E., \& Zana, Y. (2015). Face detection and individuation: Interactive and complementary stages of face processing. Psychology \& Neuroscience, 8(4), 442-466. Retrieved from http://search.proquest.com.helicon.vuw.ac.nz/docview/1710253530?accountid=14782

Costa PT, Jr., McCrae RR. (1992). Revised NEO Personality Inventory (NEO PI-R) and NEO Five-Factor Inventory (NEO-FFI) professional manual. Psychological Assessment Resources; Odessa, FL. Retrieved from: https://ipip.ori.org/newMultipleconstructs.htm

Cottrell, C. A., Neuberg, S. L., \& Li, N. P. (2007). What do people desire in others? A sociofunctional perspective on the importance of different valued characteristics. Journal of Personality and Social Psychology, 92(2), 208-231. doi:http://dx.doi.org/10.1037/0022-3514.92.2.208

Cunningham, M. R., Roberts, A. R., Barbee, A. P., Druen, P. B., \& Wu, C. (1995). "Their ideas of beauty are, on the whole, the same as ours": Consistency and variability in the cross-cultural perception of female physical attractiveness. Journal of Personality and Social Psychology, 68(2), 261-279. Retrieved from http://search.proquest.com.helicon.vuw.ac.nz/docview/618635872? accountid=14782

Darwin, C. (1872). Concluding remarks and summary. The expression of the emotions in man and animals; the expression of the emotions in man and animals (pp. 348-367, Chapter vi, 374 Pages) John Murray, London. doi:http://dx.doi.org.helicon.vuw.ac.nz/10.1037/10001-014

Davis, D., \& Brock, T. C. (1975). Use of First Person Pronouns as a Function of Increased Objective Self-Awareness and Performance Feedback. Journal of Experimental Social Psychology, 381-88. 
DeBruine, L. M. (2002). Facial resemblance enhances trust. Proceedings. Biological Sciences, 269(1498), 1307-1312. Retrieved from https://search-proquestcom.helicon.vuw.ac.nz/docview/71845085?accountid=14782

DeBruine LM (2005). Trustworthy but not lust-worthy: Context-specific effects of facial resemblance. Proceedings of the Royal Society of London B, 272: 919-922.doi: 10.1098/rspb.2004.3003

de la Mettrie, J. O. (1748) Man a Machine. Retrieved from: https://archive.org/details/manmachine00lame

de Ruiter, N. M. P. (2015). On the nature and origin of self-esteem: A complex dynamic systems perspective of nested self-esteem phenomena [Groningen]: University of Groningen

Devue, C., \& Brédart, S. (2011). The neural correlates of visual selfrecognition. Consciousness and Cognition: An International Journal, 20(1), 40-51. doi:http://dx.doi.org.helicon.vuw.ac.nz/10.1016/j.concog.2010.09.007

Di Giorgio, E., Leo, I., Pascalis, O., \& Simion, F. (2012). Is the face-perception system human-specific at birth? Developmental Psychology, 48(4), 1083-1090. doi:http://dx.doi.org.helicon.vuw.ac.nz/10.1037/a0026521

DiMatteo, C. (2017). Thinking about the self while talking to someone else: Investigating self-focus in conversation (Order No. 10634686). Available from ProQuest Dissertations \& Theses Global: Health \& Medicine; ProQuest Dissertations \& Theses Global: Social Sciences. (1986243585). Retrieved from https://search-proquestcom.helicon.vuw.ac.nz/docview/1986243585?accountid=14782

Dimberg, U., \& Öhman, A. (1996). Behold the wrath: Psychophysiological responses to facial stimuli. Motivation and Emotion, 20(2), 149-182. doi:http://dx.doi.org.helicon.vuw.ac.nz/10.1007/BF02253869

Dion, K., Berscheid, E., \& Walster, E. (1972). What is Beautiful is Good. Journal of Personality and Social Psychology 24(3), 285-290. Retrieved from: http://faculty.uncfsu.edu/tvancantfort/Syllabi/Gresearch/Readings/17Dion.pdf

Elliot, A. J. (2006). The hierarchical model of approach-avoidance motivation. Motivation and Emotion, 30(2), 111-116. doi:http://dx.doi.org.helicon.vuw.ac.nz/10.1007/s11031-006-9028-7

Ellis, H. D., Shephard, J. W.,, Davies, G. M. (1978). Identification of Familiar and Unfamiliar Faces from Internal and External Features: Some Implications for Theories of Face Recognition. Perception, 8, 431-439

Engell, A. D., Haxby, J. V., \& Todorov, A. (2007). Implicit trustworthiness decisions: Automatic coding of face properties in the human amygdala. Journal of Cognitive Neuroscience, 19(9), 1508-1519. http://dx.doi.org.helicon.vuw.ac.nz/10.1162/jocn.2007.19.9.1508

Erber, R., \& Fiske, S. T. (1984). Outcome dependency and attention to inconsistent information. Journal of Personality and Social Psychology, 47(4), 709-726. doi:http://dx.doi.org/10.1037/0022-3514.47.4.709 
Etcoff, N. L. (1984). Selective attention to facial identity and facial emotion. Neuropsychologia, 22(3), 281-295. doi:http://dx.doi.org/10.1016/00283932(84)90075-7

Fairhall, S. L., \& Ishai, A. (2007). Effective connectivity within the distributed cortical network for face perception. Cerebral Cortex, 17(10), 2400-2406. Retrieved from http://search.proquest.com.helicon.vuw.ac.nz/docview/621873110?accountid=14782

Farroni, T., Massaccesi, S., Menon, E., \& Johnson, M. H. (2007). Direct gaze modulates face recognition in young infants. Cognition, 102(3), 396-404. doi:http://dx.doi.org.helicon.vuw.ac.nz/10.1016/j.cognition.2006.01.007

Faul, F., Erdfelder, E., Buchner, A., \& Lang, A.-G. (2009). Statistical power analyses using G*Power 3.1: Tests for correlation and regression analyses. Behavior Research Methods, 41, 1149-1160.

Feingold, A. (1992). Good-looking people are not what we think. Psychological Bulletin, 111(2), 304-341. doi:http://dx.doi.org.helicon.vuw.ac.nz/10.1037/00332909.111.2.304

Fejfar, M., \& Hoyle, R. (2000). Effect of Private Self-Awareness on Negative Affect and Self-Referent Attribution: A Quantitative Review. Personality and Social Psychology Review, 4(2), 132-142.

Fiske, S. T. (1980). Attention and weight in person perception: The impact of negative and extreme behaviour. Journal of Personality and Social Psychology: Attitudes and Social Cognition, 38(6), 889-906.

Fiske, S. T., Cuddy, A. J. C., \& Glick, P. (2007). Universal dimensions of social cognition: Warmth and competence. Trends in Cognitive Sciences, 11(2), 77-83. doi:http://dx.doi.org.helicon.vuw.ac.nz/10.1016/j.tics.2006.11.005

Fletcher, G. J. O., Simpson, J. A., \& Thomas, G. (2000). The measurement of perceived relationship quality components: A confirmatory factor analytic approach. Personality and Social Psychology Bulletin, 26(3), 340-354. Retrieved from http://search.proquest.com/docview/619514285?accountid=14782

Fletcher, G. J. O., Simpson, J. A., Campbell, L., \& Overall, N. (2013). The Science of Intimate Relationships. Oxford: Wiley-Blackwell

Fockert, J., \& Wolfenstein, C. (2009). Rapid extraction of mean identity from sets of faces. The Quarterly Journal of Experimental Psychology, 62(9), 1716-1722. doi:http://dx.doi.org.helicon.vuw.ac.nz/10.1080/17470210902811249

Freeman, J. B., Schiller, D., Rule, N. O., \& Ambady, N. (2010). The neural origins of superficial and individuated judgments about ingroup and outgroup members. Human Brain Mapping, 31(1), 150-159. Retrieved from http://search.proquest.com.helicon.vuw.ac.nz/docview/622103359?accountid=14782

Froming, W. J., Walker, G. R., \& Lopyan, K. J. (1982). Public and private self-awareness: When personal attitudes conflict with societal expectations. Journal of Experimental Social Psychology, 18(5), 476-487. Retrieved from http://search.proquest.com/docview/616721918?accountid=14782 
Gainotti, G. (2007). Face familiarity feelings, the right temporal lobe and the possible underlying neural mechanisms. Brain Research Reviews, 56(1), 214-235. doi:http://dx.doi.org.helicon.vuw.ac.nz/10.1016/j.brainresrev.2007.07.009

Gawronski, B., Bodenhausen, G., \& Cooper, Harris. (2006). Associative and Propositional Processes in Evaluation: An Integrative Review of Implicit and Explicit Attitude Change. Psychological Bulletin, 132(5), 692-731.

Gentile, F., Ales, J., \& Rossion, B. (2017). Being BOLD: The neural dynamics of face perception. Human Brain Mapping, 38(1), 120-139. Retrieved from https://searchproquest-com.helicon.vuw.ac.nz/docview/1817567695? accountid=14782

Giang, T., Bell, R., \& Buchner, A. (2012). Does facial resemblance enhance cooperation? PLoS One, 7(10) doi:http://dx.doi.org/10.1371/journal.pone.0047809

Gosling, Rentfrow, \& Swann. (2003). A very brief measure of the Big-Five personality domains. Journal of Research in Personality,37(6), 504-528.

Green, J. D., \& Sedikides, C. (2001). When do self-schemas shape social perception?: The role of descriptive ambiguity. Motivation and Emotion, 25(1), 67-83. doi:http://dx.doi.org.helicon.vuw.ac.nz/10.1023/A:1010611922816

Greenberg, S. N., \& Goshen-Gottstein, Y. (2009). Not all faces are processed equally: Evidence for featural rather than holistic processing of one's own face in a faceimaging task. Journal of Experimental Psychology: Learning, Memory, and Cognition, 35(2), 499-508. doi:http://dx.doi.org/10.1037/a0014640

Greenwald, A. G., \& Banaji, M. R. (1995). Implicit social cognition: Attitudes, self-esteem, and stereotypes. Psychological Review, 102(1), 4-27. doi:http://dx.doi.org/10.1037/0033-295X.102.1.4

Greenwald, A. G., \& Farnham, S. D. (2000). Using the implicit association test to measure self-esteem and self-concept. Journal of Personality and Social Psychology, 79(6), 1022-1038. doi:http://dx.doi.org/10.1037/0022-3514.79.6.1022

Greenwald, A., McGhee, D., Schwartz, J., \& Kruglanski, Arie W. (1998). Measuring Individual Differences in Implicit Cognition: The Implicit Association Test. Journal of Personality and Social Psychology, 74(6), 1464-1480.

Greenwald, A. G., Smith, C. T., Sriram, N., Bar-Anan, Y., \& Nosek, B. A. (2009). Race Attitude Measures Predicted Vote in the 2008 U. S. Presidential Election. Analysis of Social Issues and Public Policy, 9, 241-253

Griffin, A. M., \& Langlois, J. H. (2006). Stereotype directionality and attractiveness stereotyping: Is beauty good or is ugly bad? Social Cognition, 24(2), 187-206. http://dx.doi.org.helicon.vuw.ac.nz/10.1521/soco.2006.24.2.187

Griffey, J. A. F., \& Little, A. C. (2014). Infant's visual preferences for facial traits associated with adult attractiveness judgements: Data from eye-tracking. Infant Behaviour \& Development, 37(3), 268-275. doi:http://dx.doi.org/10.1016/j.infbeh.2014.03.001

Grill-Spector, K., Knouf, N., \& Kanwisher, N. (2004). The fusiform area subserves pace perception, not generic within-category identification. Nature Neuroscience 7, $555-$ 562. doi: $10.1038 / \mathrm{nn} 1224$ 
Günaydin, G., Zayas, V., Selcuk, E., \& Hazan, C. (2012). I like you but I don't know why: Objective facial resemblance to significant others influences snap judgments. Journal of Experimental Social Psychology, 48(1), 350-353. doi:http://dx.doi.org/10.1016/j.jesp.2011.06.001

Hamilton, W. D. (1964). The genetical evolution of social behaviour. I. Journal of Theoretical Biology, 7(1), 1-16. Retrieved from https://search-proquestcom.helicon.vuw.ac.nz/docview/83461405?accountid=14782

Hansen, C. H., \& Hansen, R. D. (1988). Finding the face in the crowd: An anger superiority effect. Journal of personality and social psychology, 54(6), 917.

Harmon-Jones, E., \& Allen, J. J. B. (2001). The role of affect in the mere exposure effect: Evidence from psychophysiological and individual differences approaches. Personality and Social Psychology Bulletin, 27(7), 889-898. http://dx.doi.org.helicon.vuw.ac.nz/10.1177/0146167201277011

Haxby, J. V., Hoffman, E. A., \& Gobbini, M. I. (2000). The distributed human neural system for face perception. Trends in Cognitive Sciences, 4(6), 223-233. Retrieved from https://search-proquest-com.helicon.vuw.ac.nz/docview/621057763?accountid=14782

Haxby, J. V., Hoffman, E. A., \& Gobbini, M. I. (2002). Human neural systems for face recognition and social communication. Biological Psychiatry, 51(1), 59-67. Retrieved from http://search.proquest.com.helicon.vuw.ac.nz/docview/619713736?accountid=14782

Heatherton, T., \& Polivy, J. (1991). Development and Validation of a Scale for Measuring State Self-Esteem. Journal of Personality and Social Psychology, 60(6), 895.

Heatherton, T., \& Wyland, C. (2003). Assessing self-esteem. (pp. 219-233). American Psychological Association.

Henderson, J., Williams, M., \& Falk, C. (2005). Eye movements are functional during face learning. Memory \& Cognition, 33(1), 98-106.

Herzmann, G., Schweinberger, S. R., Sommer, W., and Jentzsch, I. (2004). What's special about personally familiar faces? A multimodal approach. Psychophysiology 41, 688701.

Higgins, E. T. (1997). Beyond pleasure and pain. American Psychologist, 52(12), 1280-1300. doi:http://dx.doi.org.helicon.vuw.ac.nz/10.1037/0003-066X.52.12.1280

Hinkley, K., Andersen, S., Geen, Russell, Kruglanski, Arie W., \& Miller, Norman. (1996). The Working Self-Concept in Transference: Significant-Other Activation and Self Change. Journal of Personality and Social Psychology, 71(6), 1279-1295.

Hugenberg, K., \& Wilson, J. P. (2013). Faces are central to social cognition. In D. Carlston, (Ed.), The Oxford Handbook of Social Cognition. Oxford University Press.

Hughes, B. L., \& Beer, J. S. (2012). Orbitofrontal cortex and anterior cingulate cortex are modulated by motivated social cognition. Cerebral Cortex, 22(6), 1372-1381. Retrieved from https://search-proquestcom.helicon.vuw.ac.nz/docview/1027508358?accountid=14782

Ishai, A. 2008. Let's face it: It's a cortical network. Neuroimage 40(2), 415-419. doi: 10.1016/j.neuroimage.2007.10.040 
Ito, T. A., Larsen, J. T., Smith, N. K., \& Cacioppo, J. T. (1998). Negative information weighs more heavily on the brain: The negativity bias in evaluative categorizations. Journal of Personality and Social Psychology, 75(4), 887-900. doi:http://dx.doi.org.helicon.vuw.ac.nz/10.1037/0022-3514.75.4.887

Jakobsen, K. V., Umstead, L., \& Simpson, E. A. (2016). Efficient human face detection in infancy. Developmental Psychobiology, 58(1), 129-136. doi:http://dx.doi.org.helicon.vuw.ac.nz/10.1002/dev.21338

Johnson, M. H. (2005). Subcortical face processing. Nature Reviews Neuroscience, 6(10), 766-786. doi:http://dx.doi.org/10.1038/nrn1766

Johnson, M. H., Senju, A., \& Tomalski, P. (2015). The two-process theory of face processing: Modifications based on two decades of data from infants and adults. Neuroscience and Biobehavioral Reviews, 50, 169-179. doi:http://dx.doi.org.helicon.vuw.ac.nz/10.1016/j.neubiorev.2014.10.009

Kanten, A. (2008). Better than average and better with time: Relative evaluations of self and others in the past, present, and future. European Journal of Social Psychology., 38(2), 343.

Kanwisher, N., McDermott, J., \& Chun, M. M. (1997). The fusiform face area: A module in human extrastriate cortex specialized for face perception. The Journal of Neuroscience, 17(11), 4302-4311. Retrieved from http://search.proquest.com.helicon.vuw.ac.nz/docview/619103049?accountid=14782

Kaniwisher, N. \& Yovel, G. (2006). The fusiform area: a cortical region specialized for the perception of faces. Phil. Trans. R. Soc. B, 361, 2109-2128. doi:10.1098/rstb.2006.1934

Kelley, H. H. (1950). The warm-cold variable in first impressions of persons. Journal of Personality, 18, 431-439. doi:http://dx.doi.org/10.1111/j.1467-6494.1950.tb01260.x

Kenny, D. A., Albright, L., Malloy, T. E., \& Kashy, D. A. (1994). Consensus in interpersonal perception: Acquaintance and the big five. Psychological Bulletin, 116(2), 245-258. Retrieved from http://search.proquest.com.helicon.vuw.ac.nz/docview/618520950?accountid=14782

Keyes, H. (2012). Categorical perception effects for facial identity in robustly represented familiar and self-faces: The role of configural and featural information. The Quarterly Journal of Experimental Psychology, 65(4), 760-772. doi:http://dx.doi.org/10.1080/17470218.2011.636822

Keyes, H., \& Dlugokencka, A. (2014). Do I Have My Attention? Speed of Processing Advantages for the Self-Face Are Not Driven by Automatic Attention Capture. PLoS ONE 9(10): e110792. https://doi.org/10.1371/journal.pone.0110792

Keenan, J.P., Ganis, G., Freund, S., \& Pascual-Leone, A. (2000). Self-face identification is increased with left hand responses. Laterality, 5, 259-268

Kernis, M.H., Goldman, B.M (2003). Stability and variability in self-concept and selfesteem. In M.R. Leary, \& J.P. Tangley (Eds.), Handbook of Self and Identity 106127. New York, NY: The Guilford Press

Keyes, H., \& Brady, N. (2010). Self-face recognition is characterized by "bilateral gain" and by faster, more accurate performance which persists when faces are inverted. The 
Quarterly Journal of Experimental Psychology, 63(5), 840-847.

doi:http://dx.doi.org.helicon.vuw.ac.nz/10.1080/17470211003611264

Kiiski, H. S. M., Cullen, B., Clavin, S. L., \& Newell, F. N. (2016). Perceptual and social attributes underlining age-related preferences for faces. Frontiers in Human Neuroscience, 10, 14. Retrieved from https://search-proquestcom.helicon.vuw.ac.nz/docview/1861917140?accountid=14782

Kriegeskorte, N., Formisano, E., Sorger, B., \& Goebel, R. (2007). Individual faces elicit distinct response patterns in human anterior temporal cortex. PNAS Proceedings of the National Academy of Sciences of the United States of America, 104(51), 2060020605. Retrieved from https://search-proquestcom.helicon.vuw.ac.nz/docview/621991198?accountid=14782

Kraus, M. W., \& Chen, S. (2010). Facial-feature resemblance elicits the transference effect. Psychological Science, 21(4), 518-522. doi:http://dx.doi.org/10.1177/0956797610364949

Krueger, J. I. (2007). From social projection to social behaviour. European Review of Social Psychology, 18, 1-35. doi:http://dx.doi.org.helicon.vuw.ac.nz/10.1080/10463280701284645

Krupp, D. B., Debruine, L. M., \& Barclay, P. (2008). A cue of kinship promotes cooperation for the public good. Evolution and Human Behaviour, 29(1), 49-55. doi:http://dx.doi.org.helicon.vuw.ac.nz/10.1016/j.evolhumbehav.2007.08.002

Kuster, F., \& Orth, U. (2013). The Long-Term Stability of Self-Esteem: Its Time-Dependent Decay and Nonzero Asymptote. Personality and Social Psychology Bulletin, 39(5), 677-690.

Langlois, J. H., Kalakanis, L., Rubenstein, A. J., Larson, A., Hallam, M., \& Smoot, M. (2000). Maxims or myths of beauty? A meta-analytic and theoretical review. Psychological Bulletin, 126(3), 390-423. doi:http://dx.doi.org/10.1037/00332909.126.3.390

Leary, M. R., \& MacDonald, G. (2003). Individual differences in self-esteem: A review and theoretical integration. In M. R. Leary, \& J. P. Tangney (Eds.), Handbook of self and identity; handbook of self and identity (pp. 401-418, Chapter xv, 703 Pages) Guilford Press, New York, NY. Retrieved from https://search-proquestcom.helicon.vuw.ac.nz/docview/620038071?accountid=14782

Leder, H., \& Bruce, V. (1998). Local and relational aspects of face distinctiveness. The Quarterly Journal of Experimental Psychology A: Human Experimental Psychology, 51a (3), 449-473. doi:http://dx.doi.org/10.1080/027249898391486

Leary and Tagney 2012: https://dornsife.usc.edu/assets/sites/782/docs/handbook_of_self_and_identity__second_edition_-_ch._4_pp._69-104_38_pages.pdf

Leveroni, C. L., Seidenberg, M., Mayer, A. R., Mead, L. A., Binder, J. R., \& Rao, S. M. (2000). Neural systems underlying the recognition of familiar and newly learned faces. The Journal of Neuroscience: The Official Journal of the Society for Neuroscience, 20(2), 878-886. Retrieved from https://search-proquestcom.helicon.vuw.ac.nz/docview/70890917?accountid=14782 
Lie, H. C., Rhodes, G., \& Simmons, L. W. (2010). Is genetic diversity associated with mating success in humans? Animal Behaviour, 79(4), 903-909.

doi:http://dx.doi.org.helicon.vuw.ac.nz/10.1016/j.anbehav.2009.12.040

Lindauer, M. (1984). Physiognomy and Art: Approaches from Above, Below, and Sideways. Visual Arts Research, 10(1), 52-65. Retrieved from http://www.jstor.org/stable/20715563

Liu, J., Harris, A., \& Kanwisher, N. (2010). Perception of face parts and face configurations: An fMRI study. Journal of Cognitive Neuroscience, 22(1), 203-211. Retrieved from http://search.proquest.com.helicon.vuw.ac.nz/docview/621975985?accountid=14782

Liu, S., Xiao, N. G., Quinn, P. C., Zhu, D., Ge, L., Pascalis, O., \& Lee, K. (2015). Asian infants show preference for own-race but not other-race female faces: The role of infant caregiving arrangements. Frontiers in Psychology, 6, 8. Retrieved from https://search-proquestcom.helicon.vuw.ac.nz/docview/1805778908?accountid=14782

Luo, W., Feng, W., He, W., Wang, N. Y., \& Luo, Y. J. (2010). Three stages of facial expression processing: ERP study with rapid serial visual presentation. Neuroimage, 49(2), 1857-1867.

Ma, D., Correll, S., \& Wittenbrink, J. (2015). The Chicago face database: A free stimulus set of faces and norming data. Behavior Research Methods, 47(4), 1122-1135. Ma, Y., \& Han, S. (2012). Functional dissociation of the left and right fusiform gyrus in self-face recognition. Human Brain Mapping, 33(10), 2255-67. http://dx.doi.org.helicon.vuw.ac.nz/10.1002/hbm.21356

Ma, F., Xu, F., \& Luo, X. (2016). Children's facial trustworthiness judgments: Agreement and relationship with facial attractiveness. Frontiers in Psychology, 7, 9. Retrieved from https://search-proquestcom.helicon.vuw.ac.nz/docview/1800136489?accountid=14782

Markus, H., \& Wurf, E. (1987). The Dynamic Self-Concept: A Social Psychological Perspective. Annual Review of Psychology, 38, 299-337.

Marsh, H. W., \& O'Mara, A. (2008). Reciprocal effects between academic self-concept, selfesteem, achievement, and attainment over seven adolescent years: Unidimensional and multidimensional perspectives of self-concept. Personality and Social Psychology Bulletin, 34(4), 542-552. doi:http://dx.doi.org.helicon.vuw.ac.nz/10.1177/0146167207312313

Mashek, D., Aron, A., \& Boncimino, M. (2003). Confusions of Self With Close Others. Personality and Social Psychology Bulletin, 29(3), 382-392.

McAleer, P., Todorov, A., \& Belin, P. (2014). How do you say 'hello'? Personality impressions from brief novel voices. PLoS One, 9(3) doi:http://dx.doi.org/10.1371/journal.pone.0090779

McArthur, L. Z., \& Berry, D. S. (1987). Cross-cultural agreement in perceptions of babyfaced adults. Journal of Cross-Cultural Psychology, 18(2), 165-192. doi:http://dx.doi.org.helicon.vuw.ac.nz/10.1177/0022002187018002003 
McConnell, A. R. (2011). The multiple self-aspects framework: Self-concept representation and its implications. Personality and Social Psychology Review, 15(1), 3-27. doi:http://dx.doi.org.helicon.vuw.ac.nz/10.1177/1088868310371101

Meinhardt-Injac, B., Boutet, I., Persike, M., Meinhardt, G., \& Imhof, M. (2017). From development to aging: Holistic face perception in children, younger and older adults. Cognition, 158, 134-146.

doi:http://dx.doi.org.helicon.vuw.ac.nz/10.1016/j.cognition.2016.10.020

Meltzoff, A. N. (2013). Origins of social cognition: Bidirectional self-other mapping and the "like-me" hypothesis. In M. R. Banaji, \& S. A. Gelman (Eds.), Navigating the social world: What infants, children, and other species can teach us; navigating the social world: What infants, children, and other species can teach us (pp. 139-144, Chapter xxiii, 424 Pages) Oxford University Press, New York,

Mende-Siedlecki P, Said CP, Todorov A. 2012. The social evaluation of faces: a metaanalysis of functional neuroimaging studies. Soc Cogn Affect Neurosci. 8. 285-299. doi: https://doi.org/10.1093/scan/nsr090

Millisecond Software, 2016. Inquisit 5 [Computer software]. Retrieved from http://www.millisecond.com.

Minear, M., \& Park, D. C. (2004). A lifespan database of adult facial stimuli. Behavior Research Methods, Instruments \& Computers, 36(4), 630-633. doi:http://dx.doi.org/10.3758/BF03206543

Mitchell, J. P., Heatherton, T. F., \& Macrae, C. N. (2002). Distinct neural systems subserve person and object knowledge. Proc Natl Acad Sci U 99(23). 15238-43. doi: 10.1073/pnas.232395699

Mitchell, J. P., Neil Macrae, C., \& Banaji, M. R. (2005). Forming impressions of people versus inanimate objects: Social-cognitive processing in the medial prefrontal cortex. NeuroImage, 26(1), 251-257. doi:http://dx.doi.org.helicon.vuw.ac.nz/10.1016/j.neuroimage.2005.01.031

Miyakoshi, M., Kanayama, N., Iidaka, T., \& Ohira, H. (2010). EEG evidence of face-specific visual self-representation. NeuroImage, 50(4), 1666-1675. doi:http://dx.doi.org.helicon.vuw.ac.nz/10.1016/j.neuroimage.2010.01.030

Montepare, J. M., \& Dobish, H. (2003). The contribution of emotion perceptions and their overgeneralizations to trait impressions. Journal of Nonverbal Behaviour, 27(4), 237254. doi:http://dx.doi.org.helicon.vuw.ac.nz/10.1023/A:1027332800296

Montepare, J. M., \& Zebrowitz-McArthur, L. (1989). Children's perceptions of babyfaced adults. Perceptual and Motor Skills, 69(2), 467-472. http://dx.doi.org.helicon.vuw.ac.nz/10.2466/pms.1989.69.2.467

Mondloch, C. J., Pathman, T., Maurer, D., Grand, R. L., \& de Schonen, S. (2007). The composite face effect in six-year-old children: Evidence of adult-like holistic face processing. Visual Cognition, 15(5), 564-577.

doi:http://dx.doi.org.helicon.vuw.ac.nz/10.1080/13506280600859383

Montepare, J. M., \& Zebrowitz-McArthur, L. (1989). Children's perceptions of babyfaced adults. Perceptual and Motor Skills, 69(2), 467-472. doi:http://dx.doi.org.helicon.vuw.ac.nz/10.2466/pms.1989.69.2.467 
Montepare, J., \& Dobish, M. (2003). The Contribution of Emotion Perceptions and Their Overgeneralizations to Trait Impressions. Journal of Nonverbal Behavior, 27(4), 237254.

Moreland, R., \& Topolinski, S. (2010). The Mere Exposure Phenomenon: A Lingering Melody by Robert Zajonc. Emotion Review, 2(4), 329-339.

Morton, J., \& Johnson, M. H. (1991). CONSPEC and CONLERN: A two-process theory of infant face recognition. Psychological Review, 98(2), 164-181. doi:http://dx.doi.org.helicon.vuw.ac.nz/10.1037/0033-295X.98.2.164

Nachson, I., \& Shechory, M. (2002). Effect of inversion on the recognition of external and internal facial features. Acta Psychologica, 109(3), 227-238. doi:http://dx.doi.org.helicon.vuw.ac.nz/10.1016/S0001-6918(01)00058-0

Namba, S., Makihara, S., Kabir, R. S., Miyatani, M., \& Nakao, T. (2017). Spontaneous facial expressions are different from posed facial expressions: Morphological properties and dynamic sequences. Current Psychology, 36(3), 593-605. doi:http://dx.doi.org.helicon.vuw.ac.nz/10.1007/s12144-016-9448-9

Narumoto, J., Okada, T., Sadato, N., Fukui, K., \& Yonekura, Y. (2001). Attention to emotion modulates fMRI activity in human right superior temporal sulcus. Cognitive Brain Research, 12(2), 225-231. Retrieved from http://search.proquest.com.helicon.vuw.ac.nz/docview/619638619?accountid=14782

Nosek BA, Bar-Anan Y, Sriram N, Axt J, Greenwald AG. (2014). Understanding and Using the Brief Implicit Association Test: Recommended Scoring Procedures. Denson T, ed. PLoS ONE. 2014;9(12):e110938. doi:10.1371/journal.pone.0110938.

Oakes, M. A., Brown, J. D., \& Cai, H. (2008). IMPLICIT AND EXPLICIT SELF-ESTEEM: MEASURE FOR MEASURE. Social Cognition, 26(6), 778-790. Retrieved from https://search-proquest-com.helicon.vuw.ac.nz/docview/229665904?accountid=14782

Ober, C., Hyslop, T., \& Hauck, W. W. (1999). Inbreeding effects on fertility in humans: Evidence for reproductive compensation. American Journal of Human Genetics, 64(1), 225-231. Retrieved from https://search-proquestcom.helicon.vuw.ac.nz/docview/69563968?accountid=14782

Oosterhof, N. N., \& Todorov, A. (2008). The functional basis of face evaluation. Proceedings of the National Academy of Sciences of the United States of America, 105(32), 11087. Retrieved from https://search.proquest.com/docview/201339957? accountid=14782

Pace, G. B. (1962). Physiognomy and Chaucer's Summoner and Alisoun. Tradito, 18, $417-$ 420. Retrieved from: http://www.jstor.org/stable/20780400

Pannese, A., \& Hirsch, J. (2011). Self-face enhances processing of immediately preceding invisible faces. Neuropsychologia, 49(3), 564-573. http://dx.doi.org.helicon.vuw.ac.nz/10.1016/j.neuropsychologia.2010.12.019

Payne, B., Cheng, C., Govorun, O., Stewart, B., \& Devine, Patricia. (2005). An Inkblot for Attitudes: Affect Misattribution as Implicit Measurement. Journal of Personality and Social Psychology, 89(3), 277-293.

Peskin, M., \& Newell, F. (2004). Familiarity Breeds Attraction: Effects of Exposure on the Attractiveness of Typical and Distinctive Faces. Perception, 33(2), 147-157. 
Pflüger, L. S., Oberzaucher, E., Katina, S., Holzleitner, I. J., \& Grammer, K. (2012). Cues to fertility: Perceived attractiveness and facial shape predict reproductive success. Evolution and Human Behavior, 33(6), 708-714. doi:http://dx.doi.org/10.1016/j.evolhumbehav.2012.05.005

Pitcher, D., Walsh, V., \& Duchaine, B. (2011). The role of the occipital face area in the cortical face perception network. Experimental Brain Research, 209(4), 481-493. Retrieved from http://search.proquest.com.helicon.vuw.ac.nz/docview/861792610?accountid=14782

Platek, S. M., Krill, A. L., \& Wilson, B. (2009). Implicit trustworthiness ratings of selfresembling faces activate brain centers involved in reward. Neuropsychologia, 47(1), 289-293. doi:http://dx.doi.org/10.1016/j.neuropsychologia.2008.07.018

Platek, S. M., \& Kemp, S. M. (2009). Is family special to the brain? an event-related fMRI study of familiar, familial, and self-face recognition. Neuropsychologia, 47(3), 849858. doi:http://dx.doi.org/10.1016/j.neuropsychologia.2008.12.027

Platek, S. M., Loughead, J. W., Gur, R. C., Busch, S., Ruparel, K., Phend, N., . . . Langleben, D. D. (2006). Neural substrates for functionally discriminating self-face from personally familiar faces. Human Brain Mapping, 27(2), 91-98. doi:http://dx.doi.org/10.1002/hbm.20168

Pratto, F., \& Bargh, J. A. (1991). Stereotyping based on apparently individuating information: Trait and global components of sex stereotypes under attention overload. Journal of Experimental Social Psychology, 27(1), 26-47. Retrieved from http://search.proquest.com/docview/617929894?accountid=14782

Puce, A., Allison, T., Gore, J. C., \& McCarthy, G. (1995). Face-sensitive regions in human extrastriate cortex studied by functional MRI. Journal of Neurophysiology, 74(3), 1192-1199. Retrieved from http://search.proquest.com.helicon.vuw.ac.nz/docview/618932341 ?accountid=14782

Rakover, S. S. (2002). Featural vs. configurational information in faces: A conceptual and empirical analysis. British Journal of Psychology, 93, 1-30. Retrieved from https://search.proquest.com/docview/199632939?accountid=14782

Rentzsch, K., \& Schröder-Abé, M. (2018). Stability and Change in Domain-specific Selfesteem and Global Self-esteem. European Journal of Personality, 32(4), 353-370.

Rhodes, G., Halberstadt, J., \& Brajkovich, G. (2001). Generalization of mere exposure effects to averaged composite faces. Social Cognition, 19(1), 57-70. doi:http://dx.doi.org.helicon.vuw.ac.nz/10.1521/soco.19.1.57.18961

Roberts, B., DelVecchio, W., \& Eisenberg, Nancy (Ed). (2000). The Rank-Order Consistency of Personality Traits From Childhood to Old Age: A Quantitative Review of Longitudinal Studies. Psychological Bulletin, 126(1), 3-25.

Robins, R. W., Hendin, H. M., \& Trzesniewski, K. H. (2001). Measuring global self-esteem: Construct validation of a single-item measure and the Rosenberg self-esteem scale. Personality and Social Psychology Bulletin, 27(2), 151-161. doi:http://dx.doi.org/10.1177/0146167201272002 
Rooney, B., Keyes, H., \& Brady, N. (2012). Shared or Separate Mechanisms for Self-Face and Other-Face Processing? Evidence from Adaptation. Frontiers in Psychology, 3, Frontiers in Psychology, 2012, Vol.3.).

Rosenberg, M., Schooler, C., Schoenbach, C., \& Rosenberg, F. (1995). Global self-esteem and specific self-esteem: Different concepts, different outcomes. American Sociological Review, 60(1), 141. Retrieved from https://search-proquestcom.helicon.vuw.ac.nz/docview/218831315?accountid=14782

Ross, L. (1977). The intuitive psychologist and his shortcomings: Distortions in the attribution process. In L. Berkowitz (Ed.), Advances in experimental social psychology (Vol. 10). (pp. 173-220). New York: Academic Press.

Rozin, P., \& Royzman, E. B. (2001). Negativity bias, negativity dominance, and contagion. Personality and Social Psychology Review, 5(4), 296-320. doi:http://dx.doi.org.helicon.vuw.ac.nz/10.1207/S15327957PSPR0504_2

Rubenstein, A. J., Kalakanis, L., \& Langlois, J. H. (1999). Infant preferences for attractive faces: A cognitive explanation. Developmental Psychology, 35(3), 848-855. doi:http://dx.doi.org.helicon.vuw.ac.nz/10.1037/0012-1649.35.3.848

Rule, N. O., \& Ambady, N. (2008). Brief exposures: Male sexual orientation is accurately perceived at 50ms. Journal of Experimental Social Psychology, 44(4), 1100-1105. Retrieved from http://search.proquest.com.helicon.vuw.ac.nz/docview/622015779?accountid=14782

Rule, N. O., \& Ambady, N. (2008a). First Impressions: Peeking at the Neural Underpinnings in Ambady, N., \& Skowronski, J. J. (Ed.), First Impressions (pp.35-56). New York: Guilford Press.

Rule, N. O., Ambady, N., Adams, R. B., Jr., Ozono, H., Nakashima, S., Yoshikawa, S., \& Watabe, M. (2010). Polling the face: Prediction and consensus across cultures. Journal of Personality and Social Psychology, 98(1), 1-15. doi:http://dx.doi.org.helicon.vuw.ac.nz/10.1037/a0017673

Rule, N. O., Ambady, N., \& Hallett, K. C. (2009). Female sexual orientation is perceived accurately, rapidly, and automatically from the face and its features. Journal of Experimental Social Psychology, 45(6), 1245-1251. doi:http://dx.doi.org/10.1016/j.jesp.2009.07.010

Rule, N. O., Krendl, A. C., Ivcevic, Z., \& Ambady, N. (2013). Accuracy and consensus in judgments of trustworthiness from faces: Behavioural and neural correlates. Journal of Personality and Social Psychology, 104(3), 409-426. Retrieved from http://search.proquest.com.helicon.vuw.ac.nz/docview/1266162999?accountid=14782

Rule, N. O., Moran, J. M., Freeman, J. B., Whitfield-Gabrieli, S., Gabrieli, J. D. E., \& Ambady, N. (2011). Face value: Amygdala response reflects the validity of first impressions. NeuroImage, 54(1), 734-741. Retrieved from http://search.proquest.com.helicon.vuw.ac.nz/docview/754055241 ?accountid=14782

Said, C. P., Sebe, N., \& Todorov, A. (2009). Structural resemblance to emotional expressions predicts evaluation of emotionally neutral faces. Emotion, 9(2), 260-264.

http://dx.doi.org.helicon.vuw.ac.nz/10.1037/a0014681 
Salva, O. R., Farroni, T., Regolin, L., Vallortigara, G., \& Johnson, M. H. (2011). The evolution of social orienting: Evidence from chicks (gallus gallus) and human newborns. PLoS One, 6(4)

doi:http://dx.doi.org.helicon.vuw.ac.nz/10.1371/journal.pone.0018802

Schaller, M. (2008). Evolutionary Bases of First Impressions. In N. Ambady \& J. Skowronski (Ed's.), First Impressions (pp. 15-34). New York: Guilford.

Schiller, D., Freeman, J. B., Mitchell, J. P., Uleman, J. S., \& Phelps, E. A. (2009). A neural mechanism of first impressions. Nature Neuroscience, 12(4), 508-514. Retrieved from http://search.proquest.com.helicon.vuw.ac.nz/docview/622271558?accountid=14782

Schneider, D. J., \& Blankmeyer, B. L. (1983). Prototype salience and implicit personality theories. Journal of Personality and Social Psychology, 44(4), 712-722. doi:http://dx.doi.org/10.1037/0022-3514.44.4.712

Schopenhauer, A. (1788-1860) Essays of Schopenhauer. Retrieved from: https://ebooks.adela ide.edu.au/s/Schopenhauer/Arthur/essays/index.html

Scott, L. S., \& Nelson, C. A. (2006). Featural and configural face processing in adults and infants: A behavioural and electrophysiological investigation. Perception, 35(8), 1107-1128. doi:http://dx.doi.org/10.1068/p5493

Shavelson, R. J., Hubner, J. J., \& Stanton, G. C. (1976). Self-concept: Validation of construct interpretations. Review of Educational Research, 46(3), 407-441. doi:http://dx.doi.org.helicon.vuw.ac.nz/10.2307/1170010

Short, L. A., Mondloch, C. J., McCormick, C. M., Carré, J. M., Ma, R., Fu, G., \& Lee, K. (2012). Detection of propensity for aggression based on facial structure irrespective of face race. Evolution and Human Behaviour, 33(2), 121-129. doi:http://dx.doi.org.helicon.vuw.ac.nz/10.1016/j.evolhumbehav.2011.07.002

Skowronski, J. J., \& Carlston, D. E. (1987). Social judgment and social memory: The role of cue diagnosticity in negativity, positivity, and extremity biases. Journal of Personality and Social Psychology, 52(4), 689-699. doi:http://dx.doi.org/10.1037/00223514.52.4.689

Skowronski, J. J., \& Carlston, D. E. (1989). Negativity and extremity biases in impression formation: A review of explanations. Psychological Bulletin, 105(1), 131-142. doi:http://dx.doi.org.helicon.vuw.ac.nz/10.1037/0033-2909.105.1.131

Slater, A., Von, d. S., Brown, E., Badenoch, M., Butterworth, G., Parsons, S., \& Samuels, C. (1998). Newborn infants prefer attractive faces. Infant Behavior \& Development, 21(2), 345-354. doi:http://dx.doi.org.helicon.vuw.ac.nz/10.1016/S0163-6383(98)90011-X

Slater, A., Bremner, G., Johnson, S. P., Sherwood, P., Hayes, R., \& Brown, E. (2000). Newborn infants' preference for attractive faces: The role of internal and external facial features. Infancy, 1(2), 265-274. doi:http://dx.doi.org/10.1207/S15327078IN0102_8

Smith, N. K., Cacioppo, J. T., Larsen, J. T., \& Chartrand, T. L. (2003). May I have your attention, please: Electrocortical responses to positive and negative stimuli. Neuropsychologia, 41(2), 171-183. 
Smith, E., Coats, S., \& Walling, D. (1999). Overlapping Mental Representations of Self, InGroup, and Partner: Further Response Time Evidence and a Connectionist Model. Personality and Social Psychology Bulletin, 25(7), 873-882.

Solso, R. L., \& McCarthy, J. E. (1981). Prototype formation of faces: A case of pseudomemory. British Journal of Psychology, 72(4), 499-503. doi:http://dx.doi.org.helicon.vuw.ac.nz/10.1111/j.2044-8295.1981.tb01779.x

Sorger, B., Goebel, R., Schiltz, C., \& Rossion, B. (2007). Understanding the functional neuroanatomy of acquired prosopagnosia. NeuroImage, 35(2), 836-852. doi:http://dx.doi.org/10.1016/j.neuroimage.2006.09.051

Speake, J. (2015) Oxford Dictionary of Proverbs (6th Ed). Oxford, United Kingdom: Oxford University Press.

Sprengelmeyer, R., Young, A. W., Baldas, E., Ratheiser, I., Sutherland, C. A. M., Müller, H., . . Orth, M. (2016). The neuropsychology of first impressions: Evidence from Huntington's disease. Cortex: A Journal Devoted to the Study of the Nervous System and Behavior, 85, 100-115. Retrieved from http://search.proquest.com.helicon.vuw.ac.nz/docview/1851132523?accountid=14782

Sugiura, M., Kawashima, R., Nakamura, K., Okada, K., Kato, T., Nakamura, A., . . Fukuda, H. (2000). Passive and active recognition of one's own face. NeuroImage, 11(1), 3648. Retrieved from https://search-proquestcom.helicon.vuw.ac.nz/docview/70920237?accountid=14782

Sugiura, M., Sassa, Y., Jeong, H., Wakusawa, K., Horie, K., Sato, S., \& Kawashima, R. (2012). Self-face recognition in social context. Human Brain Mapping, 33(6), 13641374. doi:http://dx.doi.org/10.1002/hbm.21290

Sutherland, C. A. M., Oldmeadow, J. A., \& Young, A. W. (2016). Integrating social and facial models of person perception: Converging and diverging dimensions. Cognition, 157, 257-267. Retrieved from https://search-proquestcom.helicon.vuw.ac.nz/docview/1847050347?accountid=14782

Suurmond R, van Rhee, H, Hak T. (2017). Introduction, comparison and validation of MetaEssentials: A free and simple tool for meta-analysis. Research Synthesis Methods. Vol. 8, Iss. 4, 537-553. doi.org/10.1002/jrsm.1260.

Swann, W. B., Jr., Chang-Schneider, C., \& Larsen McClarty, K. (2007). Do people's selfviews matter? self-concept and self-esteem in everyday life. American Psychologist, 62(2), 84-94. http://dx.doi.org.helicon.vuw.ac.nz/10.1037/0003066X.62.2.84

Tafarodi, R., Ho, C., \& Hadjistavropoulos, Thomas. (2006). Implicit and Explicit SelfEsteem: What Are We Measuring? Canadian Psychology/Psychologie Canadienne, 47(3), 195-202.

Talamas, S. N., Mavor, K. I., \& Perrett, D. I. (2016). Blinded by beauty: Attractiveness bias and accurate perceptions of academic performance. PLoS ONE, 11(2), 14. Retrieved from https://search-proquestcom.helicon.vuw.ac.nz/docview/1796693695?accountid=14782

Tanaka, J. W., Curran, T., Porterfield, A. L., \& Collins, D. (2006). Activation of pre-existing and acquired face representations: The N250 event-related potential as an index of 
face familiarity. Journal of Cognitive Neuroscience, 18(9), 1488-1497.

doi:http://dx.doi.org.helicon.vuw.ac.nz/10.1162/jocn.2006.18.9.1488

Tao, R., Zhang, S., Li, Q., \& Geng, H. (2012). PLoS ONE, 7(10), 6. http://dx.doi.org.helicon.vuw.ac.nz/10.1371/journal.pone.0047103

Taylor, M. J., Arsalidou, M., Bayless, S. J., Morris, D., Evans, J. W., \& Barbeau, E. J. (2009). Neural correlates of personally familiar faces: Parents, partner and own faces. Human Brain Mapping, 30(7). Retrieved from http://search.proquest.com.helicon.vuw.ac.nz/docview/622052507?accountid=14782

Teige-Mocigemba, S., Becker, M., Sherman, J. W., Reichardt, R., \& Christoph Klauer, K. (2017). The affect misattribution procedure: In search of prejudice effects. Experimental Psychology, 64(3), 215-230. http://dx.doi.org/10.1027/1618$3169 / \mathrm{a} 000364$

Thorndike, E. L. (1920). A constant error in psychological ratings. Journal of Applied Psychology, 4(1), 25-29. doi:http://dx.doi.org/10.1037/h0071663

Todorov, A., Baron, S. G., \& Oosterhof, N. N. (2008). Evaluating face trustworthiness: A model based approach. Social Cognitive and Affective Neuroscience, 3(2), 119-127. doi:http://dx.doi.org.helicon.vuw.ac.nz/10.1093/scan/nsn009

Tong, F., \& Nakayama, K. (1999). Robust representations for faces: Evidence from visual search. Journal of Experimental Psychology: Human Perception and Performance, 25(4), 1016-1035. doi:http://dx.doi.org.helicon.vuw.ac.nz/10.1037/0096-1523.25.4.1016

Tong, F., Nakayama, K., Moscovitch, M., Weinrib, O., \& Kanwisher, N. (2000). Response properties of the human fusiform face area. Cognitive Neuropsychology, 17(1-3), 257-279. Retrieved from http://search.proquest.com.helicon.vuw.ac.nz/docview/619457820?accountid=14782

Tottenham, N., Tanaka, J. W., Leon, A. C., McCarry, T., Nurse, M., Hare, T. A., Nelson, C. (2009). The NimStim set of facial expressions: Judgments from untrained research participants. Psychiatry Research, 168(3), 242-249.

doi:http://dx.doi.org/10.1016/j.psychres.2008.05.006

Tracy, J. L., \& Robins, R. W. (2008). The automaticity of emotion recognition. Emotion, 8(1), 81-95.

doi:http://dx.doi.org.helicon.vuw.ac.nz/10.1037/1528-3542.8.1.81

Tranel, D., Damasio, A. R., \& Damasio, H. (1988). Intact recognition of facial expression, gender, and age in patients with impaired recognition of face identity. Neurology, 38(5), 690-696. doi:http://dx.doi.org/10.1212/WNL.38.5.690

Treisman, A., \& Souther, J. (1985). Search asymmetry: A diagnostic for preattentive processing of separable features. Journal of Experimental Psychology: General, 114(3), 285-310. doi:http://dx.doi.org.helicon.vuw.ac.nz/10.1037/00963445.114.3.285

Triandis, H. C. (1989). The self and social behavior in differing cultural contexts. Psychological Review, 96(3), 506-520. doi:http://dx.doi.org.helicon.vuw.ac.nz/10.1037/0033-295X.96.3.506 
Trzesniewski, K. H., Donnellan, M. B., \& Robins, R. W. (2003). Stability of self-esteem across the life span. Journal of Personality and Social Psychology, 84(1), 205-220. doi:http://dx.doi.org.helicon.vuw.ac.nz/10.1037/0022-3514.84.1.205

Tsukiura, T., \& Cabeza, R. (2011). Shared brain activity for aesthetic and moral judgments: Implications for the beauty-is-good stereotype. Social Cognitive and Affective Neuroscience, 6(1), 138-148. Retrieved from http://search.proquest.com.helicon.vuw.ac.nz/docview/900620737?accountid=14782

Uleman, J. S., Saribay, S. A., \& Gonzalez, C. (2008). Spontaneous inferences, implicit impressions, and implicit theories. Annual Review of Psychology, 59, 329-360.

Valenza, E., Simion, F., Cassia, V. M., \& Umiltà, C. (1996). Face preference at birth. Journal of Experimental Psychology: Human Perception and Performance, 22(4), 892-903. doi:http://dx.doi.org.helicon.vuw.ac.nz/10.1037/0096-1523.22.4.892

Verosky, S. C., \& Todorov, A. (2010). Differential neural responses to faces physically similar to the self as a function of their valence. NeuroImage, 49(2), 1690-1698. doi:http://dx.doi.org.helicon.vuw.ac.nz/10.1016/j.neuroimage.2009.10.017

Visconti di, O. C., Wheeler, K. G., Cipolli, C., \& Gobbini, M. I. (2017). Familiarity facilitates feature-based face processing. PLoS One, 12(6) doi:http://dx.doi.org.helicon.vuw.ac.nz/10.1371/journal.pone.0178895

von Soest, T., Wichstrøm, L., \& Kvalem, I. L. (2016). The development of global and domain-specific self-esteem from age 13 to 31. Journal of Personality and Social Psychology, 110(4), 592-608.

doi:http://dx.doi.org.helicon.vuw.ac.nz/10.1037/pspp0000060

Walker, M., \& Vetter, T. (2016). Changing the personality of a face: Perceived big two and big five personality factors modelled in real photographs. Journal of Personality and Social Psychology, 110(4), 609-624. Retrieved from http://search.proquest.com.helicon.vuw.ac.nz/docview/1710261694?accountid=14782

Weigold, A., Weigold, I. K., Natera, S. N., \& Russell, E. J. (2013). The role of face familiarity in judgments of personality and intelligence. Current Psychology: A Journal for Diverse Perspectives on Diverse Psychological Issues, 32(3), 242-251. doi:http://dx.doi.org.helicon.vuw.ac.nz/10.1007/s12144-013-9177-2

Weisbuch, M., Unkelbach, C., \& Fiedler, K. (2008). Remnants of the recent past: Influences of priming on first impressions. In N. Ambady \& J. J. Skowronski, First Impressions (pp. 289-312). New York: Guilford Press

Willis, M. L., Palermo, R., \& Burke, D. (2011). Judging approachability on the face of it: The influence of face and body expressions on the perception of approachability. Emotion, 11(3), 514-523. doi:http://dx.doi.org.helicon.vuw.ac.nz/10.1037/a0022571

Willis, J., \& Todorov, A. (2006). First impressions: Making up your mind after a 100-ms exposure to a face. Psychological Science, 17(7), 592-598. doi:http://dx.doi.org.helicon.vuw.ac.nz/10.1111/j.1467-9280.2006.01750.x

Wilkinson, N., Paikan, A., Gredebäck, G., Rea, F., \& Metta, G. (2014). Staring us in the face? an embodied theory of innate face preference. Developmental Science, 17(6), 809-825. doi:http://dx.doi.org.helicon.vuw.ac.nz/10.1111/desc.12159 
Winkielman, P., \& Cacioppo, J. T. (2001). Mind at ease puts a smile on the face: Psychophysiological evidence that processing facilitation elicits positive affect. Journal of Personality and Social Psychology, 81(6), 989-1000. http://dx.doi.org.helicon.vuw.ac.nz/10.1037/0022-3514.81.6.989

Wilson, T., Schooler, J., \& Tesser, Abraham. (1991). Thinking Too Much: Introspection Can Reduce the Quality of Preferences and Decisions. Journal of Personality and Social Psychology, 60(2), 181-192.

Wojciszke, B., Bazinska, R., \& Jaworski, M. (1998). On the dominance of moral categories in impression formation. Personality and Social Psychology Bulletin, 24(12), 12511263. http://dx.doi.org.helicon.vuw.ac.nz/10.1177/01461672982412001

Young, A., De Haan, E., \& Newcombe, F. (1990). Unawareness of impaired face recognition. Brain and Cognition, 14(1), 1-18.

Young, A. W., Newcombe, F., de Haan, ,E.H., Small, M., \& Hay, D. C. (1993). Face perception after brain injury. selective impairments affecting identity and expression. Brain: A Journal of Neurology, 116 (Pt 4), 941-959. Retrieved from https://search.proquest.com/docview/75897746? accountid=14782

Zajonc, R. (2001). Mere Exposure: A Gateway to the Subliminal. Current Directions in Psychological Science, 10(6), 224-228.

Zajonc, R. B. (1968). Attitudinal effects of mere exposure. Journal of Personality and Social Psychology, 9(2), 1-27. doi:http://dx.doi.org.helicon.vuw.ac.nz/10.1037/h0025848

Zayas, V., \& Shoda, Y. (2005). Do Automatic Reactions Elicited by Thoughts of Romantic Partner, Mother, and Self Relate to Adult Romantic Attachment? Personality and Social Psychology Bulletin, 31(8), 1011-1025.

Zebrowitz, L. A., Bronstad, P. M., \& Lee, H. K. (2007). The contribution of face familiarity to ingroup favouritism and stereotyping. Social Cognition, 25(2), 306-338. doi:http://dx.doi.org.helicon.vuw.ac.nz/10.1521/soco.2007.25.2.306

Zebrowitz, L. A., Franklin, R. G., Jr., Hillman, S., \& Boc, H. (2013). Older and younger adults' first impressions from faces: Similar in agreement but different in positivity. Psychology and Aging, 28(1), 202-212. doi:http://dx.doi.org.helicon.vuw.ac.nz/10.1037/a0030927

Zebrowitz, L. A., Franklin, R. G., Jr., Boshyan, J., Luevano, V., Agrigoroaei, S., Milosavljevic, B., \& Lachman, M. E. (2014). Older and younger adults' accuracy in discerning health and competence in older and younger faces. Psychology and Aging, 29(3), 454-468. doi:http://dx.doi.org.helicon.vuw.ac.nz/10.1037/a0036255

Zebrowitz, L. A., Hall, J. A., Murphy, N. A., \& Rhodes, G. (2002). Looking smart and looking good: Facial cues to intelligence and their origins. Personality and Social Psychology Bulletin, 28(2), 238-249. doi:http://dx.doi.org/10.1177/0146167202282009

Zebrowitz, L. A., Kikuchi, M., \& Fellous, J. (2010). Facial resemblance to emotions: Group differences, impression effects, and race stereotypes. Journal of Personality and Social Psychology, 98(2), 175-189. doi:http://dx.doi.org.helicon.vuw.ac.nz/10.1037/a0017990 
Zebrowitz, L. A., \& Montepare, J. M. (1992). Impressions of babyfaced individuals across the life span. Developmental Psychology, 28(6), 1143-1152. doi:http://dx.doi.org.helicon.vuw.ac.nz/10.1037/0012-1649.28.6.1143

Zebrowitz, L. A., Montepare, J. M., \& Lee, H. K. (1993). They don't all look alike: Individual impressions of other racial groups. Journal of Personality and Social Psychology, 65(1), 85-101. Retrieved from http://search.proquest.com.helicon.vuw.ac.nz/docview/618341017?accountid=14782

Zebrowitz, L. A., \& Montepare, J. M. (2005). Appearance DOES matter. Science, 308(5728), 1565-1566. doi:http://dx.doi.org/10.1126/science.1114170

Zebrowitz, L. A., \& Montepare, J. M. (2008). Social psychological face perception: Why appearance matters. Social and Personality Psychology Compass, 2(3), 1497-1517. doi:http://dx.doi.org.helicon.vuw.ac.nz/10.1111/j.1751-9004.2008.00109.x

Zebrowitz, L. A., \& Montepare, J. M. (2008a). First Impressions from Facial Appearance Cues. In N. Ambady \& J. Skowronski (Ed's.), First Impressions (pp. 15-34). New York: Guilford.

Zebrowitz, L. A., \& Montepare, J. M. (2015). Faces and First Impressions. In M. Mikulincer \& P. R. Shaver (Ed's), APA Handbook of Personality and Social Psychology: Vol 1. Attitudes and Social Cognition (pp. 251-276). doi: 10.1037/14341-008

Zebrowitz, L. A., \& Rhodes, G. (2004). Sensitivity to "bad genes" and the anomalous face overgeneralization effect: Cue validity, cue utilization, and accuracy in judging intelligence and health. Journal of Nonverbal Behavior, 28(3), 167-185. doi:http://dx.doi.org.helicon.vuw.ac.nz/10.1023/B:JONB.0000039648.30935.1b

Zebrowitz, L. A., Wang, R., Bronstad, P. M., Eisenberg, D., Undurraga, E., Reyes-García, V., \& Godoy, R. (2012). First impressions from faces among U.S. and culturally isolated tsimane' people in the Bolivian rainforest. Journal of Cross-Cultural Psychology, 43(1), 119-134. Retrieved from http://search.proquest.com.helicon.vuw.ac.nz/docview/918756429?accountid=14782

Zebrowitz, L. A., White, B., \& Wieneke, K. (2008). Mere exposure and racial prejudice: Exposure to other-race faces increases liking for strangers of that race. Social Cognition, 26(3), 259-275. doi:http://dx.doi.org.helicon.vuw.ac.nz/10.1521/soco.2008.26.3.259

Zebrowitz, L. A., \& Zhang, Y. (2012). Neural evidence for reduced apprehensiveness of familiarized stimuli in a mere exposure paradigm. Social Neuroscience, 7(4), 347358. doi:http://dx.doi.org.helicon.vuw.ac.nz/10.1080/17470919.2011.628409

Zhang, H., Japee, S., Nolan, R., Chu, C., Liu, N., \& Ungerleider, L. G. (2016). Face-selective regions differ in their ability to classify facial expressions. NeuroImage, 130, 77-90.

Retrieved from http://search.proquest.com.helicon.vuw.ac.nz/docview/1785256133?accountid=14782

Zhen, Z., Fang, H., \& Liu, J. (2013). The hierarchical brain network for face recognition. PLoS One, 8(3) doi:http://dx.doi.org.helicon.vuw.ac.nz/10.1371/journal.pone.0059886

Zhen, Z., Yang, Z., Huang, L., Kong, X., Wang, X., Dang, X., Liu, J. (2015). Quantifying interindividual variability and asymmetry of face-selective regions: A probabilistic 
functional atlas. NeuroImage, 113, 13-25. Retrieved from https://search-proquestcom.helicon.vuw.ac.nz/docview/1727667683?accountid=14782 


\section{Appendix A \\ Rosenberg Self-Esteem Scale}

Instructions:

On the next several screens you will be presented with statements dealing with your general feelings about yourself. Use the following scale to rate the degree to which you agree or disagree with each statement:

$$
\begin{aligned}
& 1=\text { Strongly Agree } \\
& 2=\text { Agree } \\
& 3=\text { Disagree } \\
& 4=\text { Strongly Disagree }
\end{aligned}
$$

The scale will appear on each screen.

Just click the number on the scale to indicate your level of agreement.

Items:

1. On the whole, I am satisfied with myself.

2. At times I think I am no good at all.

3. I feel that I have a number of good qualities.

4. I am able to do things as well as most other people.

5. I feel I do not have much to be proud of.

6. I certainly feel useless at times.

7. I feel that I'm a person of worth, at least on an equal plane with others.

8. I wish I could have more respect for myself.

9. All in all, I am inclined to feel that I am a failure.

10. I take a positive attitude toward myself. 


\author{
Appendix B \\ Implicit Association Test
}

Block 1:

In this task, you will be presented with single words in the middle of the screen. Your task will be to categorise these words as pleasant or unpleasant.

If the word that appears is something PLEASANT, press the "A" key

If the word that appears is something UNPLEASANT, press the "L" key

These labels will also appear on the screen to remind you

This is a timed task, so respond as quickly as you can while also being as accurate as possible. You should leave your index fingers on the A and L keys throughout the task.

Block 2: Your task in the next block will be to categorise words as representing the SELF or OTHERS.

If the word that appears relates to SELF, press the "A" key

If the word that appears relates to OTHER, press the "L" key

Block 3: Your task in the next block will be to categorise words as representing the SELF or OTHERS.

If the word that appears relates to OTHER, press the "A" key

If the word that appears relates to SELF, press the "L" key

Block 4: In the next block, we are going to combine the previous two tasks

If the word that appears relates to something PLEASANT or to SELF, press the "A" key If the word that appears relates to something UNPLEASANT or to OTHER, press the "L" key

Block 5: In the next block, we are going to combine the previous two tasks

If the word that appears relates to something PLEASANT or to OTHER, press the "A" key If the word that appears relates to something UNPLEASANT or to SELF, press the "L" key

Stimuli words (by category):

\begin{tabular}{llll} 
Self & Other & Positive & Negative \\
\hline I & they & Caress & Abuse \\
me & them & Cuddle & Agony \\
my & their & Diamond & Assault \\
mine & theirs & Glory & Brutal \\
self & other & Gold & Corpse \\
& & Health & Death \\
& Joy & Filth \\
& & Kindness & Killer \\
& & Lucky & Poison \\
& & Peace & Slum \\
& Sunrise & Stink \\
& & Truth & Torture \\
& & Warmth & Vomit
\end{tabular}


Appendix C

Me/Not Me Task

Instructions:

On the next series of trials, a single word will appear on the screen.

Your task is to indicate whether or not that word generally describes you.

If the word does describe you, press "A" on the keyboard

If the word does NOT describe you, press "L" on the keyboard

That is:

$\mathrm{A}=$ "Me"

$\mathrm{L}=$ "Not Me"

Positive Items

Negative Items

\begin{tabular}{llll}
\hline adventurous & helpful & arrogant & jealous \\
affectionate & honest & boastful & lazy \\
agreeable & independent & careless & materialistic \\
brave & intuitive & conservative & mean \\
bright & loyal & cowardly & moody \\
careful & modest & cruel & nervous \\
charming & persistent & cunning & obsessive \\
compassionate & polite & cynical & pessimistic \\
courteous & practical & foolish & ruthless \\
creative & quiet & greedy & sarcastic \\
determined & reserved & gullible & secretive \\
discreet & resourceful & impatient & selfish \\
energetic & self-confident & impolite & silly \\
enthusiastic & sensitive & impulsive & stubborn \\
faithful & shy & inconsiderate & timid \\
friendly & thoughtful & indecisive & unpredictable \\
generous & understanding & intolerant & unreliable \\
hard-working & versatile & irresponsible & vain
\end{tabular}


Appendix D

NEO-5 Domains

Instructions:

"In the next block, you will be presented with a series of characteristics that may or may not describe you.

For example, do you agree that you seldom feel blue, compared to most other people?

You will be responding using the following scale:

$1=$ strongly disagree

$2=$ somewhat disagree

$3=$ neither agree nor disagree

$4=$ somewhat agree

$5=$ strongly agree

For each item shown, click the number that best indicates the extent to which you agree or disagree with the statement.

Be as honest as possible, but rely on your initial feeling and do not think too much about each item."

\section{$\underline{\text { Neuroticism Items }}$}

I often feel blue.

I dislike myself.

I am often down in the dumps.

I have frequent mood swings.

I panic easily.

I am filled with doubts about things.

I feel threatened easily.

I get stressed out easily.

I fear for the worst.

I worry about things.

\section{$\underline{\text { Extraversion Items }}$}

I feel comfortable around people.,

I make friends easily.

I am skilled in handling social situations.

I am the life of the party.

I know how to captivate people.

I start conversations.

I warm up quickly to others.

I talk to a lot of different people at parties.

I don't mind being the center of attention.

I cheer people up.

\section{$\underline{\text { Neuroticism (Reversed) Items }}$}

I seldom feel blue.

I feel comfortable with myself.

I rarely get irritated.

I am not easily bothered by things.

I am very pleased with myself.

I am relaxed most of the time.

I seldom get mad.

I am not easily frustrated.

I remain calm under pressure.

I rarely lose my composure.

\section{Extraversion (Reversed) Items}

I have little to say.

I keep in the background.

I would describe my experiences as somewhat dull.

I don't like to draw attention to myself.

I don't talk a lot.

I avoid contacts with others.

I am hard to get to know.

I retreat from others.

I find it difficult to approach others.

I keep others at a distance. 
$\underline{\text { Openness Items }}$

I believe in the importance of art.

I have a vivid imagination.

I tend to vote for liberal political

candidates.

I carry the conversation to a higher level.

I enjoy hearing new ideas.

I enjoy thinking about things.

I can say things beautifully.

I enjoy wild flights of fantasy.

I get excited by new ideas.

I have a rich vocabulary.
Openness (Reversed) Items

I am not interested in abstract ideas.

I do not like art.

I avoid philosophical discussions.

I do not enjoy going to art museums.

I tend to vote for conservative political candidates.

I do not like poetry.

I rarely look for a deeper meaning in things.

I believe that too much tax money goes to support artists.

I am not interested in theoretical

discussions.

I have difficulty understanding abstract ideas.

\section{$\underline{\text { Agreeableness (Reversed) Items }}$}

I have a sharp tongue.

I have a good word for everyone.

I believe that others have good intentions.

I respect others.

I accept people as they are.

I make people feel at ease.

I am concerned about others.

I trust what people say.

I sympathize with others' feelings.

I am easy to satisfy.

I treat all people equally.

$\underline{\text { Conscientiousness Items }}$

I am always prepared.

I pay attention to details.

I get chores done right away.

I carry out my plans.

I make plans and stick to them.

I complete tasks successfully.

I do things according to a plan.

I am exacting in my work.

I finish what I start.

I follow through with my plans.
I cut others to pieces.

I suspect hidden motives in others.

I get back at others.

I insult people.

I believe that I am better than others.

I contradict others.

I make demands on others.

I hold a grudge.

I am out for my own personal gain.

$\underline{\text { Conscientiousness (Reversed) Items }}$

I waste my time.

I find it difficult to get down to work.

I do just enough work to get by.

I don't see things through.

I shirk my duties.

I mess things up.

I leave things unfinished.

I don't put my mind on the task at hand.

I make a mess of things.

I need a push to get started. 


\section{Appendix E \\ Ten Item Personality Inventory}

Instructions:

On the next several screens you will be presented with a statement that starts with "I view myself as..." and then lists some personality traits that may or may not apply to you.

Click the number on the scale to indicate the extent to which you agree or disagree with that statement.

The scale runs from:

$1=$ "Strongly disagree" to

$7=$ "Strongly Agree"

You should rate the extent to which the pair of traits applies to you, even if one characteristic applies more strongly than the other.

The scale will appear on each screen.

Just click the number on the scale to indicate your level of agreement.

1. extraverted, enthusiastic

2. critical, quarrelsome

3. dependable, self-disciplined

4. anxious, easily upset

5. open to new experiences, complex

6. reserved, quiet

7. sympathetic, warm

8. disorganised, careless

9. calm, emotionally stable

10. conventional, uncreative 
Appendix F

Self-descriptive/ Self-Irrelevant Task

General Instructions:

"On the next screen will be a list of 60 traits.

You will first be asked to select 6 words from this list that you feel best describe you.

That is, these are words that you would use to describe yourself.

After that, you will be asked to select 6 words that are irrelevant to how you describe yourself."

Descriptive selection instructions:

"Select the six traits that best describe you."

"Now we are going to have you rate the traits that you selected.

How important is this trait to how you define yourself?

"Now rate them based on how important they are to how you think about other people"

Irrelevant selection instructions:

"Select the six traits that are most IRRELEVANT to how you think about yourself"

"Now we are going to have you rate the traits that you selected.

How important is this trait to how you define yourself?

"Now rate them based on how important they are to how you think about other people"

Items:

adventurous

aggressive

assertive

caring

charming

committed

competent

confident

controlling

creative

critical

cynical

decisive

dependable

emotional

flexible

fun-loving

generous

honest

impatient impulsive

insensitive

introverted

judgmental

leader

literal

logical

loyal

moral

observant

organised

patient

perfectionist

pessimistic

practical

responsible

risk-taker

selfless

serious

sociable straightforward

supportive

suspicious

sympathetic

team-player

traditional

understanding

upbeat

volatile

friendly

modest

careful

clever

kind

gracious

industrious

lazy

deceptive

proud

warm 
Appendix G - EFA Factor Loadings of individual self-selection items for the four studies (Orthogonal rotation with Varimax, Eigenvalues greater than 1.0)

Study 1

\begin{tabular}{lrc} 
Component Loadings & & \\
\hline & RC 1 & Uniqueness \\
\hline Self_competent & 0.484 & 0.766 \\
Self_confident &. & 0.873 \\
Self_creative &. & 0.852 \\
Self_friendly & 0.710 & 0.496 \\
Self_helpful & 0.767 & 0.411 \\
Self_intelligent &. & 0.977 \\
Self_sincere & 0.444 & 0.803 \\
Self_trustworthy & 0.643 & 0.586 \\
\hline
\end{tabular}

study 3 , unlimited presentation

Component Loadings

\begin{tabular}{lcc}
\hline & RC 1 & Uniqueness \\
\hline Self_competent & 0.603 & 0.637 \\
Self_confident & 0.597 & 0.644 \\
Self_creative & 0.443 & 0.804 \\
Self_friendly & 0.667 & 0.555 \\
Self_helpful & 0.761 & 0.421 \\
Self_intelligent & 0.472 & 0.777 \\
Self_sincere & 0.520 & 0.730 \\
Self_trustworthy & 0.782 & 0.388 \\
\hline
\end{tabular}

Study 4, unmatched stimuli

Component Loadings

\begin{tabular}{lcc}
\hline & RC 1 & Uniqueness \\
\hline Self_competent & 0.554 & 0.693 \\
Self_confident & 0.490 & 0.760 \\
Self_creative & 0.551 & 0.697 \\
Self_friendly & 0.741 & 0.450 \\
Self_helpful & 0.799 & 0.362 \\
Self_intelligent &. & 0.978 \\
Self_sincere & 0.643 & 0.586 \\
Self_trustworthy & 0.754 & 0.431 \\
\hline
\end{tabular}

Study 2

\begin{tabular}{lrc} 
Component Loadings & & \\
\hline & RC 1 & Uniqueness \\
\hline Self_competent &. & 0.883 \\
Self_confident &. & 0.895 \\
Self_creative &. & 0.998 \\
Self_friendly & 0.616 & 0.621 \\
Self_helpful & 0.629 & 0.605 \\
Self_intelligent &. & 0.935 \\
Self_sincere & 0.648 & 0.581 \\
Self_trustworthy & 0.750 & 0.438 \\
\hline
\end{tabular}

Study 3 , limited presentation

Component Loadings

\begin{tabular}{lcc}
\hline & RC1 & Uniqueness \\
\hline lim_competent &. & 0.873 \\
lim_confident & 0.545 & 0.703 \\
lim_creative & 0.521 & 0.728 \\
lim_friendly & 0.731 & 0.465 \\
lim_helpful & 0.687 & 0.529 \\
lim_intelligent &. & 0.874 \\
lim_sincere &. & 0.851 \\
lim_trustworthy & 0.800 & 0.361 \\
\hline
\end{tabular}

Study 4, matched stimuli

Component Loadings

\begin{tabular}{lcc}
\hline & RC 1 & Uniqueness \\
\hline Match_competent &. & 0.996 \\
Match_confident & 0.428 & 0.817 \\
Match_creative & 0.574 & 0.670 \\
Match_friendly & 0.827 & 0.315 \\
Match_helpful & 0.768 & 0.410 \\
Match_intelligent &. & 0.989 \\
Match_sincere & 0.649 & 0.579 \\
Match_trustworthy & 0.797 & 0.364 \\
\hline
\end{tabular}


APPENDIX H - T-Tests for Individual Traits Across the Four Studies

STUDY 1: T-tests for Individual Traits

One Sample T-Test

\begin{tabular}{lrccr}
\hline & \multicolumn{1}{c}{$\mathrm{t}$} & $\mathrm{df}$ & $\mathrm{p}$ & Cohen's d \\
\hline Self_sincere & 0.414 & 87 & 0.680 & 0.044 \\
Self_helpful & 1.323 & 87 & 0.189 & 0.141 \\
Self_confident & -1.231 & 87 & 0.222 & -0.131 \\
Self_friendly & -0.233 & 87 & 0.817 & -0.025 \\
Self_trustworthy & 0.468 & 87 & 0.641 & 0.050 \\
Self_competent & -0.759 & 87 & 0.450 & -0.081 \\
Self_creative & 2.019 & 87 & 0.047 & 0.215 \\
Self_intelligent & -0.618 & 87 & 0.538 & -0.066 \\
\hline
\end{tabular}

Note. Student's t-test.

Note. For all tests, the alternative hypothesis specifies that the population mean is different from 0.5 .

STUDY 2: T-tests for Individual Traits

One Sample T-Test

\begin{tabular}{lrccr}
\hline & $\mathrm{t}$ & $\mathrm{df}$ & $\mathrm{p}$ & Cohen's d \\
\hline Self_sincere & 1.848 & 84 & 0.068 & 0.200 \\
Self_helpful & 2.358 & 84 & 0.021 & 0.256 \\
Self_confident & -1.460 & 84 & 0.148 & -0.158 \\
Self_friendly & 1.856 & 84 & 0.067 & 0.201 \\
Self_trustworthy & 0.963 & 84 & 0.338 & 0.104 \\
Self_competent & 1.140 & 84 & 0.258 & 0.124 \\
Self_creative & 1.055 & 84 & 0.295 & 0.114 \\
Self_intelligent & 1.890 & 84 & 0.062 & 0.205 \\
\hline
\end{tabular}

Note. Student's t-test.

Note. For all tests, the alternative hypothesis specifies that the population mean is different from 0.5 . 
STUDY 3: T-tests for Individual Traits

One Sample T-Test

\begin{tabular}{lrccr}
\hline & $\mathrm{t}$ & $\mathrm{df}$ & $\mathrm{p}$ & Cohen's d \\
\hline Self_sincere & -0.907 & 74 & 0.367 & -0.105 \\
Self_helpful & -0.117 & 74 & 0.907 & -0.014 \\
Self_confident & 0.405 & 74 & 0.687 & 0.047 \\
Self_friendly & 0.124 & 74 & 0.901 & 0.014 \\
Self_trustworthy & -1.445 & 74 & 0.153 & -0.167 \\
Self_competent & 0.839 & 74 & 0.404 & 0.097 \\
Self_creative & 1.330 & 74 & 0.188 & 0.154 \\
Self_intelligent & -1.577 & 74 & 0.119 & -0.182 \\
lim_sincere & -0.762 & 74 & 0.448 & -0.088 \\
lim_helpful & -2.641 & 74 & 0.010 & -0.305 \\
lim_confident & 1.560 & 74 & 0.123 & 0.180 \\
lim_friendly & -1.100 & 73 & 0.275 & -0.128 \\
lim_trustworthy & -0.682 & 73 & 0.497 & -0.079 \\
lim_competent & -1.889 & 74 & 0.063 & -0.218 \\
\hline lim_creative & -1.239 & 74 & 0.219 & -0.143 \\
lim_intelligent & -1.895 & 73 & 0.062 & -0.220 \\
\hline
\end{tabular}

Note. Student's t-test.

Note. For all tests, the alternative hypothesis specifies that the population mean is different from 0.5 . 
STUDY 4: T-tests for Individual Traits

One Sample T-Test

\begin{tabular}{lrrrr}
\hline & $\mathrm{t}$ & $\mathrm{df}$ & $\mathrm{p}$ & Cohen's d \\
\hline Self_sincere & 0.502 & 76 & 0.617 & 0.057 \\
Self_helpful & 0.454 & 76 & 0.651 & 0.052 \\
Self_confident & 0.493 & 76 & 0.623 & 0.056 \\
Self_friendly & 2.284 & 76 & 0.025 & 0.260 \\
Self_trustworthy & 2.283 & 76 & 0.025 & 0.260 \\
Self_competent & 2.017 & 76 & 0.047 & 0.230 \\
Self_creative & 1.567 & 76 & 0.121 & 0.179 \\
Self_intelligent & 2.587 & 76 & 0.012 & 0.295 \\
Match_sincere & 0.600 & 76 & 0.551 & 0.068 \\
\hline Match_helpful & 1.736 & 76 & 0.087 & 0.198 \\
\hline Match_confident & -0.078 & 76 & 0.938 & -0.009 \\
Match_friendly & 0.387 & 76 & 0.700 & 0.044 \\
\hline Match_trustworthy & 1.999 & 76 & 0.049 & 0.228 \\
Match_competent & 0.596 & 76 & 0.553 & 0.068 \\
\hline Match_creative & 2.002 & 76 & 0.049 & 0.228 \\
Match_intelligent & 1.213 & 76 & 0.229 & 0.138 \\
\hline
\end{tabular}

Note. Student's t-test.

Note. For all tests, the alternative hypothesis specifies that the population mean is different from 0.5 . 